\title{
NUTRITIONAL PREDICTORS OF DEPRESSION IN A COHORT OF COMMUNITY-DWELLING ELDERLY
}

CANADIANS: NUAGE COHORT

Laura Andres Rossi Gougeon

School of Dietetics and Human Nutrition

McGill University

Quebec, Canada

July 2014

A thesis submitted to McGill University in partial fulfilment of the requirements of the degree of Doctor of Philosophy

(c) Laura Andres Rossi Gougeon, 2014 


\section{ABSTRACT}

Depression is associated with decreased quality of life and high mortality risk at all ages and, despite having lower prevalence in community-dwelling seniors compared to other stages of the life span or institutionalized elderly, it negatively affects seniors' health outcomes. Most evidence linking late-life depression, defined as first onset after 65 years of age, with dietary factors comes from cross-sectional studies, which cannot provide information on whether declines in diet were a consequence of depression - the reverse causality hypothesis. The Quebec Longitudinal Study on Nutrition and Aging (NuAge) provides an ideal setting to explore such a relationship among a healthy, community-dwelling elderly population. Diet is hypothesized to be a factor associated with depression. Some longitudinal evidence from studies with middle-aged adults suggests that dietary patterns such as the Mediterranean or patterns deemed "healthy" are protective against depression, while "western" and "unhealthy" patterns are risk factors for the disease. B-vitamins are important cofactors in neurotransmitter synthesis and in the enzymes of the one-carbon metabolism, which has been hypothesized to have an aetiological role in depression through its neurotoxic derivates, such as homocysteine. Nonetheless, it is still largely unknown how depression affects nutrient intake in the elderly population, raising the question of the directionality of the association. Therefore, 
the three objectives of this thesis were to explore the longitudinal associations of i) dietary patterns and macronutrient intake and of ii) $B_{6}, B_{12}$ and folate intakes with the incidence of depression in late life; and iii) to investigate whether depression significantly affects short-term nutrient intakes (reverse causality effect) in comparison to intakes among non-depressed seniors.

Data for this study have been obtained from the NuAge cohort, a 4-y longitudinal study of 1,793 community-dwelling men and women aged 68 to 82 years at baseline. The main outcome is incidence of depression as defined by scores in the 30-item Geriatric Depression Scale $\geq 11$ and or antidepressant medication use over the three years of follow-up. Participants were free of depression at the study's baseline through the exclusion of those with GDS scores $\geq 11$ or antidepressant use at the time of the recruitment. Individuals with invalid or missing dietary information were also excluded. Dietary patterns were created through principal component analysis on amount (grams) of food items consumed in each of the 32 predefined food categories. Sex-specific tertiles of intake were created from the mean of three non-consecutive 24h-recalls. Multiple logistic regression models were adjusted for several demographic, health, and social confounders. For the study of the reverse causality hypothesis, we conducted a case-control nested within the NuAge cohort. Participants free of 
depression at baseline who developed depression at some point of follow-up were matched by age group and sex with non-depressed participants in a 1:1 ratio. The mean 3-day intakes of energy, protein, saturated fat, dietary fibre, $\mathrm{B}_{6}$, $B_{12}$, and folate at the time point of depression were compared with intakes the year prior between depressed and non-depressed groups using a $2 \times 2 \times 2$ (group×stressful life event×time) mixed-model repeated measures ANCOVA. Multiple imputation method through linear regression was used for missing data.

Incidence of depression over the three years of follow-up was $12.5 \%$ ( $n=170,63 \%$ women). Principal component analysis on 32 food categories revealed three dietary patterns: varied diet, traditional diet, and convenience diet. Only varied diet was protective of depression incidence before adjustment for confounders. None of the three patterns were associated with the outcome in fully adjusted models. Tertiles of total energy intake were, however, inversely associated with depression incidence in all multivariate models (highest tertile, fully adjusted OR $0.55,95 \% \mathrm{CI} 0.34-0.87)$.

Men in the highest tertile of $B_{12}$ intake from food had lower risk of depression compared to those in the lowest tertile (fully adjusted OR 0.42, 95\% $\mathrm{Cl}$ 0.20-0.90). Higher $\mathrm{B}_{6}$ intake from food was protective among women (multivariate OR $0.57,95 \% \mathrm{Cl} 0.39-0.96$ ), but the effect was dependent on total 
energy intake (fully adjusted OR $0.70,95 \% \mathrm{Cl} 0.37-1.30$ ). Neither intakes from food+supplements (total) nor folate intake showed detectable benefits.

The study of the reverse causality effect, in which depression leads to a change in intake, showed no evidence of such a phenomenon, at least in the short term. Community-dwelling seniors deemed depressed at some time point of follow-up did not decrease their nutrient intake significantly over time compared to non-depressed seniors, with the exception of small declines in $\mathrm{B}_{12}$ over time.

Taken together, these findings suggest that differences in quantity of food (energy intake) are more strongly associated with the likelihood of developing depression in the following years, as measured by the GDS and antidepressant use, among generally healthy seniors living in the community than small differences in quality (dietary patterns). Nutrients may, in fact, predict depression better than food items, particularly non-energy adjusted $B_{6}$ in women and energyadjusted $B_{12}$ in men, whose lower intakes were associated with increased risk for depression. These vitamins could be a proxy for other behavioural or biological risk factors, or they could have direct, but different, roles in the mental health of men and women. An examination of how newly depressed seniors fared on dietary change indicated that they were resilient to change despite their depression. 
Programs aimed to promote affective health among generally healthy, community-dwelling seniors should focus on helping them to maintain their nutrient intake, regardless of small variations in food quality. 


\section{RÉSUMÉ}

La dépression est associée à une diminution de la qualité de vie et des risques élevés de mortalité à tous les âges. Dépression chez les personnes âgées peut être définie comme la première apparition après 65 ans. Malgré une prévalence plus faible chez les personnes âgées vivant dans la communauté par rapport à d'autres stades de la durée de vie, elle affecte négativement la santé et augmente les risques de plusieurs maladies et même de la mort précoce. La plupart des preuves reliant les facteurs alimentaires à la dépression chez les personnes âgées proviennent d'études transversales, qui ne peuvent pas fournir des informations sur la direction de l'association. L'étude longitudinale québécoise sur la nutrition comme déterminant d'un vieillissement réussi (NuAge) offre un cadre idéal pour explorer cette relation entre nutrition et dépression chez la population âgée en bonne santé vivant dans la communauté. Certaines données longitudinales provenant d'études avec des adultes d'âge moyen suggèrent que les habitudes alimentaires comme la Méditerranée ou jugés «sains» sont protecteurs contre la dépression, tandis que les modèles «occidentaux» et «malsains» sont des facteurs de risque de la maladie. Les vitamines B sont importantes co-facteurs dans la synthèse des neurotransmetteurs et des enzymes du métabolisme du carbone, qui a été émis I'hypothèse d'avoir un rôle étiologique dans la dépression par l'intermédiaire de 
ses dérivés neurotoxiques, tels que l'homocystéine. Les trois objectifs de cette thèse étaient d'explorer les associations longitudinales i) des habitudes alimentaires et des macronutriments, aussi bien que ii) des vitamines $B_{6}, B_{12}$ et folate, avec l'incidence de la dépression chez les personnes âgées ; et iii) de déterminer si la dépression affecte considérablement les apports nutritionnels à court terme (effet de causalité inverse) par rapport à l'apport chez les personnes âgées non-déprimés.

Les données de cette étude ont été obtenus à partir de la cohorte NuAge, une étude longitudinale de quatre ans, avec 1793 hommes et femmes vivant indépendamment dans la communauté, et âgé de 68 ans à 82 ans à l'inclusion. Le principal résultat est l'incident de la dépression défini par les résultats dans le Geriatric Depression Scale $\geq 11$ et ou l'utilisation de médicaments antidépresseurs au cours des trois années de suivi. Les participants étaient libres de la dépression à la base de l'étude par l'exclusion de ceux avec des scores GDS $\geq 11$ ou l'utilisation des antidépresseurs au moment du recrutement. Nous avons exclu aussi les participants avec des informations diététiques non valides ou manquantes. Tertiles de l'apport selon le sexe ont été créés à partir de la moyenne des trois $24 \mathrm{H}$ rappels non-consécutives. Les habitudes alimentaires ont été créées par analyse en composante principale. Des modèles de 
régression logistique multiple ont été ajustés pour tenir compte de plusieurs facteurs de confusion démographique, de santé et sociaux. Pour l'étude de I'hypothèse de causalité inverse, nous avons mené une étude cas-témoins auprès de la cohorte NuAge. Les participants libres de dépression au départ qui ont développé une dépression à un point de suivi ont été appariés selon le groupe d'âge et le sexe avec des participants non déprimés dans un rapport de 1:1. Les apports d'énergie, de protéines, de graisses saturées, de fibres alimentaires, et de $B_{6}, B_{12}$, et folate au moment du diagnostic ont été comparés avec prises l'année précédente entre les groupes déprimés et non déprimés à l'aide d'un $2 \times 2 \times 2$ (groupe $2 \times$ événement de vie stressant $\times$ temps) modèle linéaire mixte généralisé avec des co-variables. La méthode d'imputation multiple a été utilisée pour les données manquantes.

Incidence de la dépression au cours des trois années de suivi était de 12,5 $\%(n=170,63 \%$ de femmes). Analyse en composante principale sur 32 catégories d'aliments a révélé trois modes d'alimentation : « variée », « traditionnelle » et «de commodité ». Seulement l'alimentation « variée » a été associée à une inférieure incidence de dépression avant ajustement pour les facteurs confondants. Aucun des trois modèles n'a été associé à l'issue de modèles entièrement ajustés. Cependant, la consommation totale d'énergie a été 
inversement associée à l'incidence de la dépression dans tous les modèles multivariés (tertile plus élevé, OR ajusté $0,55,95 \%$ IC 0,34-0,87).

Hommes dans le tertile le plus élevé de l'apport de vitamine $B_{12}$ provenant de la diète avaient un risque inférieur de dépression par rapport à ce du tertile le plus bas (OR ajusté 0,42, IC 95\% 0,20-0,90). Une consommation plus élevée de $B_{6}$ provenant de la diète avait un effet protecteur chez les femmes (OR ajusté 0,57, IC 95\% 0,39-0,96), mais l'effet était dépendant de l'apport énergétique (OR ajusté 0,70, IC 95\% 0,37-1,30). Les apports alimentaires totaux (nourriture+suppléments) et l'apport de folate n'ont pas eu des associations détectables.

L'étude de l'effet de causalité inverse, dans laquelle la dépression entraîne une modification de l'apport, n'a montré aucune preuve d'un tel phénomène, au moins à court terme. Personnes âgées vivant dans la communauté réputées déprimé n'a pas diminué leur apport en nutriments au fil du temps par rapport aux personnes âgées non-déprimés, à l'exception de légères baisses de $B_{12}$.

Ensemble, ces résultats indiquent que les différences de quantité (de l'apport énergétique) est plus fortement associés à 3 ans de l'incidence de la dépression chez les personnes âgées en bonne santé général vivant dans la communauté que de petites différences dans la qualité (schéma alimentaires). 
Nutriments peuvent, en effet, prédire la dépression mieux que des schémas alimentaires, en particulier l'apport « brut » de $\mathrm{B}_{6}$ chez les femmes et de $\mathrm{B}_{12}$ ajusté d'énergie chez les hommes. Des apports plus faibles de ces vitamines ont été associés à un risque accru de dépression. Un examen de la façon que les personnes âgées nouvellement déprimés s'en tirent sur un changement de régime alimentaire a indiqué qu'ils étaient résistants au changement en dépit de leur dépression.

Enfin, les programmes visant à promouvoir la santé affective entre les personnes âgées en bonne santé générale et habitant à la communauté devraient se concentrer sur les aidant à maintenir un apport nutritionnel raisonnable, indépendamment de petites variations de qualité. 


\section{ADVANCE OF SCHOLARLY KNOWLEDGE}

\section{Original contribution to knowledge}

The scientific literature lacks in population-based, longitudinal studies with healthy, free-living older adults; hence, most of the evidence linking diet and diseases comes from studies conducted among young and middle-aged populations, but depression seems to behave differently and have different risk factors across the life span. In late life, evidence is from cross-sectional studies, whose design cannot adequately shed light on the directionality of the dietdepression relationship. Well-designed, longitudinal studies in the elderly are needed to help clarify the contradictory evidence in the literature.

All three studies described in this doctoral dissertation had a prospective design, providing strong new evidence on the effects of dietary patterns and nutrients on the incidence of depression later in life, as well as how incident depression affects short-term nutrient intakes. Therefore, this work uniquely examined the direction of both the risk and the time of dietary intakes and depression in the community-living elderly population. Besides the paucity of evidence in the literature, most related studies do not present the advantage of the extremely well-measured variables using validated and age-appropriate tools, particularly in terms of dietary data, as presented in this work. 
Using data from a representative sample of the older Canadian population living in the community, we demonstrated how energy intake is an important protective factor, while different dietary patterns seem not to be as important, and that intakes of certain B-vitamins are linked with the likelihood of becoming depressed by preceding its onset. Moreover, incident depression has little effect on the intakes of key nutrients in the short-term, demonstrating a potential dietary resilience.

\section{Research publications in refereed scientific journals}

Gougeon L.; Payette H.; Morais, J.A.; Gaudreau P.; Shatenstein, B.; GrayDonald K. Dietary patterns and incidence of depression in a cohort of community-dwelling older Canadians. (Journal of Nutrition, Health \& Aging, in press)

\section{Research manuscript in preparation for submission to refereed journals}

Gougeon L.; Payette H.; Morais, J.A.; Gray-Donald K. Prospective evaluation of the directionality of the depression-nutrient intake relationship in a cohort of healthy community-dwelling older Canadians: The reverse causality hypothesis. 
Gougeon L.; Payette H.; Morais, J.A.; Gray-Donald K. Vitamin $\mathrm{B}_{6}$ and $\mathrm{B}_{12}$ from food, but not folate, are associated with the incidence of depression in a cohort of healthy community-dwelling older Canadians.

\section{Abstracts and presentations}

Gougeon, L., Gray-Donald, K., Morais, J.A., Payette, H. (accepted) Diet and latelife depression: A reverse causality study in community-dwelling older adults. The NuAge Study. Accepted for oral presentation at the $67^{\text {th }}$ Annual Scientific Meeting of the Gerontological Society of America. Washington, DC, November 5-9, 2014. Symposium title: Nutrition as a Determinant of Healthy Aging: New Results from the NuAge Study. Chair: Dr. Pierrette Gaudreau.

Gougeon, L., Gray-Donald, K., Morais, J.A., Payette, H. (2013) Dietary patterns are not associated with a 3-year incidence of depression among healthy elderly Quebecers. The NuAge Study. Applied Physiology, Nutrition, and Metabolism, 38(4), 433-476. $4^{\text {th }}$ Annual Scientific Meeting of the Canadian Nutrition Society (CNS-SCN). May 30 - June2, 2013. Québec City, QC, Canada. (Poster)

Gougeon, L., Morais, J.A., Payette, H., Gray-Donald, K. (2013) Dietary B 6 and $\mathrm{B}_{12}$, but not folate, are associated with a 3-year incidence of depression 
among healthy elderly Quebecers. The NuAge Study. 42nd Annual

Scientific and Educational Meeting of the Canadian Association on

Gerontology (CAG-ACG). October 17 - 19, 2013. Halifax, NS, Canada.

(Poster) 


\section{CONTRIBUTION OF AUTHORS TO MANUSCRIPTS}

For all manuscripts, the candidate contributed to the development of research questions and study design, prepared data, conducted and interpreted all statistical analyses, and wrote the manuscripts. For manuscript 1 (dietary patterns), the candidate created food groupings. For manuscripts 1 (dietary patterns) and 2 (B-vitamins), the candidate prepared the dietary data to be analysed by categorizing food items, averaging daily intakes, and creating quantiles of factor scores (manuscript 1) or intakes (manuscript 2). For the third manuscript (reverse causality), the candidate was involved in cleaning up the 24hour recall data for time points 2 and 4 for the participants selected for the study and whose dietary data were available.

Dr. Katherine Gray-Donald, the candidate's supervisor and a co-principal investigator on the NuAge longitudinal study, contributed to the development of the concepts and designs of the three studies. Dr. Gray-Donald supervised statistical analysis and interpretation of data for all manuscripts. She also helped in writing and edited the manuscripts presented in this dissertation.

Dr. Hélène Payette, the candidate's committee member and the principal investigator on the NuAge longitudinal study, was involved in providing specific guidance on the acquisition of the NuAge datasets, on the study designs, 
interpretation of data, and editing all manuscripts and abstracts submitted to peer-review committees.

Dr. José Morais, the candidate's committee member and a co-principal investigator on the NuAge longitudinal study, guided the candidate regarding medical aspects of the studies, such as antidepressant medications to be considered as part of the outcome measure, provided feedback on manuscripts and abstracts, as well as other general guidance as needed.

Drs. Pierrette Gaudreau and Bryna Shatenstein, co-principal investigators on the NuAge longitudinal study, helped revising the first manuscript on dietary patterns for initial submission to a peer-review journal. 


\section{ACKNOWLEDGEMENTS}

The journey for my Ph.D. degree was complex and challenging. Despite being a mountainous experience—as expected—I have never learned and grown so much professionally and personally in my life as I did in these past six yearssurpassing all expectations. I would like to express my deep appreciation and gratitude for my advisor, mentor, and role model, Dr. Katherine Gray-Donald, for the patient guidance and mentorship she provided to me all these years in every realm of my life. She has inspired (and will continue to inspire) me to become not only a much more refined, well-rounded researcher and critical thinker, but also a dynamic mother and a resilient woman. Her continued support and encouragement were essential in my journey. To her, I will be forever grateful.

I would also like to thank my committee members, Dr. Hélène Payette and Dr. Jose Morais, equally sources of inspiration, dedication, and perseverance, for their support, guidance, and unique perspectives contributed to this work. I was also fortunate to have Louise Johnson-Down on board with her extensive technical skills and knowledge, and, more importantly, patience for the times I felt stuck. I must express my gratitude to Dr. Danielle St-Arnaud-McKenzie, who has a wealth of knowledge in aging research and guided me in my dissertation topic when I felt completely lost. 
I am also thankful for everyone in the graduate office, but mostly Lise Grant and Francine Tardif for their constant support and administrative help throughout my time in the Ph.D. program, making the ride much more pleasant. Lise Trottier, from Université Sherbrooke and others at that office were also always prompt and helpful, to whom I send my gratitude as well.

I am also indebted to my colleague and friend, JiaWei Wang, who endured with me most of my years as a PhD candidate, never letting me down. Surely many friends should be named here, but, fearing I would inadvertently miss someone, I just thank to all of them.

Finally, my deepest gratitude goes out for my family. Felipe, I would not have had the ability to endure this journey with all its ups and downs without your infinite patience, support, and encouragement every single day. Daniel, thanks for being the sunshine in my life. To my mother, father, and sister my biggest thank you for always being there for me. Aunt Angelica, I did not forget you. Thank you all so very much. 


\section{DEDICATION}

For Daniel, my pride and joy; Felipe, my source of endless support; Aline and Gercilio, my beloved parents; and Julia, my sister and confider. 


\section{TABLE OF CONTENTS}

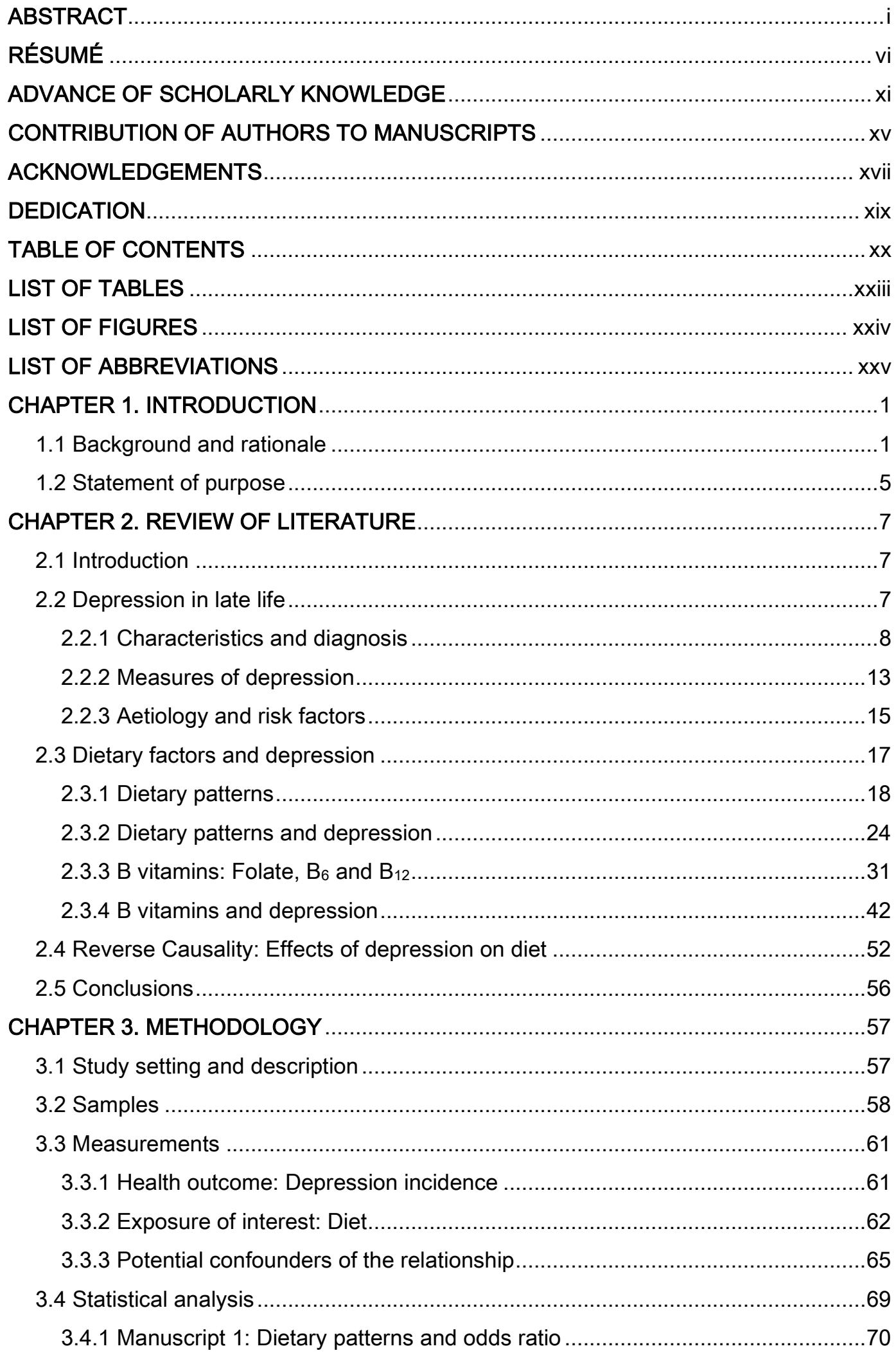




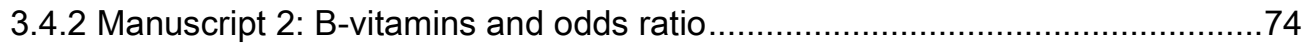

3.4.3 Manuscript 3: Reverse causality of diet-depression relationship ...................75

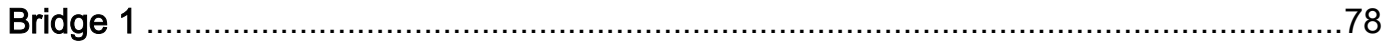

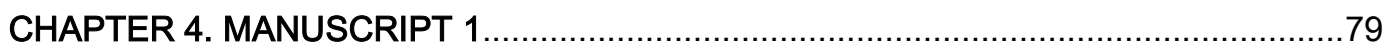

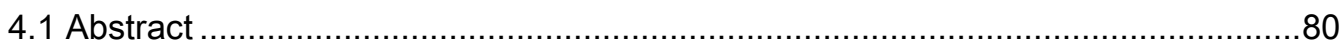

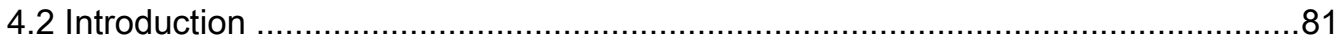

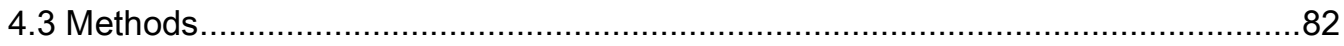

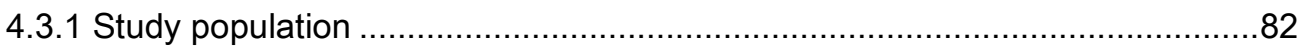

4.3.2 Dietary assessment and dietary patterns at baseline ................................. 83

4.3.3 Main outcome measure: Depression incidence ..............................................84

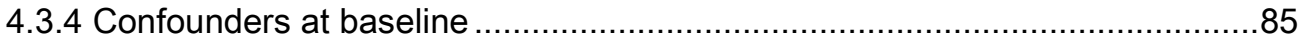

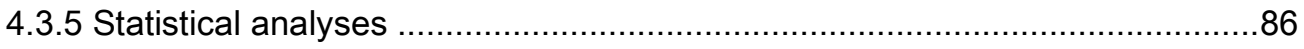

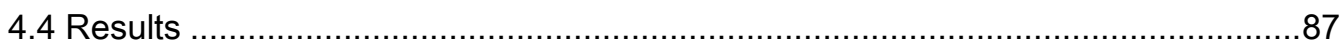

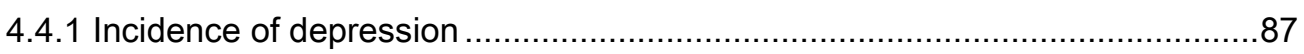

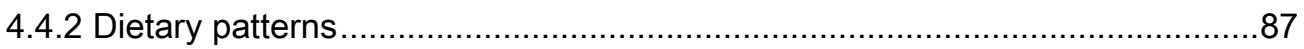

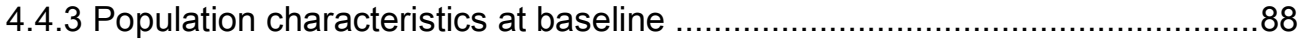

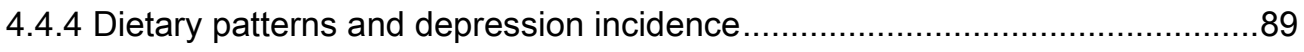

4.4.5 Macronutrient intake and depression incidence ....................................... 89

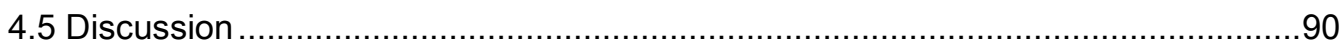

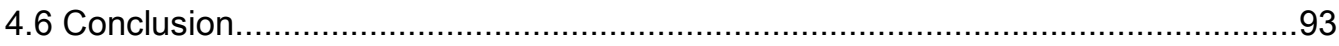

4.7 Acknowledgments and conflict of interest disclosure ........................................94

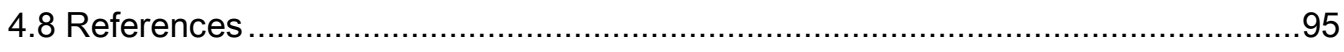

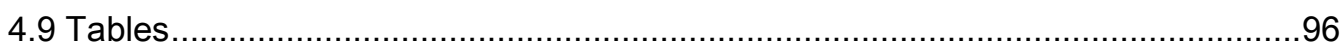

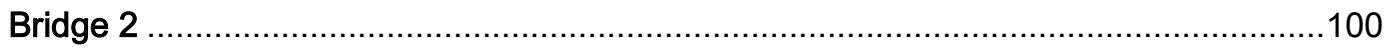

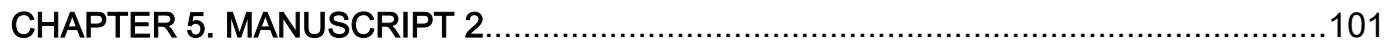

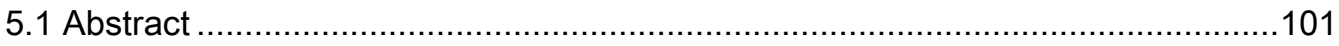

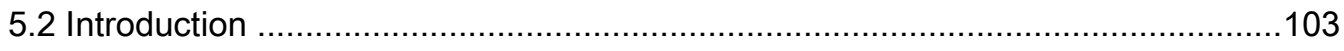

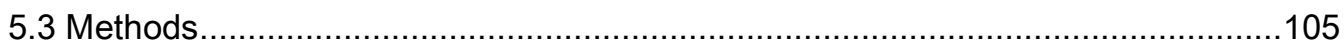

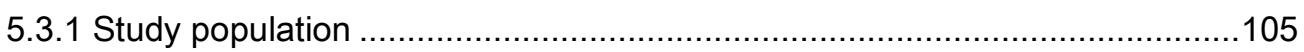

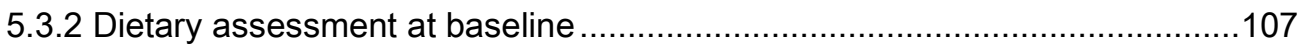

5.3.3 Main outcome measure: Incident depression ..........................................108

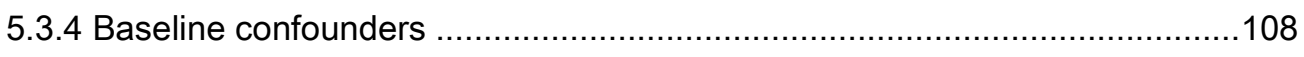

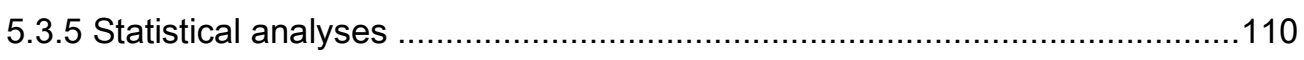

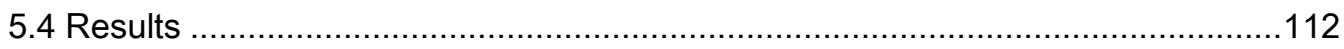

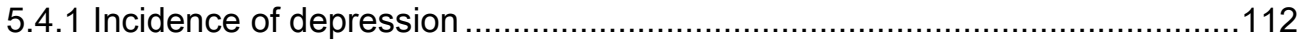

5.4.2 Baseline characteristics between depressed and not-depressed .................113

5.4.3 Associations between B vitamins and depression incidence ......................113 
5.5 Discussion .115

5.6 Conclusion 119

5.7 Acknowledgements and conflict of interest disclosure ...................................120

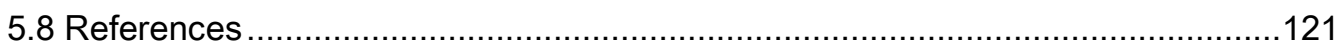

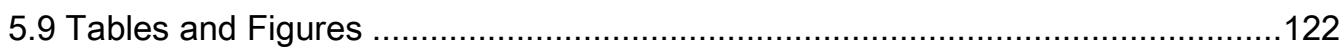

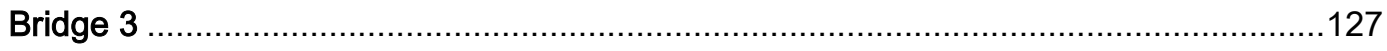

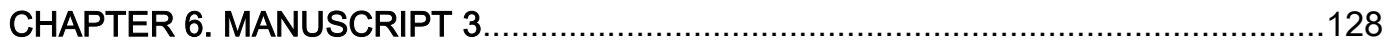

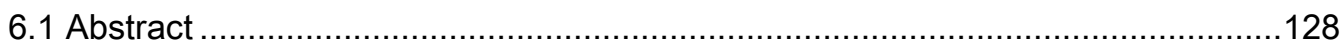

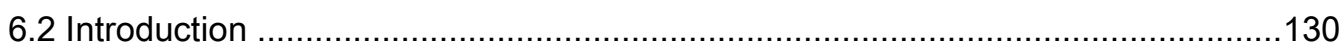

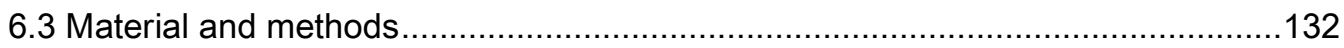

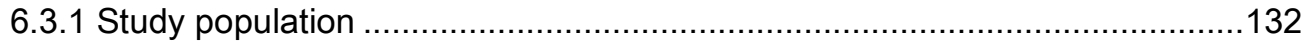

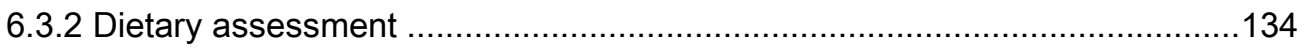

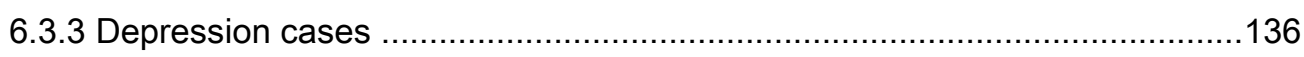

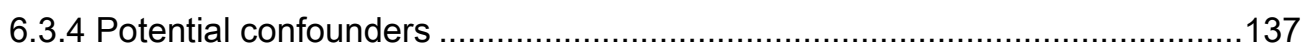

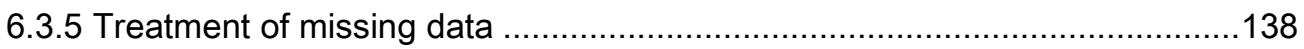

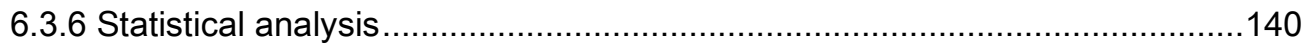

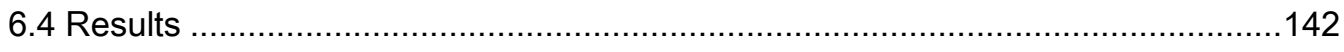

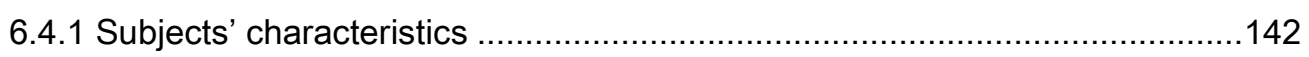

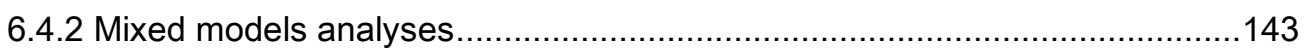

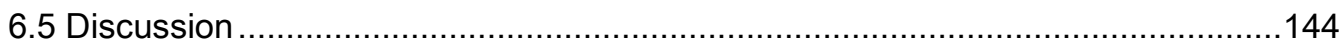

6.6 Acknowledgements and conflict of interest disclosure ...................................150

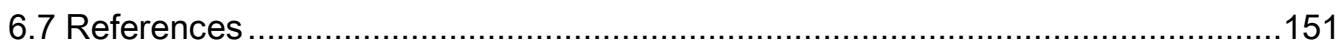

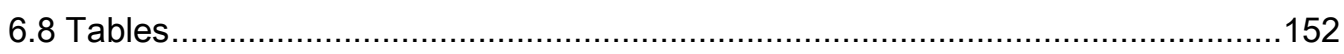

CHAPTER 7. OVERALL SUMMARY AND CONCLUSIONS ....................................157

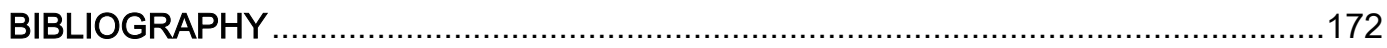

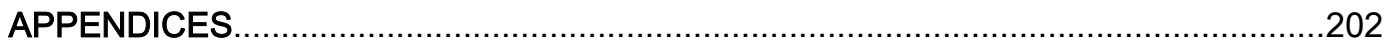

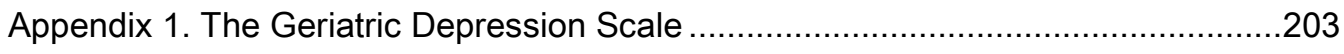

Appendix 2. Manuscript 1: Supplementary Tables .............................................205 


\section{LIST OF TABLES}

Table 1: Some cohort studies that investigated the association of dietary patterns with depression, mood, or psychological distress in community-dwelling older adults (>60y).

Table 2: Some cohort studies that investigated the association of B-vitamins (folate, $\mathrm{B}_{6}$ or $\mathrm{B}_{12}$ ) with depression incidence in community-dwelling adults (>35y).....

Table 3: Some randomized clinical trial studies that investigated the effect of B-vitamin supplementation (folate, $\mathrm{B}_{6}$ and/or $\mathrm{B}_{12}$ ) on depression and included older adults $(\geq 60 \mathrm{y}) \ldots \ldots \ldots \ldots . . . .49$ Table 4: Participants' baseline characteristics according to tertiles of dietary pattern scores $(\mathrm{N}=$ $1,358)$

Table 5: Participants' baseline characteristics according to the incidence of depression over three-years of follow-up $(\mathrm{N}=1,358)$

Table 6: Associations between tertiles of dietary pattern scores at baseline and incidence of depression over three years of follow-up $(\mathrm{N}=1,358)$.

Table 7: Associations between total energy intake at baseline and incidence of depression over three years of follow-up $(N=1,335)$

Table 8: Baseline characteristics according to the incidence of depression over three years of follow-up

Table 9: Associations between $B_{6}, B_{12}$, and folate intakes from food at baseline and incidence of depression over three years of follow-up

Table 10: Participants' demographic characteristics at recruitment

Table 11: Demographic characteristics of depressed and non-depressed subjects at the year prior (T.0) and at the year of detection (T.1)

Table 12: Dietary intakes of key nutrients for depressed and non-depressed subjects at the year prior (T.0) and at the year of detection (T.1)

Table 13: Mixed-model variables for saturated fat and B-vitamins, with estimates \pm SEM and significance, in community dwelling older Canadians .... 156 


\section{LIST OF FIGURES}

Figure 1: Diagram of one-carbon metabolism pathway in brain tissue showing the reactions involving $\mathrm{B}_{6}, \mathrm{~B}_{12}$ and folate

Figure 2: Schematic illustration of the correlation between the food categories with high factor loadings ( $\geq 0.2$ ) (indicated above each respective arrow) on component 1 (labeled, hence, "varied diet") 73

Figure 3: Box plot showing the distribution of $\mathrm{B}_{6}$ intake from diet according to sex and depression incidence (as per GDS scores $\geq 11$ and/or antidepressant use).

Figure 4: Box plot showing the distribution of $\mathrm{B}_{12}$ intake from diet according to sex and depression incidence (as per GDS scores $\geq 11$ and/or antidepressant use).....

Figure 5: Box plot showing the distribution of folate intake (as dietary folate equivalent [DFE]) from diet according to sex and depression incidence (as per GDS scores $\geq 11$ and/or antidepressant use) 


\section{LIST OF ABBREVIATIONS}

$\begin{array}{ll}\text { 3MS } & \text { Modified Mini-Mental State examination } \\ \text { AHFS } & \text { American Hospital Formulary System } \\ \text { APA } & \text { American Psychiatric Association } \\ \text { APNM } & \text { Applied Physiology, Nutrition and Metabolism } \\ \text { BDI } & \text { Beck Depression Inventory } \\ \text { BHMT } & \text { Betainehomocysteine methyltransferase } \\ \text { BMI } & \text { Body Mass Index } \\ \text { CES-D } & \text { Center for Epidemiologic Studies Depression scale } \\ \text { CCHS } & \text { Canadian Community Health Survey } \\ \text { CHAP } & \text { Chicago Health and Aging Project } \\ \text { CHMS } & \text { Canadian Health Measures Survey } \\ \text { CI } & \text { Confidence Interval } \\ \text { CIHR } & \text { Canadian Institute of Health Research } \\ \text { CRP } & \text { C-reactive Protein } \\ \text { DFE } & \text { Dietary Folate Equivalent } \\ \text { DIN } & \text { Drug Identification Numbers } \\ \text { DIN-HM } & \text { Homeopathic Medicine Number } \\ \text { DRI } & \text { Dietary Reference Intakes } \\ \text { DSM } & \text { Diagnostic and Statistical Manual of Mental } \\ \text { dTMP } & \text { Deoxythymidine Monophospate } \\ \text { dUMP } & \text { Deoxyuridine Monophosphate } \\ \text { EAR } & \text { Estimated Average Requirement } \\ \end{array}$




\begin{tabular}{ll} 
FFQ & Food Frequency Questionnaire \\
FRSQ & Fonds de la Recherche en Santé du Québec \\
GDS & Geriatric Depression Scale \\
GLM & General Linear Model \\
Hcys & Homocysteine \\
HEI & Healthy Eating Index \\
HPL & 18-item Human Population Laboratory Depression Scale \\
HR & Hazards Ratio \\
ICD & International Classification of Diseases \\
IL-6 & Interleukin-6 \\
IV & Independent Variable(s) \\
K10 & Kessler Psychological Distress Scale \\
MAS & Elderly Activity Inventory Questionnaire \\
MDI & Major Depression Inventory \\
MedDietScore & Mediterranean Diet Score \\
MHI-5 & 5-item Mental Health Inventory \\
MINI & Mini-International Neuropsychiatric Interview \\
MMA & Methylmalonic Acid \\
MRI & Magnetic Resonance Imaging \\
MTHFR & Methylenetetrahydrofolate reductase \\
NPN & Natural Product Number \\
NuAge & Quebec Longitudinal Study on Nutrition and Aging \\
OARS & Older Americans Resources and Services \\
\hline
\end{tabular}




$\begin{array}{ll}\text { OMFAQ } & \text { OARS Multidimensional Functional Assessment Questionnaire } \\ \text { OR } & \text { Odds Ratio } \\ \text { PA } & \text { Physical Activity } \\ \text { PASE } & \text { Physical Activity Scale for the Elderly } \\ \text { PCA } & \text { Principal Component Analysis } \\ \text { PHQ-9 } & \text { Patient Health Questionnaire-9 } \\ \text { PLP } & \text { Pyridoxal phosphate } \\ \text { POMS } & \text { Profile of Mood States Questionnaire } \\ \text { RAMQ } & \text { Régie de l'Assurance Maladie du Québec } \\ \text { RDA } & \text { Recommended Dietary Allowance } \\ \text { RDC } & \text { Research Diagnostic Criteria } \\ \text { RR } & \text { Relative Risk } \\ \text { SAH } & \text { S-adenosylhomocysteine } \\ \text { SAM } & \text { S-adenosylmethionine } \\ \text { SD } & \text { Standard Deviation } \\ \text { SEM } & \text { Standard Error of the Mean } \\ \text { SES } & \text { Social-Economic Status } \\ \text { SMAF } & \text { Système de Mesure de l'Autonomie Fonctionnelle } \\ \text { THF } & \text { Tethahydrofolate } \\ \text { US } & \text { United States of America } \\ \text { y } & \text { Years } \\ & \end{array}$




\section{CHAPTER 1. INTRODUCTION}

\subsection{Background and rationale}

Scientists, health professionals, and the government increasingly recognize the impacts of global aging on several aspects of our society: health care, pensions and retirement, living arrangements, among many others. Older adults are a vulnerable population; in other words, diseases can impact significantly on their functioning level and quality of life more easily than among other populations (Flaskerud \& Winslow, 1998). Therefore, there is an increased demand for research on modifiable factors that can help older adults to maintain a high functioning level and good life quality through the prevention of debilitating diseases, such as depression.

Depression is one of the most prevalent and costly of all mental disorders and a leading cause of disability, affecting one in four people over their lifetime (Stanner, Thompson, Buttriss, \& British Nutrition Foundation, 2009). In people older than 65 y of age, depression can reach prevalence rates as high as $30 \%$, depending on region, ethnicity, and diagnostic method (Djernes, 2006; Gottfries, 2001). In the Canadian Community Health Survey, 5.4\% of Canadians aged 15 and older cited symptoms consistent with a mood disorder (Statistics Canada, 2013b). The most common type of mood disorder was a major depressive episode: $4.7 \%$ of the population aged $\geq 15$ y met the World Health Organization - 
Composite International Diagnostic Interview 3.0 criteria for the disease in the last 12 months (Pearson, Ali, \& Janz, 2013). Over the course of the last 10 to 15 $y$, depression rates did not change, but Canadians reported greater diagnosis of mood disorders and use of antidepressant medication, suggested to be a reflection in the changes in diagnostic practice, mental health literacy, or willingness to report mental health concerns (Pearson, et al., 2013; Simpson, Meadows, Frances, \& Patten, 2012). Among Canadians aged 65 and older, the 12-month incidence of depression were approximately $2 \%$ (Pearson, et al., 2013). Among elderly Quebecers, it is the mental disorder with the highest incidence: $3.4 \%$ of new cases in 12 months (Preville et al., 2010). The numbers may not speak, however, to the gravity of the disease; it is its consequences and its impact on the overall quality of life that bring mental health disorders to the spotlight of research and health care. Since 1990, depression has been increasing in rank as a leading cause of disability-adjusted life years in the global burden of disease (Murray et al., 2013) and accounted for 31.7 to 49.2 percent of disability-adjusted life years caused by mental and substance use disorders in 2010 (Whiteford et al., 2013). Researchers predict that, by 2030, depression will be the second leading cause of illness worldwide, second only to HIVIAIDS (Mathers \& Loncar, 2006). 
Caregiving associated with depressive symptoms in elderly Americans represents a yearly cost of about US $\$ 9$ billion (Langa, Valenstein, Fendrick, Kabeto, \& Vijan, 2004). Despite being the commonest and the most reversible mental health problem in old age (D. N. Anderson, 2001), depression is largely underdiagnosed and not properly treated (Wittchen et al., 2011). Somatization, which is common among the depressed elderly (Ellis, Robinson, \& Crawford, 2006), plays a role in masking the depressive symptoms (D. N. Anderson, 2001) and in increasing the use of services (Sheehan \& Banerjee, 1999).

Depression can significantly impact an individual's life and that of society. Depressed, community-dwelling seniors aged 65 and older have been shown to have up to 1.5 times the risk for all-cause mortality (Hamer, Bates, \& Mishra, 2011) and almost twice the risk for incident disability in activities of daily living and mobility (Penninx, Leveille, Ferrucci, van Eijk, \& Guralnik, 1999) than nondepressed seniors. Furthermore, depression is risk factor for cardiovascular diseases (Galimanis, Mono, Arnold, Nedeltchev, \& Mattle, 2009), low bone mineral density and, consequently, fractures (Mezuk, Eaton, \& Golden, 2008), and cognitive decline (Palsson \& Skoog, 1997). Mild depression is also recognized as a risk factor for decreased activities of daily living: It significantly increased the likelihood of a senior having a physical disability and decreased the probability of their recovery from a disability in the course of six years, 
independently of contributing factors such as age, sex, and education (CroninStubbs et al., 2000). Moreover, in a community sample of 443 adults aged 30 to $98 y$, age was not associated with psychological and social aspects of quality of life, but depression was (Brown \& Roose, 2011). Prevention and management are indispensable to reduce the impacts of depression in the long-term (Schoevers et al., 2006). The study of modifiable factors potentially associated with depression in late-life is warranted.

Diet and physical activity are two modifiable factors that are associated with depression in the general population (Bodnar \& Wisner, 2005; Cassidy et al., 2004; Kohatsu, 2005) and in the elderly (Blake, Mo, Malik, \& Thomas, 2009; Bridle, Spanjers, Patel, Atherton, \& Lamb, 2012). The study of dietary factors is of high interest, as they permeate all potential aetiological factors of depression (biological, social, and psychological) (Lopresti, Hood, \& Drummond, 2013), as explained later in the literature review chapter of this dissertation. The investigation of nutritional factors such as nutrient intakes or dietary patterns is also justified by the vulnerability of elderly people to nutrient deficiencies (McCormack, 1997) due to the physiological anorexia from aging (Donini, Savina, \& Cannella, 2003; Drewnowski \& Shultz, 2001; Marian \& Sacks, 2009) and other physiological changes related to nutrient metabolism, and digestive and 
compensatory systems (de Castro \& Stroebele, 2002; Russell, 2000).

Malnutrition is more prevalent and, hence, of greater concern among seniors in acute or long-term care than in the community (Brownie, 2006). Very low prevalence rates of vitamin deficiency (Colapinto, O'Connor, \& Tremblay, 2011; MacFarlane, Greene-Finestone, \& Shi, 2011) and inadequate intakes (Shakur, Tarasuk, Corey, \& O'Connor, 2012) are reported in the Canadian population. Nonetheless, studies with healthy older persons living in the community can shed light on whether different types of existing diets and levels of observed intakes are translated into different risk levels for depression in certain populations, which is still largely unknown. Such knowledge can guide health professionals and health policies to a more effective prevention of a disorder (Areán \& Reynolds III, 2005).

\subsection{Statement of purpose}

The central hypothesis of this observational study is that diet and nutrients are modifiable factors associated with depression incidence ${ }^{1}$ in late life, which, in turn, is associated with increased morbidities and decreased life quality in this population. On the basis of this hypothesis, the overall objectives set out for this study are the following:

\footnotetext{
1 Depression incidence as estimated by scores in the Geriatric Depression Scale (GDS) or antidepressant medication use during the 3 years of follow-up.
} 
1. To assess the association between existing dietary patterns and the risk of depression incidence over the three years of follow-up.

2. To assess whether seniors who have higher observed intakes (compared to peers with lower intakes) of vitamin $B_{6}, B_{12}$ and folate are protected against incident depression over the three years of follow-up.

3. To investigate the reverse causality effect (directionality) of depression on dietary intakes by assessing nutrient intakes at the year depression was detected and at the year prior among a group of depressed older adults and their age-sex matched non-depressed counterparts.

In summary, the main interest of this work lies in the different patterns of eating (e.g. healthy versus unhealthy) and the different levels of intakes (low versus high) observed in a group of generally healthy, community-dwelling elderly Canadians and the associations between these dietary factors with depression. The following two chapters elaborate on the literature supporting these objectives and the methodology used to achieve them. 


\section{CHAPTER 2. REVIEW OF LITERATURE}

\subsection{Introduction}

This chapter presents the major and more relevant findings in the scientific literature on depression and its association with dietary factors, with a focus on generally healthy, community-dwelling older adults. It begins with a general description of the affective disease, the study of dietary patterns, and then the B vitamins, followed by the available evidence on the relationship between these dietary factors with depression. Lastly, the evidence on the effects of depression on intakes (reverse causality effect) is examined.

\subsection{Depression in late life}

Despite popular belief, depression is not a normal part of aging. It is a serious medical condition, characterized by disturbance in mood and withdrawal from pleasurable activities, independent of age (American Psychiatric Association, 2000). Demographic studies indicate that, at a given point in time, the prevalence of depressive disorders (with clinically significant symptoms requiring intervention) among people 65 years of age and older is approximately $15 \%$, but can reach rates as high as 30 percent, depending on region, ethnicity, and diagnostic method (Djernes, 2006; Gottfries, 2001). Despite some evidence that aging is associated with an intrinsic reduction in susceptibility to depression 
compared to young adults, it is not clear whether this decrease comes from aging or cohort effects (Kohn, Gum, \& King-Kallimanis, 2008; Wild et al., 2011). It is questioned whether their reduced susceptibility could be due to decreased emotional responsiveness with age, increased emotional control and/or psychological immunization to stressful experiences (Jorm, 2000; van Kessel, 2013). Nonetheless, major depression and non-major depressive syndromes in late life are shown to be associated with emotional and physical suffering, decreased quality of life (Gallegos-Carrillo et al., 2009), increased mortality (Blazer, Hybels, \& Pieper, 2001; Hamer, et al., 2011), declines in cognition (Royall, Palmer, Chiodo, \& Polk, 2011) and functional status (Avila-Funes, Melano-Carranza, Payette, \& Amieva, 2007; Cronin-Stubbs, et al., 2000; Iwasa et al., 2009; Stuck et al., 1999), and increased risk for both low bone mineral density and fractures (Mezuk, Eaton, \& Golden, 2008).

\subsubsection{Characteristics and diagnosis}

Depression is a mood disorder commonly described as unipolar depressive disorder and has several subtypes according to the severity of the symptoms (mild, moderate, and severe). "Late-life" or "late-onset" depression refers to depressive syndromes that arise in adults older than 65 years of age (Alexopoulos, 2005). Diagnosis is based on a set of symptom patterns defined in 
clinical diagnostic manuals, more commonly the Diagnostic and Statistical Manual of Mental Disorders (DSM) from the American Psychiatric Association (APA). Until 1980, there were three existent criteria, the Research Diagnostic Criteria (RDC) (Spitzer, Endicott, \& Robins, 1978) and the WHO's International Classification of Diseases (ICD-10), and APA's DSM-II. In 1980, the APA revised and extensively updated the DSM-II into a third version (DSM-III), which unified those criteria. Thereafter, the DSM started to be more widely used, particularly in the research setting (Mezzich, 2002).

A fifth edition of the diagnostic criteria (DSM-V) was released in 2013 with changes in classifications and word clarity, but neither the core criterion symptoms to diagnose a major depressive episode nor the requisite duration of at least two weeks has changed (American Psychiatric Association, 2013). Besides the required presence of either depressed mood or anhedonia, other five (out of the nine core criterion symptoms related to clinically significant distress or impairment in social, occupational, or other important areas of life) must also be present to make the diagnosis: weight loss/gain, sleep difficulty, loss of energy, psychomotor retardation, loss of interest or pleasure in usual activities, feelings of self-reproach or guilt, complaints of diminished ability to concentrate and recurrent thoughts of death or suicide (American Psychiatric Association, 2000). A major depression episode can manifest at different degrees of severity: mild or 
moderate/severe. Episodes of major depression are deemed mild when functioning appears normal but requires considerably increased effort (American Psychiatric Association, 2000). Minor depression, as opposed to major depression, is characterized by the presence of depressed mood or anhedonia plus two to four other symptoms for at least two weeks (American Psychiatric Association, 2000).

These revisions in classification and word clarity would not, however, influence the choice of initial treatment, which is largely based on such factors as the symptom profile, the presence of co-occurring disorders or psychosocial stressors, and the patient's prior treatment experience and preference (American Psychiatric Association, 2010; Unützer, 2007). In cases of mild to moderate major depressive disorder, the APA recommends antidepressant medication as the choice for initial treatment (American Psychiatric Association, 2010). Selective serotonin-reuptake inhibitors (SSRIs) are the most often used antidepressant medication as first-line treatments (Unützer, 2007).

Despite the revisions, the new DSM-V continued not to take into account the singularities in older adults' depression compared to those of younger adults (Ellison, Kyomen, \& Verma, 2008). These core symptoms rely on self-report and depend, therefore, upon the patient's ability to recognize and name depressive experiences, which requires abstract thinking and communication that may 
become impaired in the context of depression or cognitive dysfunction (Ellison, et al., 2008). The patient may focus on somatic concerns, changes in pleasure and engagement, feelings of decreased self-esteem and worthlessness, ruminative thinking, and delusions more than on mood—described as "depression without sadness" and common in this population (Gallo \& Rabins, 1999). An older, depressed patient may also have difficulty in distinguishing disturbances of sleep, energy, and appetite associated with depression from those of feared or actual physical illness (Ellison, et al., 2008), but such disturbances constitute an important component of the DSM criteria. Concurrent chronic or disabling illnesses, e.g. diabetes, cardiovascular disease, renal disease, arthritis, and stroke, further confound the diagnosis of depression in late life, as patient's complaints might be attributed to the comorbidity or its treatment, which might produce collateral effects that mimic depression symptoms (Huang, Dong, Lu, Yue, \& Liu, 2010). Parkinson's disease, for example, can produce a mood disorder responsive to antidepressants, whereas coronary artery disease induces depression-like symptoms (fatigue, insomnia) that must be addressed through treatment of the primary medical condition (Ellison, et al., 2008). Elderly depression is sometimes difficult to distinguish from dementia, but some patients do show depressive symptoms as an initial sign of the disease (Takeda \& Tanaka, 2010). Community-dwelling older people with late-onset depression 
seem significantly less likely to report a family history of depression and a previous hospitalisation for depression and to have greater cognitive impairment compared to subjects with early-onset depression (Gallagher et al., 2010). The common complaint of physical symptoms, rather than psychiatric symptoms—or somatization—also precludes the diagnosis in the elderly. In a study of psychiatric patients aged $\geq 60$ years, psychological symptoms of depression were independent predictors of somatization, but not medical comorbidities (Drayer et al., 2005). As a result of psychological distress, patients can magnify the perception of somatic symptoms—or "somatosensory amplification"-further increasing patients' focus on somatic complaints (Ellison, et al., 2008).

For all the aforementioned factors, depression in late life is unique, difficult to diagnose, and, hence, less treated. More so for those living in the community, where medical help is not always sought or as available as in an institutional setting (Frederick et al., 2007). Studies of risk factors can uncover potential ways for prevention and help to improve the life quality of the growing elderly population. Medical diagnosis of depression requires extensive clinical interviews, which are costly and arduous. Depression questionnaires or scales have been developed and validated to assist clinicians and researchers in detecting depression as effectively as possible, and their use has been recommended in primary care practice as screening tools (Unützer, 2007). 


\subsubsection{Measures of depression}

Depression scales have been used for decades and are, therefore, among the best-established of health measurements available (McDowell, 2006). Most scales are validated against medically diagnosed major depressive disorder using the DSM or the ICD criteria. There are basically two types of depression measurements: self-rating and clinician-rating scales, commonly used in epidemiological and clinical studies, respectively (McDowell, 2006). Some health questionnaires also contain items or brief sub-scales that measure depression or mood.

The increasing availability and effectiveness of such scales made epidemiological studies of depression easier and less costly. Nonetheless, different scales can provide different pictures of the prevalence and incidence of depression in a certain population, depending on what and how questions ask for depressive-like feelings, the population studied, what criteria were used to validate the tool, and whether the scale was self- or clinician-rated (Patten, Wang, Beck, \& Maxwell, 2005). Moreover, because depression is characterized by multiple coexistent symptoms that manifest differently from one person to another, measurements must cover its entire dimensions of symptoms: affective (crying, sadness, apathy), cognitive (thoughts of hopelessness, helplessness, suicide, worthlessness, guilt), and somatic (sleep disturbance, change in energy 
level, appetite, sleep, elimination) (Ellison, et al., 2008). It is the choice of coverage of each dimension that distinguishes the scales and their applications.

The Geriatric Depression Scale (GDS) (Brink et al., 1982) is one of the most commonly used self-rating scales to assess and screen depression in gerontological studies. It was first developed and validated by Brink and Yesavage, in 1982, in response to the need of addressing the differences in the course of depression in this population compared to the young. Although other scales such as the Center for Epidemiologic Studies Depression Scale (CES-D) (Radloff, 1977) are also used in studies of the elderly, the main advantages of the GDS measurement tool revolve around its focus on how depression manifests in the elderly population and its excellent reliability and validity in regards to both thoroughness and results (with higher coefficients than those normally seen in other instruments) (McDowell, 2006). Numerous studies have been using it since, thus facilitating comparison across studies.

The GDS tool contains 30 questions with a yes/no format, in which every answer favouring depression-like symptoms sums one point with higher values reflecting depression severity (Appendix 1). Cut-off points for diagnosis and severity of depression were set according to the Research Diagnostic Criteria (RDC) for a medically diagnosed major affective disorder (depression) (Spitzer, et al., 1978), which has been encompassed by the aforementioned DSM criteria. 
Therefore, as a screening tool, cut-off scores from 0 to 10 points are considered within the normal range (non-depressed), 11 to 20 points indicate mild major depression, and 21 to 30 , moderate to severe major depression with a sensitivity of 84 percent and specificity of 95 percent for each level (Brink, et al., 1982; McDowell, 2006; Yesavage et al., 1983).

Its questions represent the core of geriatric depression such as lowered affect, inactivity, irritability, withdrawal, distressing thoughts, and negative judgements about past, present, and future (Brink, et al., 1982). The timeframe is the past week. Examples of questions include, "Are you basically satisfied with your life?", "Have you dropped many of your activities and interests?", and "Do you feel that your life is empty?" (Brink, et al., 1982; McDowell, 2006). The tool was validated in a group of older adults ( $>55$ years old) who were either normal elderly living in the community with no complaints of depression and no history of mental illness, or subjects hospitalized for depression (Yesavage, et al., 1983).

\subsubsection{Aetiology and risk factors}

The origin of late-life depression is still unclear. Models propose an interaction of the three biological, psychological, and social dimensions (Blazer \& Hybels, 2005). Research suggests that biological factors, such as neurotransmitter dysfunction, endocrine changes, vascular-based depression, 
inflammation, and, possibly, nutrition, play an important role in the origins of depressive symptoms in the elderly (Alexopoulos, 2005; Krishnan, 2002).

Nevertheless, stroke, loss of hearing, loss of vision, cardiac disease and chronic lung disease, for example, can further aggravate all three aetiology dimensions and are, therefore, risk factors for increased depression (Huang, Dong, et al., 2010). In a meta-analysis, although both poor self-rated health status and the presence of chronic disease, such as heart and lung disease, arthritis, hypertension and diabetes, were deemed risk factors for depression among the elderly, having poor self-rated health status was more strongly associated with depression than chronic disease (Huang et al., 2010).

Several psychological and social factors, which can influence perceived health status, are also considered risk factors for depression in late-life. Bereavement, social isolation, disability from medical illness, need for rehabilitation, alcohol or substance abuse (Bruce, 2002), prior depression, stressful life events, living conditions (e.g. living alone or with a partner), low income, and decreased education level seem important risk factors among elderly community subjects (Cole \& Dendukuri, 2003). Furthermore, women appear to be more at risk than men regardless of age (Cole \& Dendukuri, 2003; Vink, Aartsen, \& Schoevers, 2008). In contrast, physical activity, active social 
network, and religion are considered protective factors (Blazer \& Hybels, 2005;

Bots, Tijhuis, Giampaoli, Kromhout, \& Nissinen, 2008; Fox, 1999).

Nutrition and diet are determined by both biological and social dimensions, warranting the study of their potential association with late-life depression.

Biologically, diet can affect nutritional status (Hickson, 2006), and, in turn, mental health (Davison et al., 2012), and it is dictated by social determinants, e.g. socialeconomic status (Payette \& Shatenstein, 2005). Furthermore, like physical activity, diet is a modifiable factor that plays a role in psychiatric diseases (Freeman, 2010), including depression (Kohatsu, 2005). Recently, a systematic review of randomised controlled trials concluded that nutritional education as a major focus of a complex intervention (e.g. with other health promotion activities) can potentially reduce depression in people over 65 years who live at home (K. Young, Bunn, Trivedi, \& Dickinson, 2011).

\subsection{Dietary factors and depression}

Diet permeates the aetiological dimensions of depression, which strengthens the diet-depression relationship. At a biological level, diet and other lifestyle factors like sleep and exercise mediate the development, progression and treatment of major depression disorder. They play a role in the dysregulated biological and physiological pathways associated with the disease, such as the 
immune-inflammatory pathways, hypothalamic-pituitary-adrenal (HPA) axis, neurotransmitter processes, neuroprogression, and oxidative stress and antioxidant defence systems (Kaplan, Crawford, Field, \& Simpson, 2007; Kohatsu, 2005; Lopresti, et al., 2013). At a social and psychological level, eating is not an automatic process, like breathing, and is determined to a large extent by a person's cultural, social, and psychological pressures (Elsner, 2002). Hence, eating is also strongly associated with or influenced by psychosocial components of elderly depression, e.g. bereavement, social engagement, social-economic status (Elsner, 2002; Johnson, 2002; Sapolsky, 2004).

This sub-section will focus on dietary patterns and the three B vitamins of interest and the evidence linking their potential association with depression.

\subsubsection{Dietary patterns}

Research on dietary or eating patterns has been expanding for several reasons: i) people eat meals with a variety of foods with both nutrients and nonnutrients that likely have interactive and synergistic or cumulative effects; ii) these effects may be sufficiently large to be more easily detected compared to "single-nutrient" analyses; iii) some nutrients are highly correlated (e.g. K and Mg), making it difficult to examine their separate effects; and iv) statistically 
significant associations can occur simply by chance when a large number of nutrients or food items are studied (Hu, 2002; Kant, 2004; Tucker, 2010).

There are basically two types of dietary pattern approaches: a priori, e.g. indices or scores, and a posteriori, e.g. factor analysis. Although these approaches were extensively reviewed by Kant $(1996,2004)$, I will briefly describe them here.

\subsubsection{A priori dietary patterns}

A priori approaches define dietary patterns theoretically through the use of current (or prior) knowledge on what is considered a healthy or protective diet to assign scores that measure compliance to a desirable dietary pattern or guideline (Kant, 2004; Waijers, Feskens, \& Ocké, 2007). They can be nutrient-based or food- and food group-based. Examples include the health eating index (HEI), diet quality score, DASH diet², and the Mediterranean Diet Score (MedDietScore) (Kant, 2004).

A priori techniques have a greater intuitive appeal compared to a posteriori approaches. Studies using them seem to find significant associations with health outcomes more successfully, particularly when it comes to the Mediterranean Diet (Roman, Carta, Martinez-Gonzalez, \& Serra-Majem, 2008; Willett, 2006).

\footnotetext{
$2 \mathrm{DASH}$ diet $=$ Dietary Approaches to Stop Hypertension diet protocol.
} 
Critics argue, however, that existing indices do not predict morbidity or mortality significantly better than individual dietary factors (Waijers, et al., 2007). The main concern revolves around the arbitrary decisions regarding the basis for their creation, the scoring method, and the establishment of a cut-off, all of which may not adequately address correlations in intake between dietary components, such as energy intake and micronutrient intake (Waijers, et al., 2007). Moreover, indices are not immediately translatable across different food cultures, as it happens with the Mediterranean pattern itself, for example, and are based on dietary knowledge available in the literature, which may not be the real optimal diet for a certain health condition, for instance (Tucker, 2010). Thus, while research using a priori methods can confirm (or disprove) what is already known to be a healthy or desirable diet, it cannot uncover new patterns of eating that could be equally or more strongly linked to decreased disease risks or increased health status, for example—but a posteriorimethods can.

\subsubsection{A posteriori dietary patterns}

A posteriori approaches derive patterns empirically through the use of datadriven methods and without a prior hypothesis of what is deemed healthy or desirable. The most common techniques are factor analysis, cluster analysis, and reduced ranked regression (Hu, 2002; Kant, 2004; Tucker, 2010). In reduced 
rank regression, the least used of these approaches, factor scores of food combinations (from factor analysis technique) are "forced" to maximize their predictive power in relation to a set of intermediate variables, such as inflammation markers or lipid concentrations (Tucker, 2010).

Principal component analysis (PCA) is the most common form of factor analysis. Food items from dietary questionnaires, such as food frequency questionnaires, 24-hour recalls, and dietary record, are categorized into meaningful food groups. PCA is then run on the intakes of these food categories (e.g. daily grams or number of portions) to aggregate specific ones on the basis of the degree to which each food category in the dataset is correlated with one another. PCA aggregates these correlated categories in "principal components," with which each food group will have an associated factor loading—more intuitively seen as a correlation factor. Each principal component retained from PCA receives a label that best describes it according to the food categories that showed high factor loadings on that component, finally constituting a dietary pattern. Each study participant receives a summary score on each pattern (or principal component) that can be interpreted as "levels of adherence" to that pattern. These scores have good statistical power and can then be used in regression analysis either as continuous variables or in quantiles to examine the 
relationships between the various eating patterns and the health outcome of interest (Hu, 2002; Tucker, 2010). More details on PCA are given in chapter 3.

As it can be inferred from the description above, factor analysis is much less intuitive compared to a priori approaches and, therefore, requires advanced statistical knowledge for the user to apply and interpret it adequately. The scores pose another limitation because they are somewhat abstract. The process of deciding how many and what food groups to include in the PCA, the source of information [e.g. weight consumed of each food group, energy-adjusted weight, percentage contribution to energy of each food group, binary intake (consumed/not consumed)] and how many components to retain is relatively subjective - though there are generally accepted criteria to minimize subjectivity-and may lead to different score combinations. On the other hand, $a$ posterioriapproaches can reveal patterns of eating that are currently unknown to be protective or beneficial to health conditions or that are specific to an ethnic or sub-population group. This very advantage is also a shortcoming, as patterns from factor analysis may not necessarily reflect optimal diets and are not generalizable to different populations. Nonetheless, dietary patterns from PCA have been increasingly present in nutrition research not only as means to understand better the relationships between diet and diseases, but also because they can be more easily translated into health messages to the population of 
interest (e.g. A. L. Anderson et al., 2011; Bamia et al., 2005; Beaudry, Galibois, \& Chaumette, 1998; Chocano-Bedoya et al., 2013).

While factor analysis does not separate individuals into groups according to their intakes, cluster analysis creates groups (or clusters) of individuals based on maximally separate eating patterns, with descriptions of mean intakes in each pattern (Bailey et al., 2006; Hu, 2002; Tucker, 2010). Although cluster analysis and PCA seem to identify similar dietary patterns when presented with the same dataset, they require different format of the food-group variable to perform best (Bailey, et al., 2006; Hearty \& Gibney, 2009). It has been suggested that PCA can be advantageous over cluster analysis because every individual contributes with a score, and they are not separated into groups (or clusters); some people can have high or low scores in more than one pattern and do not perfectly conform to one specific pattern (Hu, 2002; Tucker, 2010). Furthermore, exactly because cluster analysis creates groups, it requires further analysis to adequately interpret the patterns identified (e.g. comparing dietary profiles across clusters) and much larger sample sizes due to its decreased power to detect associations with outcomes (Hu, 2002; Tucker, 2010). 


\subsubsection{Dietary patterns and depression}

Cross-sectional studies are not the best design to investigate the association of diet and depression because of a possible reverse causation in the relationship; in other words, it is unclear whether a poor diet, for example, leads to depression or whether the depression triggered changes in diet. Nevertheless, several cross-sectional studies with community-dwelling adults, mostly in middle age (e.g. Beydoun, Shroff, Beydoun, \& Zonderman, 2010; Nanri, Kimura, et al., 2010; Rienks, Dobson, \& Mishra, 2013) and some in old age (e.g. Mamplekou et al., 2010; Payne, Haines, Chambless, Anderson, \& Steffens, 2007; Payne, Hybels, Bales, \& Steffens, 2006; Samieri et al., 2008), were conducted in several countries. Studies with middle-aged adults have found at least one significant association between dietary measurements (e.g. patterns, diet scores, specific food items) and depression—mostly a protective effect of high diet quality scores (Beydoun, et al., 2010; Jacka, Mykletun, Berk, Bjelland, \& Tell, 2011; Kuczmarski et al., 2010) and of patterns deemed "healthy" or "traditional" (Jacka, et al., 2011; Nanri, Kimura, et al., 2010; Rienks, et al., 2013). Among older adults, evidence is contradictory, as both the measurements and the results are inconsistent across studies. Higher consumption of fish and olive oil—but not high Mediterranean Diet Scores (Mamplekou, et al., 2010)—, increasing percent of energy from alcohol (Payne, et al., 2006), "healthy diet" cluster in women (Samieri, et al., 
2008), and vegetable intakes above 2,100 g/week (Woo et al., 2006) were associated with lower depression prevalence or depression scores. On the other hand, seniors with a high cholesterol diet (Payne, et al., 2006) and in a "pasta eaters" cluster (Samieri, et al., 2008) had increased depression scores. In a cross-sectional study of 54 elderly with current or prior vascular depression [as defined by the presence of certain types of hyperintensities on brain magnetic resonance imaging (MRI)], the number of servings of whole-fat dairy and whole grains was positively associated with increased brain lesion volumes in multivariate analyses, which, according to the authors, were the aetiology of these seniors' vascular-based depression (Payne, et al., 2007).

Longitudinal studies provide a more adequate setting to investigate the relationship of diet and depression (Guralnik \& Kritchevsky, 2010; Newman, 2010). Studies in the middle-aged adult population have shown significant associations between some dietary patterns and the risk of depression, but not without discrepancy (Akbaraly et al., 2009; Le Port et al., 2012; McMartin, Jacka, \& Colman, 2013; Rienks, et al., 2013; Sanchez-Villegas, Henriquez, BesRastrollo, \& Doreste, 2006).

Akbaraly et al. (2009) detected two dietary patterns through PCA among 3,486 middle-aged British participants in the Whitehall II prospective cohort: 
"Processed food" pattern (loaded high in sweetened desserts, fried food, processed meat, refined grains and high-fat dairy products) and "whole food" pattern (represented by vegetables, fruits and fish). After adjustment for several social and health confounders, the processed food pattern was a risk factor for depression five years later, whereas the whole food pattern was protective. In sensitivity analysis of depression incidence, in which the authors excluded participants considered depressed at baseline, the "whole food" pattern was no longer protective.

Also using PCA, Le Port and colleagues (2012) identified six food patterns among 3,132 women and eight patterns among 9,262 men aged 35-50 at recruitment and followed for approximately 10 years in the GAZEL cohort in France. After controlling for health and social confounders, women in the highest quartile of "snacking" or "low-fat" pattern scores showed increased risk for depression $(\mathrm{P}$ trend $<0.01)$, while those with high adherence to the "healthy" and "traditional" patterns had decreased risk $(P$ trend $<0.001)$. Among men, "low-fat," "western," "fat-sweet," and "snacking" patterns were associated with an increased risk of depression ( $P$ trend $<0.001$, "low fat" $<0.01$ ), and a "healthy" pattern, with a decreased risk ( $\mathrm{P}$ trend $<0.001)$. The "healthy" pattern was, however, no longer protective in both men and women when participants 
deemed depressed at baseline were excluded from analysis. Therefore, it is not clear whether a "healthy" pattern was indeed protective of new onset depression.

In the Australian Longitudinal Study on Women's Health, Rienks et al.

(2013) used the dietary data from 6,060 participants (50-55y), free of depression at baseline, to identify six dietary patterns in PCA: "cooked vegetables," "fruit," "Mediterranean style" (garlic, peppers, mushrooms, salad greens, pasta and red wine), "meat and processed meat," "dairy" and "high fat and sugar." Only the "Mediterranean-style" pattern was protective of depressive symptoms three years later [multivariate odds ratio (OR) $0.83,95 \%$ confidence interval $(\mathrm{Cl}) 0.75-0.91$ ]. When they considered quintiles of adherence to the "Mediterranean-style" diet, those in the highest quintile were $37 \%$ less likely to report depressive symptoms, (multivariate $\mathrm{OR} 0.63,95 \% \mathrm{Cl} 0.47-0.85$ ) compared with the first quintile (reference). It is noteworthy that, among all six patterns, the "Mediterraneanstyle" pattern was the only one with the characteristics of a varied diet, which includes a diversity of food groups, whereas the other patterns were characterized by only one or two specific food groups.

A study with 10,094 Spanish university graduates (20-55y) observed a decreased 4-year risk of depression (self-reported physician-made diagnosis) among participants with high Mediterranean Diet Scores (an a priori approach)- 
higher scores were also positively related to total energy intake (SanchezVillegas, Delgado-Rodriguez, et al., 2009).

As people age, changes in eating behaviours and food choices occur (Drewnowski \& Shultz, 2001; Elsner, 2002), so longitudinal associations between food patterns and depression risk may differ in older adults. To our knowledge, very few cohort studies explored the diet-depression relationship in the healthy elderly population. Table 1 compiles the main longitudinal studies investigating dietary patterns and depression in community-dwelling elderly.

Mediterranean-like diets seem to attract great interest, but evidence appears more contradictory in older adults than in middle-aged adults. When such diets are measured with a priori approaches, e.g. using Mediterranean Diet Scores, the association seems stronger than when a posteriori techniques are used (Hodge, Almeida, English, Giles, \& Flicker, 2013; Skarupski, Tangney, Li, Evans, \& Morris, 2013), as seen in Table 1. 
Table 1: Some cohort studies that investigated the association of dietary patterns with depression, mood, or psychological distress in community-dwelling older adults (>60y).a

\begin{tabular}{|c|c|c|c|c|}
\hline $\begin{array}{l}\text { Author, } \\
\text { Country, } \\
\text { Follow-up }\end{array}$ & Participants & Main variables & Covariates & Findings \\
\hline $\begin{array}{l}\text { (Woo, Ho, } \\
\& \text { Yu, } \\
\text { 2002) } \\
\text { China, 3y }\end{array}$ & $\begin{array}{l}\text { Hong Kong } \\
\text { Chinese men and } \\
\text { women aged } \geq 70 y \\
(\mathrm{~N}=1,071)\end{array}$ & $\begin{array}{l}\text { IV: Frequency of consumption of } \\
\text { fruits, vegetables, soy products, and } \\
\text { fish } \\
\text { Outcome: Depression (GDS) }\end{array}$ & Age and self-perceived health & $\begin{array}{l}\text { Incidence: } 32 \%(\mathrm{n}=339) \\
\text { - No association between fruits, vegetables, soy } \\
\text { products, or fish intakes and risk of depression } \\
\text { after adjustment. }\end{array}$ \\
\hline $\begin{array}{l}\text { (Chocano- } \\
\text { Bedoya, et } \\
\text { al., 2013) } \\
\text { US, 22y }\end{array}$ & $\begin{array}{l}\text { Middle-aged and } \\
\text { elderly women ( } 50- \\
77 y \text { at baseline) in } \\
\text { the Nurses' Health } \\
\text { Study }(\mathrm{N}=50,605)\end{array}$ & $\begin{array}{l}\text { IV: Dietary patterns (PCA): Prudent } \\
\text { vs. Western } \\
\text { Outcome: Clinical depression (strict } \\
\text { definition: reported clinical diagnosis } \\
\text { AND use of antidepressants; broad } \\
\text { definition: clinical diagnosis OR } \\
\text { antidepressant use) }\end{array}$ & $\begin{array}{l}\text { BMI, PA, total energy, total } \\
\text { caffeine, smoking status, } \\
\text { menopause status, use of } \\
\text { hormonal replacement } \\
\text { therapy, marital status, } \\
\text { multivitamin use, retired, } \\
\text { participation in community } \\
\text { groups, diagnosis of some } \\
\text { chronic diseases, mental } \\
\text { health at baseline (MHI-5) }\end{array}$ & $\begin{array}{l}\text { Incidence: Strict definition: } 5.9 \% \text { ( } n=3,002) \text {; Broad } \\
\text { definition: } 14.6 \% \text { ( } n=7,413) \\
\text { - Under the strict definition: No association of } \\
\text { dietary patterns with depression risk. } \\
\text { - Under the broad definition: Women with the } \\
\text { highest scores for the Western pattern had } 15 \% \\
\text { higher risk of depression ( } 95 \% \mathrm{Cl} 1.04-1.27) \text { than } \\
\text { women with the lowest scores. } \\
\text { - After additional adjustment for psychological } \\
\text { scores at baseline, results were no longer } \\
\text { significant (RR } 1.09 ; 95 \% \mathrm{Cl} 0.99-1.21) \text {. }\end{array}$ \\
\hline $\begin{array}{l}\text { (Hodge, et } \\
\text { al., 2013) } \\
\text { Australia, } \\
12 y\end{array}$ & $\begin{array}{l}\text { Healthy men and } \\
\text { women }(50-69 y) \text { not } \\
\text { using } \\
\text { antidepressant or } \\
\text { anxiolytic } \\
\text { medications at } \\
\text { baseline }(\mathrm{N}=8,660)\end{array}$ & $\begin{array}{l}\text { IV 1: Dietary patterns (PCA): } \\
\text { Modified Mediterranean-style } \\
\text { pattern vs. Australian Dietary } \\
\text { Pattern } \\
\text { IV 2: Mediterranean Diet Score (a } \\
\text { priorı) } \\
\text { Outcome: Psychological distress } \\
\text { (K10 scores } \geq 20 \text { ) }\end{array}$ & $\begin{array}{l}\text { PA, education, smoking status, } \\
\text { history of arthritis, kidney } \\
\text { stones or gallstones, dietary } \\
\text { energy intake, SES, social } \\
\text { support }\end{array}$ & $\begin{array}{l}\text { Incidence: } 9 \%(\mathrm{n}=731) \\
\text { Higher energy intakes were associated with higher } \\
\text { psychological distress 12y later. } \\
\text { - Weak protection from the Australian dietary } \\
\text { pattern on psychological distress. } \\
\text { - No association with the Modified Mediterranean- } \\
\text { style pattern. } \\
\text { - Inverse association with Mediterranean Diet } \\
\text { Scores. }\end{array}$ \\
\hline
\end{tabular}

(continued on next page) 


\begin{tabular}{|c|c|c|}
\hline $\begin{array}{l}\text { Author, } \\
\text { Country, } \\
\text { Follow-up }\end{array}$ & Participants & Main variables \\
\hline $\begin{array}{l}\text { (Skarupski, } \\
\text { et al., }\end{array}$ & \multirow{3}{*}{$\begin{array}{l}\text { CHAP participants } \\
\text { (community- } \\
\text { dwelling, aged } \geq \\
65 y, 59 \% \text { African } \\
\text { American, no } \\
\text { depression at the } \\
\text { baseline) }(\mathrm{N}=3,502)\end{array}$} & $\begin{array}{l}\text { IV: Mediterranean Diet Score (a } \\
\text { priori method) }\end{array}$ \\
\hline 2013) & & \multirow{2}{*}{$\begin{array}{l}\text { Outcome: Depression (10-item } \\
\text { CES-D) }\end{array}$} \\
\hline US, 7.4y & & \\
\hline $\begin{array}{l}\text { (Lucas et } \\
\text { al., 2014) }\end{array}$ & \multirow{3}{*}{$\begin{array}{l}\text { Middle-aged and } \\
\text { elderly women }(50- \\
77 y) \text { in the Nurses' } \\
\text { Health Study } \\
(\mathrm{N}=43,685) \text { free of } \\
\text { depression at } \\
\text { baseline }\end{array}$} & $\begin{array}{l}\text { IV: Dietary pattern associated with } \\
\text { selected inflammatory biomarkers }\end{array}$ \\
\hline US, $12 y$ & & (reduced ranked regression) \\
\hline & & $\begin{array}{l}\text { Outcome: Clinical depression (strict } \\
\text { definition: reported clinical diagnosis } \\
\text { AND use of antidepressants; broad } \\
\text { definition: reported clinical diagnosis } \\
\text { OR antidepressant use) }\end{array}$ \\
\hline
\end{tabular}

a Main variables, Covariates, and Findings present only information relevant to this thesis and exclude other unrelated variables, such as overall mortality, physical activity, smoking, or new diseases. Acronyms: BMI = body mass index; CES-D = Center for Epidemiologic Studies Depression Scale; CHAP = Chicago Health and Aging Project; $\mathrm{Cl}=$ Confidence Interval; GDS = Geriatric Depression Scale; IV = Independent Variable(s); K10 = Kessler Psychological Distress Scale; MHI-5 = 5item Mental Health Inventory; OR = Odds ratio; PA = physical activity; PCA: Principal Component Analysis; RR = relative risk; SE = standard error; SES = socialeconomic status; US = United States of America; $y=$ years. 
From the longitudinal studies in middle-aged and older adults, it can be observed that inconsistences seem more pronounced when baseline depression was considered in a sensitivity or ancillary analysis, leading to relative attenuation of the findings (Akbaraly, et al., 2009; Chocano-Bedoya, et al., 2013; Le Port, et al., 2012; Woo, et al., 2002). Given the limited and controversial evidence, particularly among the elderly, we investigated the longitudinal association between depression incidence and dietary patterns of communitydwelling older adults in Canada. The study of foods (as opposed to nutrients) can result in more easily attainable health messages and recommendations for the older population.

\subsection{3 $B$ vitamins: Folate, $B_{6}$ and $B_{12}$}

Parallel to the study of foods and their association with health conditions, the investigation of nutrients is warranted for their role in biological and organic reactions and processes. Moreover, different foods are sources of difference nutrients. The interest in B vitamins comes particularly from their role in the nervous system, as described in this section.

The hypothesized association between B vitamins and depression dates from the 1960's, when clinicians began to observe a strong correlation between folate-deficiency states and depression (Alpert, Mischoulon, Nierenberg, \& Fava, 
2000). Hence, in the 1980s, research testing the relationship between other Bvitamins with mental health, particularly depression, started to advance (AbouSaleh \& Coppen, 1986; S. N. Young \& Ghadirian, 1989).

B vitamins are water-soluble vitamins that generally function as coenzymes in chemical reactions; folate, vitamin $\mathrm{B}_{6}$ and $\mathrm{B}_{12}$ are particularly important in the nervous system (Institute of Medicine, 2006; Whitney \& Rolfes, 2008). The subsequent sections of this chapter describe their roles in these reactions and then present the guiding evidence that founds the interest in these three vitamins (e.g. Akhondzadeh, Gerbarg, \& Brown, 2013; Bottiglieri, 2013; Cole \& Dendukuri, 2003; Folstein et al., 2007; Harbottle \& Schonfelder, 2008; Reynolds, 2006).

\subsubsection{Folate}

Folate is a generic term that encompasses both the vitamin naturally occurring in foods (food folate or pteroylpolyglutamates) and the artificial form present in fortified food and dietary supplements (folic acid or pteroylmonoglutamic acid), the latter being more stable and more bioavailable (Institute of Medicine, 2006; Whitney \& Rolfes, 2008). Folate's main chemically reduced form, the tetrahydrofolate (THF), acts as a co-factor conveyor of onecarbon units at various states of oxidation in one-carbon transfer reactions (M. Johansson et al., 2009; Lamprecht \& Lipkin, 2003). In sum, folate functions as a 
coenzyme in the metabolism of nucleic and amino acids. The one-carbon metabolism is explained in more detail later.

Dietary reference values for the healthy North-American population are established on the basis of Dietary Folate Equivalent (DFE), in which 1 DFE is equivalent to $1 \mathrm{mcg}$ of food folate, $0.6 \mathrm{mcg}$ of folic acid (fortified food or supplements) consumed with food and $0.5 \mathrm{mcg}$, if consumed on an empty stomach. Based on erythrocyte folate maintenance, the Dietary Reference Intakes (DRI) stipulate an Estimated Average Requirement (EAR) of 320 DFE mcg of folate per day for both males and females aged $\geq 51$, and a recommended dietary allowance (RDA) of 400 DFE mcg. Rich food sources of folate include fortified grain products, dark green vegetables, and beans and legumes (Institute of Medicine, 2006). The virtually non-existent folate deficiency among Canadians at all ages (Colapinto, et al., 2011) has been largely attributed to the mandatory fortification of white flour with folic acid. Among communitydwelling older Canadians, there has been a steady and significant increase in folate status since the fortification policy in 1998 (Garcia, Day, Zanibbi, \& Zunzunegui, 2008). It seems, however, that still a considerable proportion of people consume diets below the recommended intakes. Data from a representative sample of Canadians in the Canadian Community Health Survey (CCHS) cycle $2.2(\mathrm{~N}=34,381)$, whose distribution of intakes were adjusted for 
within-person variation, indicate that the prevalence of inadequate folate intake from diet alone is up to $40 \%$ in women and $22 \%$ in men aged 51 and older (Shakur, et al., 2012), although supplementation mitigated these rates by bringing the prevalence rate of inadequacy to lower than $5 \%$ (Shakur, et al., 2012).

\subsubsection{Vitamin $B_{6}$}

Vitamin $B_{6}$ is found in a variety of foods, being meats, fish, poultry, potatoes and other starchy vegetables, legumes, non-citrus fruits, fortified ready-to-eat cereals, liver, and soy products the best sources. The term comprises three main forms (pyridoxine, pyridoxal, and pyridoxamine) and their 5'-phosphate derivates, and all of which can be converted to the coenzyme pyridoxal phosphate (PLP) (Institute of Medicine, 2006; Whitney \& Rolfes, 2008). PLP is involved in the process of nonessential amino acid synthesis by transferring amino groups $\left(\mathrm{NH}_{2}\right)$ from an amino acid to a keto acid, helping to transform tryptophan into niacin or into the neurotransmitter serotonin, for example (Whitney \& Rolfes, 2008). Vitamin $\mathrm{B}_{6}$ also plays a key role in the one-carbon metabolism.

Vitamin $B_{6}$ requirements are set to produce a plasma PLP level of at least $20 \mathrm{nmol} / \mathrm{L}$, reflecting in an EAR of $1.4 \mathrm{mg} / \mathrm{day}$ for males and $1.3 \mathrm{mg} / \mathrm{day}$ for females aged $\geq 51$, and an RDA of $1.7 \mathrm{mg} /$ day and $1.5 \mathrm{mg} /$ day, respectively (Institute of Medicine, 2006). Elderly persons are considered at-risk for low $\mathrm{B}_{6}$ 
status mostly due to chronic diseases and increased probability of drug-nutrient interactions (Gibson, 2005b), though clinical signs and symptoms of deficiency have been never reported in intakes greater than $0.5 \mathrm{mg} /$ day, despite the EAR being above $1.0 \mathrm{mg} /$ day for most age groups (Institute of Medicine, 2006).

Data from the CCHS 2.2 showed a $16 \%$ prevalence rate of inadequate intakes of vitamin $\mathrm{B}_{6}$ from diet alone in men and $28 \%$ in women aged $51 \mathrm{y}$ and older (Shakur, et al., 2012). A similar study on 4,384 US residents observed that inadequacy of $B_{6}$ from diet alone reached $34 \%$ among men, and $49 \%$ among women aged $\geq 71 \mathrm{y}$ (Sebastian, Cleveland, Goldman, \& Moshfegh, 2007). Although supplementation decreased these rates to some extent in both US and Canadian populations, supplement consumption was greater among seniors in the US (43\%) (Sebastian, et al., 2007) than in Canada (<30\%) (Shakur, et al., 2012).

\subsubsection{Vitamin $B_{12}$}

Naturally occurring $B_{12}$ vitamin (or cobalamin) is found primarily in foods of animal origin. Vitamin $B_{12}$ maintains the sheath that surrounds and protects nerve fibers and promotes their normal growth. Bone cell activity and metabolism also depend on this vitamin. Like folate and $\mathrm{B}_{6}$, it also functions as a coenzyme in the one-carbon metabolism necessary for the recycling of homocysteine (Hcys) (M. Johansson, et al., 2009; Whitney \& Rolfes, 2008). 
The requirements are based on the intake needed to maintain hematological status and normal serum vitamin $B_{12}$ values. The EAR assumes that only $50 \%$ of the $B_{12}$ consumed is absorbed and is set at $2.0 \mathrm{mcg} /$ day for both males and females aged 51 and older. The RDA for this age group is 2.4 $\mathrm{mcg} / \mathrm{day}$, but it is recommended that most of this amount be obtained through fortified food or dietary supplements due to a potential presence of atrophic gastritis, a thinning of the stomach lining that affects 10 to $30 \%$ of older adults and decreases the secretion of chloric acid and intrinsic factor, necessary for adequate absorption of the vitamin (Institute of Medicine, 2006; Whitney \& Rolfes, 2008).

In 1999, soon after the mandate of folate fortification of flour, an Ontariowide study used laboratory data to assess serum $B_{12}$ levels in 637 adults aged $57.4-59.4 \mathrm{y}$. Ten percent had serum levels $\leq 150 \mathrm{pmol} / \mathrm{L}$ (threshold used for deficiency), and the average serum level (geometric mean) was $322.0 \mathrm{pmol} / \mathrm{L}$ (Ray, Cole, \& Boss, 2000). In a retrospective cross-sectional study during the pre-fortification period (1996-1997) and near-complete post-fortification period (1998-2000), a research team from Ontario and British Columbia assessed folate and $B_{12}$ deficiency in over 4,500 women aged $\geq 65 y$ (Ray, Vermeulen, Langman, Boss, \& Cole, 2003). The proportion of women deemed $B_{12}$ deficient (serum $B_{12}$ $<150 \mathrm{pmol} / \mathrm{L}$ ) decreased from $12.4 \%$ to $9.7 \%$, which was less pronounced than 
folate deficiency (6.3\% to $0.88 \%$ ) (Ray, et al., 2003). The authors argued that occult cobalamin deficiency, in which a deficiency in $B_{12}$ may exist without the haematological symptoms (megaloblastic anemia), could become a common disorder among the elderly population and advocated that food be fortified with the vitamin (Ray, et al., 2000). Parallel to these investigations, Garcia and colleagues (2008) assessed cobalamin status in 281 community-dwelling Ontarians aged 65 to $89 y$ at recruitment from 1997 to 2004 . At baseline, prevalence rates of cobalamin levels $<165 \mathrm{pmol} / \mathrm{L}$ were low among supplement users (3\%), but similar to the other B vitamins among non-users (20\%) (Garcia, et al., 2008) and greater than the prevalence rates seen in the studies by Ray et al. $(2000,2003)$. This proportion decreased to $0 \%$ among users and $3 \%$ among non-users of supplements on the course of seven years, but the proportion of users of oral supplements containing $B_{12}$ increased from $25 \%$ in 1997-1998 to $46 \%$ in 2002-2004, as well as the mean dosage (from $21.6 \mathrm{mcg}$ to $73.2 \mathrm{mcg}$ ) (Garcia, et al., 2008). In contrast, according to the latest CCHS 2.2, inadequate intakes of $B_{12}$ from diet alone are less prevalent than the rates for folate or $B_{6}$, reaching $14 \%$ among women and less than $5 \%$ among men aged $\geq 51$ y (Shakur, et al., 2012).

Low nutrient intakes (macro- and/or micronutrients) have been shown to be independently associated to frailty in older persons (Bartali et al., 2006) and to 
significantly increase the likelihood of malnutrition (Hickson, 2006). In turn, being at risk for malnutrition has been associated with poor health outcomes, such as declines in good physical health days over 18 months (Keller, Østbye, \& Goy, 2004) and increased future hospitalization (Jensen, Friedmann, Coleman, \& Smiciklas-Wright, 2001). In 2008-2009, 62\% of depressed Canadian seniors men and women were considered at risk of malnutrition, almost twice the rate for nondepressed seniors (33\%) (Ramage-Morin \& Garriguet, 2013).

Important deficiency of any of these three vitamins will lead to hematological, neurological, and gastrointestinal symptoms, including anemia (megaloblastic anemia if folate is deficient, or pernicious anemia, if $B_{12}$ ), loss of concentration, disorientation, and dementia (Institute of Medicine, 2006). The similarities in clinical symptoms that occur when these vitamins are deficient or when their metabolism is disrupted can be explained not only by their role in the central nervous system, but also by their intimate relationship in the methylation process known as the one-carbon metabolism (Bottiglieri, 2013).

\subsubsection{One-carbon metabolism}

Figure 1 presents the schematic pathway of the one-carbon metabolism (methylation and nucleotide synthesis), highlighting the enzymatic reactions that require folate-, $B_{12^{-}}$, and $B_{6}$-derived coenzymes. Besides these vitamins, dietary 
intake directly influences several other components, including choline, betaine, methionine, cysteine, and riboflavin (vitamin $B_{2}$ ) (M. Johansson, et al., 2009).

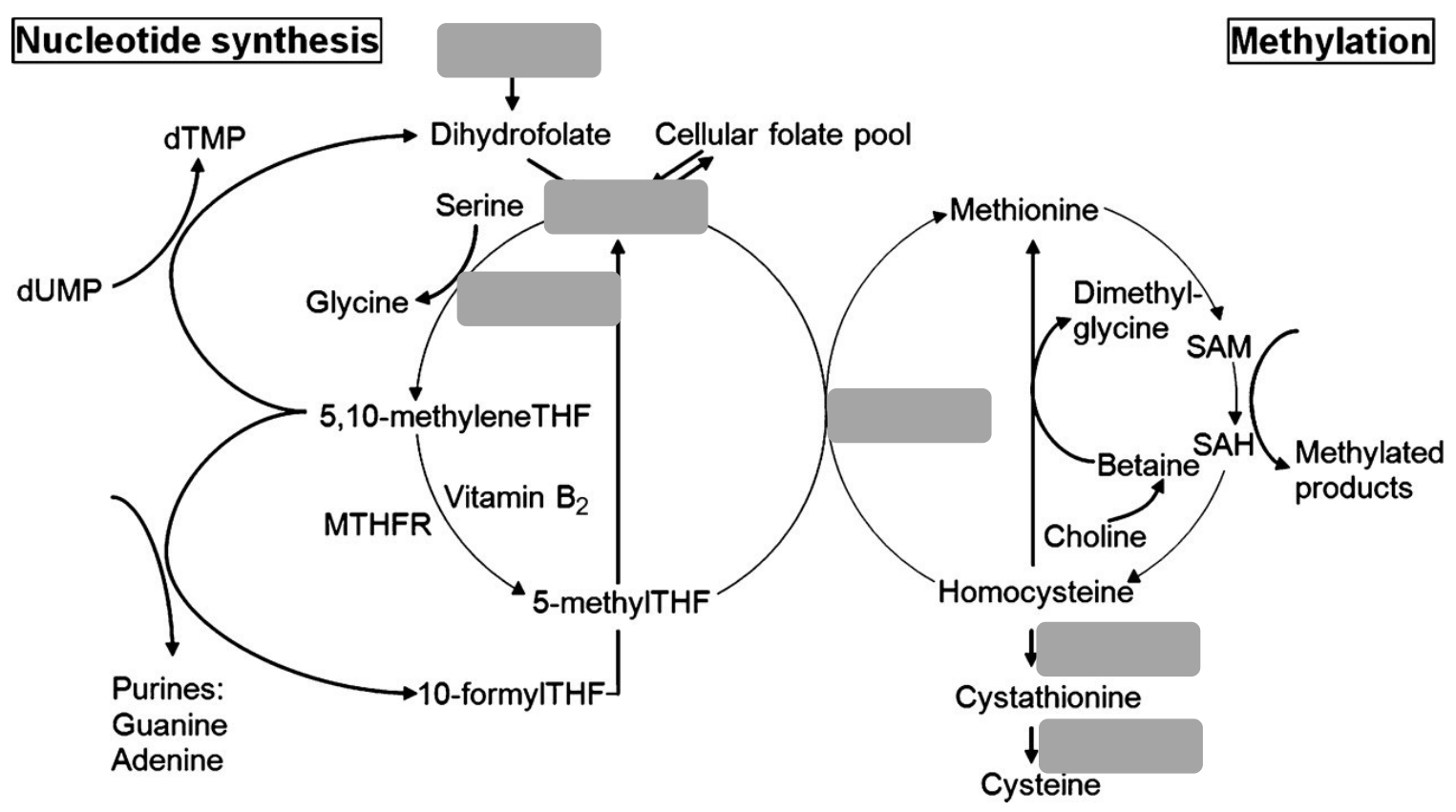

Figure 1: Diagram of one-carbon metabolism pathway in brain tissue showing the reactions involving $B_{6}, B_{12}$ and folate (gray highlights). Abbreviations: dTMP: Deoxythymidine Monophospate; dUMP: Deoxyuridine monophosphate; THF: tethahydrofolate; SAM: S-adenosylmethionine; SAH: S-adenosylhomocysteine. [Copyright to the American Association for Cancer Research. Reproduced with permission. Highlight of vitamins are my own. (Source: M. Johansson, et al., 2009).]

The methionine derivative, S-adenosylmethionine (SAM), is the universal methyl $\left(\mathrm{CH}_{3}\right)$ donor for the methylation of a variety of acceptor substrates, including nucleic acids, proteins, phospholipids, myelin, polysaccharides, choline, and catecholamines. Homocysteine (Hcys) is the intermediate product in the one-carbon metabolism and can be recycled into methionine by two different enzymatic pathways: the betainehomocysteine methyltransferase (BHMT), which 
operates mainly in rodents, and the $\mathrm{B}_{12}$-dependent methionine synthase.

Alternatively, Hcys can also be metabolized to cysteine through the sequential action of two vitamin $B_{6}-$ dependent enzymes in the transsulfuration pathway (Coppen \& Bolander-Gouaille, 2005; M. Johansson, et al., 2009; Lamprecht \& Lipkin, 2003).

As previously mentioned, THF is the chemically reduced form of folate. Three derivatives of THF are associated with crucial metabolic pathways in the one-carbon metabolism: 5-methylTHF, which is required for methionine synthesis; 5,10-methyleneTHF, which is essential for the synthesis of a pyrimidine component of DNA; and 10-formylTHF, which is a co-factor for purine synthesis (Lamprecht \& Lipkin, 2003). Vitamin $\mathrm{B}_{6}$ serves as a co-enzyme in the synthesis of 5,10-methyleneTHF from THF. 5-methylTHF is transformed to 5,10methyleneTHF by a $B_{2}$-dependant enzyme, methylenetetrahydrofolate reductase (MTHFR), and is the donor of methyl group for the recycling of Hcys (M. Johansson, et al., 2009).

The link between $B_{12}$ and folate happens in the recycling of Hcys into methionine by the $\mathrm{B}_{12}$-dependent methionine synthase, which is activated when it receives a methyl group from 5-methylTHF, a folate derivate from the nucleotide synthesis pathway. In other words, when folate gives up its methyl 
group, the vitamin $\mathrm{B}_{12}$ coenzyme becomes activated (Bottiglieri, 2013; Whitney \& Rolfes, 2008).

The neurological symptoms observed in the deficiency of folate, vitamin $B_{12}$ or $\mathrm{B}_{6}$ can be largely explained by their role in the one-carbon metabolism. Tissues of the central nervous system are entirely dependent on methyl groups derived from the methionine synthase-mediated recycling of Hcys (Coppen \& Bolander-Gouaille, 2005; M. Johansson, et al., 2009). In addition, the accumulation of Hcys, a consequence of vitamin-B deficiency, has been demonstrated to be toxic to neurons and blood vessels, inducing DNA strand breakage, oxidative stress, and apoptosis (Coppen \& Bolander-Gouaille, 2005; Folstein, et al., 2007; M. Johansson, et al., 2009; Lamprecht \& Lipkin, 2003; Parnetti, Bottiglieri, \& Lowenthal, 1997). Studies have shown increased prevalence of folate or $\mathrm{B}_{12}$ deficiency and elevated Hcys among neuropsychiatry patients with dementia, cognitive impairment, or mood disorder (Coppen \& Bolander-Gouaille, 2005; Folstein, et al., 2007; Ortega et al., 1996; Reif, Schneider, Kamolz, \& Pfuhlmann, 2003; Reynolds, 2006; Smith, 2008; Tolmunen, Hintikka, Voutilainen, et al., 2004), although this observation is not a consensus, inclusive among the elderly population (Beydoun, et al., 2010; Bjelland, Tell, Vollset, Refsum, \& Ueland, 2003; Forti et al., 2010; Ng, Feng, Niti, 
Kua, \& Yap, 2009; Nilsson, Gustafson, \& Hultberg, 2006; Robinson et al., 2011;

Tiemeier et al., 2002). While the decreased absorption of $B_{12}$ with aging, as explained earlier, would make older adults more susceptible to increased Hcys levels, it seems that higher Hcys levels are seen in geriatric patients than in seniors living in the community (Folstein, et al., 2007).

The well-known role of B vitamins in the nervous cells and the more recent findings about their importance in the one-carbon metabolism have sparkled researchers' interest in their effect on brain metabolism and function at all ages, especially in relation to nervous-system development, repair, mood, aging, cognitive function, and dementia (Reynolds, 2006).

\subsubsection{B vitamins and depression}

The actual mechanisms by which B vitamins would influence depressive states are still elusive, but it has been suggested that folate, $B_{6}$, and $B_{12}$ are associated with depression in two ways. First, they are needed in the brain for the synthesis of neurotransmitters linked to mood and emotional behaviour (norepinephrine, serotonin, and dopamine) (Fava \& Mischoulon, 2009). The second possibility is the "homocysteine hypothesis" of depression. As detailed in the previous section, B-vitamins are the source of coenzymes that participate in the one-carbon metabolism. Disruptions in this pathway can increase Hcys oxidized derivates that have toxic effects in the brain and the vascular 
endothelium, believed to be part of the disease aetiology (Baune et al., 2012;

Bhat, 2009; Bottiglieri, 2013; Folstein, et al., 2007; Lucas, et al., 2014; Selhub, 2002).

Even though clinical symptoms of deficiency of these three vitamins are rare (Institute of Medicine, 2006) and less than a quarter of older Canadians seem to be deficient and/or have low intakes (e.g. Garcia, et al., 2008; Ray, et al., 2000; Shakur, et al., 2012), it is questioned whether people with observed higher intakes of these B vitamins would be more protected against depression than their counterparts with lower intakes, in which case the vitamins' role on mental health would go beyond frank vitamin deficiency (Bottiglieri, 2013). Crosssectional studies conducted in different countries with adults of different ages, including older adults, have shown depression to be associated with lower Bvitamin intakes or deficiency status (e.g. Beydoun, et al., 2010; Bjelland, et al., 2003; Dimopoulos et al., 2007; Merete, Falcon, \& Tucker, 2008). Systematic reviews on the associations between folate, $B_{6}$ and/or $B_{12}$ and depression seem to agree that low status of these vitamins, either as deficiency or lower quantiles, is common in depressed patients (Bottiglieri, 2013; Coppen \& Bolander-Gouaille, 2005; Gilbody, Lightfoot, \& Sheldon, 2007; Williams et al., 2005). However, evidence compiled in these reviews comes mostly from cross-sectional studies of the young population and that often explored nutritional deficiency states in 
depression prevalence or treatment. Nevertheless, the available cross-sectional evidence correlating depression and B vitamins supports a more detailed investigation on the direction of the association through longitudinal studies.

Four population-based studies that have explored the longitudinal association of B vitamins and depression incidence in either young or older adults living in the community were found (Table 2) (Astorg et al., 2008; Kim et al., 2008; Skarupski et al., 2010; Tolmunen, Hintikka, Ruusunen, et al., 2004). Among older adults, Skarupski et al. (2010) explored vitamin intakes, while Kim et al. (2008) studied $B_{6}$ and $B_{12}$ status. During a follow-up of $7.2 \pm 2.7 \mathrm{y}$, higher intakes of $B_{6}$ from diet+supplements were associated with decreased depression incidence after adjustment for demographic and lifestyle variables, but not when measurements of health status were included; $B_{12}$ from diet+supplements was independently associated with depression scores (Table 2) (Skarupski, et al., 2010). In the study by Kim and colleagues (2008), lower folate and of vitamin $B_{12}$ levels (as quintiles) in the serum at baseline, as well as a greater declines in serum $B_{12}$ (as quintiles of change) were associated with a higher risk of incident depression after $2.4 \pm 0.3 y$ of follow-up (Table 2). 
Table 2: Some cohort studies that investigated the association of B-vitamins (folate, $\mathrm{B}_{6}$ or $\mathrm{B}_{12}$ ) with depression incidence in community-dwelling adults $(>35 y)^{a}$

\begin{tabular}{|c|c|c|c|c|}
\hline $\begin{array}{c}\text { Author, Country, } \\
\text { Follow-up }\end{array}$ & Participants & Main variables & Covariates & Findings \\
\hline $\begin{array}{l}\text { (Tolmunen, } \\
\text { Hintikka, } \\
\text { Ruusunen, et al., } \\
\text { 2004) } \\
\text { Finland•, 13y }\end{array}$ & $\begin{array}{l}\text { Middle-aged men (42- } \\
60 \mathrm{y})(\mathrm{N}=2,360)\end{array}$ & $\begin{array}{l}\text { IV: Baseline dietary folate } \\
\text { and } \mathrm{B}_{12} \text { (4-day food record) } \\
\text { Outcome: Severe } \\
\text { depression incidence } \\
\text { (Discharge diagnosis of } \\
\text { depressive disorder) }\end{array}$ & $\begin{array}{l}\text { Age and examination year, } \\
\text { current SES, baseline HPL } \\
\text { depression score, energy- } \\
\text { adjusted intake of fibre, } \\
\text { vitamin C, and total fat. }\end{array}$ & $\begin{array}{l}\text { Incidence: } 2 \%(\mathrm{n}=47) \\
\text { - Those below the median of energy-adjusted } \\
\text { folate intake had higher risk of getting } \\
\text { discharge diagnosis of depression (RR } 2.53 \text {, } \\
95 \% \mathrm{Cl} 1.17-5.48 \text { ) during follow-up period. } \\
\text { - No effect of vitamin } \mathrm{B}_{12} \text {. }\end{array}$ \\
\hline $\begin{array}{l}\text { (Astorg, et al., } \\
\text { 2008) } \\
\text { France , 8y }\end{array}$ & $\begin{array}{l}\text { 1,864 middle-aged men } \\
\text { and women (35-60y) } \\
\text { Cases: } 304 \text { (overall: } 78 \\
\text { men, } 226 \text { women; } \\
\text { without history of } \\
\text { depression: } 61 \text { men, } \\
192 \text { women) } \\
\text { Controls. } 1,560\end{array}$ & $\begin{array}{l}\text { IV: Dietary folate (Six } 24 \mathrm{~h}- \\
\text { dietary record } \\
\text { questionnaire/year) } \\
\text { Outcome: Depression } \\
\text { incidence (use of } \\
\text { antidepressant medication) }\end{array}$ & $\begin{array}{l}\text { Age, intervention group, } \\
\text { marital status, education, } \\
\text { socio-professional category, } \\
\text { total energy intake. }\end{array}$ & $\begin{array}{l}\text { Incidence: } 10 \% \text { in men, } 21 \% \text { in women. } \\
\text { - No significant association between folate } \\
\text { intake and the risk of one or more depressive } \\
\text { episodes. } \\
\text { - Decreased recurrence in men with high folate } \\
\left.\text { intake ( } 3^{\text {rd }} \text { tertile: } 95 \% \mathrm{Cl} 0.06-0.98\right) \text {, but not in } \\
\text { cases without depression history ( } 3^{\text {rd }} \text { tertile: } \\
95 \% \mathrm{Cl} 0.05-1.25,) \text {. }\end{array}$ \\
\hline $\begin{array}{l}\text { (Kim, et al., 2008) } \\
\text { Korea , 2.4 } \pm 0.3 y\end{array}$ & $\begin{array}{l}\text { Community-dwelling } \\
\text { older men and women } \geq \\
65 y(N=521)\end{array}$ & $\begin{array}{l}\text { IV: Baseline serum folate } \\
\text { and } \mathrm{B}_{12} \text { (quintiles) } \\
\text { Outcome: Depression } \\
\text { incidence (Geriatric Mental } \\
\text { State schedule) }\end{array}$ & $\begin{array}{l}\text { Age, gender, education, } \\
\text { cognitive status, disability, } \\
\text { smoking, alcohol consumption, } \\
\text { PA, vascular risk, serum } \\
\text { creatinine, vitamin } \\
\text { supplementation. Folate level, } \\
\text { B }_{12} \text { level, Hcys level as } \\
\text { applicable. }\end{array}$ & $\begin{array}{l}\text { Incidence: from } 6 \% \text { to } 20 \% \text {, depending on } \\
\text { quintiles of blood levels. } \\
\text { - Lower baseline levels of folate }(95 \% \mathrm{Cl} 1.01 \text { - } \\
\text { 1.54) and } \mathrm{B}_{12}(95 \% \mathrm{Cl} 1.03-1.54) \text { associated } \\
\text { with a higher risk of incident depression. } \\
\text { - Incident depression was associated with a } \\
\text { decline in vitamin } \mathrm{B}_{12} \text { before adjustment for } \\
\text { folate or Hcys }(95 \% \mathrm{Cl} 1.01-1.88) \text {. }\end{array}$ \\
\hline
\end{tabular}

(continued on the next page) 


\begin{tabular}{|c|c|c|c|c|}
\hline $\begin{array}{l}\text { Author, Country, } \\
\text { Follow-up }\end{array}$ & Participants & Main variables & Covariates & Findings \\
\hline $\begin{array}{l}\text { (Skarupski, et al., } \\
2010) \\
\text { US } \$, 7.2 \pm 2.7 \text { y }\end{array}$ & $\begin{array}{l}\text { Community-dwelling men } \\
\text { and women aged } \geq 65 y \\
(59 \% \text { African-American }) \\
(\mathrm{N}=3,503)\end{array}$ & $\begin{array}{l}\text { IV: Baseline dietary and } \\
\text { total } B_{6}, B_{12} \text {, folate intakes } \\
\text { (FFQ) } \\
\text { Outcome: Depression } \\
\text { incidence (Short CES-D } \\
\text { [cut off } \geq 4 \text { ]) }\end{array}$ & $\begin{array}{l}\text { Model 1: Age, sex, race, } \\
\text { education, income, } \\
\text { antidepressant use, time lag, } \\
\text { and interaction with time. } \\
\text { Model 2: model } 1+\text { smoking, } \\
\text { alcohol use, and interactions } \\
\text { with time. } \\
\text { Model 3: model } 1+\text { cognitive } \\
\text { function, physical disability, } \\
\text { and interactions with time. } \\
\text { Intakes were energy adjusted. }\end{array}$ & $\begin{array}{l}\text { Incidence: } 13.7 \% \text { at } 1^{\text {st }}, 10.7 \% \text { at } 2^{\text {nd }} \text {, and } 13.4 \% \\
\text { at } 3^{\text {rd }} \text { follow-up. } \\
\text { - Higher intakes of } \mathrm{B}_{6} \text { from diet+supplements } \\
\text { were associated with decreased depression } \\
\text { incidence in model } 2 \text { only }(95 \% \mathrm{Cl} 0.997- \\
0.999, \mathrm{p}=0.04) \text {. } \\
\text { - Higher intakes of } \mathrm{B}_{12} \text { from diet+supplements } \\
\text { were associated with decreased depression } \\
\text { incidence in all models }(95 \% \mathrm{Cl} 0.997-0.999 \text {, } \\
\mathrm{p}=0.01) \text {. } \\
\text { - No effect of intakes from food. } \\
\text { - No effect of folate. }\end{array}$ \\
\hline
\end{tabular}

a Main variables, Covariates, and Findings columns contain only information relevant to this thesis and exclude other unrelated variables such as measurements of homocysteine or a cross-sectional analysis. $*$ Mandatory fortification of flour with folic acid since 1998 . No mandatory folate fortification policies to date.

Acronyms: $\mathrm{BMI}=$ body mass index; $\mathrm{CES}-\mathrm{D}=$ Center for Epidemiologic Studies Depression Scale; $\mathrm{Cl}=$ Confidence Interval; FFQ = Food frequency questionnaire; Hcys = Homocysteine; HPL = 18-item Human Population Laboratory Depression Scale; IV = independent variable; OR = Odds ratio; PA = Physical activity; RR = relative risk; SES = social-economic status; US = United States of America; $y=$ years . 
The other two studies included middle-aged adults. Finnish men below the median of energy-adjusted folate intake had higher risk of getting discharge diagnosis of depression during the 13 years of follow-up than those who had a folate intake above the median (Tolmunen, Hintikka, Ruusunen, et al., 2004). In contrast, folate intake showed no significant association with an 8-year depression risk among French men and women with no history of depression (Astorg, et al., 2008) (Table 2). The paucity and contradiction of the available longitudinal evidence are unequivocal.

A few randomized trials on B-vitamin supplementation and its effect on seniors' affective health have been conducted and are compiled in Table 3. In Denmark, 140 individuals (19-92y, median 75y, 70\% women) with an increased plasma methylmalonic acid $(0.40-2.00 \mathrm{nmol} / \mathrm{L})$-a biochemical marker for $\mathrm{B}_{12}$ deficiency — were randomized to receive weekly $1 \mathrm{mg}$ of $\mathrm{B}_{12}$ intravenously for four weeks or placebo (saline solution). There was no improvement in depression scores in the treatment group compared to the placebo group 3 months after the start of the treatment (Hvas, Juul, Lauritzen, Nexo, \& Ellegaard, 2004). In Australia, five double-blinded, placebo-controlled randomized trials involving older adults tested the potential effect of B-vitamin supplementation on depression risk in post-stroke patients (Almeida et al., 2010), on cognition and 
mood in women (Bryan, Calvaresi, \& Hughes, 2002), on the potentiation of antidepressant medication or on the 2-year depression risk in communitydwelling seniors with elevated psychological distress (H. Christensen et al., 2011; Walker et al., 2010), and on the 2-year depression risk in elderly men with a history of or being treated for hypertension (Ford et al., 2008). Only the trial with stroke survivors ( $n=137,63.0 \pm 11.4 \mathrm{y}$ ) found a protective effect of daily supplementation with $2 \mathrm{mg}$ folic acid, $25 \mathrm{mg}$ vitamin $\mathrm{B}_{6}$, and $0.5 \mathrm{mg}$ vitamin $\mathrm{B}_{12}$ daily for 1 to 10.5 years (7y average) compared to placebo (adjusted hazard ratio $0.48 ; 95 \% \mathrm{Cl} 0.31-0.76)$. This was, however, the longest of those trials and studied people hospitalized for an important illness. All others, which had a maximum duration of two years, did not find a significant difference in depression scores between the study groups (Table 3). Besides the short duration, participants' characteristics were very particular, e.g. they had a specific health or psychological condition or included women only. 
Table 3: Some randomized clinical trial studies that investigated the effect of B-vitamin supplementation (folate, $\mathrm{B}_{6}$ and/or $\left.B_{12}\right)$ on depression and included older adults $(\geq 60 y)^{a}$

\begin{tabular}{|c|c|c|c|c|}
\hline $\begin{array}{l}\text { Author, } \\
\text { Country }\end{array}$ & $\begin{array}{l}\text { Study design } \\
\text { Participants }\end{array}$ & Intervention & Outcome & Main Findings and comments \\
\hline $\begin{array}{l}\text { (Bryan, et al., } \\
\text { 2002) } \\
\text { Australia }\end{array}$ & $\begin{array}{l}\text { Randomized, double-blind, } \\
\text { placebo-controlled trial of folate, } \\
\text { vitamin } B_{12} \text { and } B_{6} \\
\text { supplementation on cognitive } \\
\text { performance and mood. } \\
56 \text { young }(20-30 y), 80 \text { middle- } \\
\text { aged ( } 45-55 \text { y) and } 75 \text { older } \\
(65-92 \text { y) healthy women } \\
(n=211)\end{array}$ & $\begin{array}{l}\text { 1) Folic acid }(750 \mathrm{mcg}) \text {; } \\
\text { 2) B12 }(15 \mathrm{mcg}) \text {; } \\
\text { 3) } \mathrm{B}_{6}(75 \mathrm{mg}) \text {; } \\
\text { 4) Placebo } \\
\text { Daily for } 5 \text { weeks }(\mathrm{n}=47-59)\end{array}$ & $\begin{array}{l}\text { Cognition (several tests) } \\
\text { and depression/mood } \\
\text { (CES-D and POMS) } \\
\text { measured at baseline } \\
\text { and at } 5 \text { weeks. } \\
\text { Other: FFQ at baseline }\end{array}$ & $\begin{array}{l}\text { - Supplementation had a significant } \\
\text { positive effect on some measures of } \\
\text { memory performance only, and no effect } \\
\text { on mood. } \\
\text { - Dietary intake status was associated with } \\
\text { some measures of cognition but not } \\
\text { mood. } \\
\text { Comment: The observed improvement on } \\
\text { cognition could be due to a learning effect. }\end{array}$ \\
\hline $\begin{array}{l}\text { (Hvas, et al., } \\
\text { 2004) } \\
\text { Denmark }\end{array}$ & $\begin{array}{l}\text { Randomized, double-blind, } \\
\text { placebo-controlled trial of } \\
\text { vitamins } \mathrm{B}_{12} \text { on cognitive } \\
\text { function and symptoms of } \\
\text { depression. } \\
140 \text { individuals (19-92y, median } \\
75 \mathrm{y}, 70 \% \text { women) with an } \\
\text { increased plasma MMA ( } 0.40- \\
2.00 \text { nmol/I) not previously } \\
\text { treated with vitamin } \mathrm{B}_{12} \text {. }\end{array}$ & $\begin{array}{l}\text { 1) Injections of } 1 \mathrm{mg} \\
\text { Cyanocobalamin (BetolvexR); } \\
\text { 2) } 1 \mathrm{~mL} \text { isotonic sodium chloride } \\
\text { (control) } \\
\text { Weekly for } 4 \text { weeks. }\end{array}$ & $\begin{array}{l}\text { Depression (MDI scores) } \\
\text { at baseline and } 3 \text { mo. } \\
\text { later }\end{array}$ & $\begin{array}{l}\text { - Both in the treatment and the placebo } \\
\text { group, cognitive function and depression } \\
\text { scores improved, but the treatment group } \\
\text { did not differ from the placebo group ( } p= \\
0.18 \text { ) within the } 3 \text {-month study period. } \\
\text { - The depression score was not associated } \\
\text { with plasma cobalamins }(p=0.13 \text { ), } \\
\text { erythrocyte folate }(p=0.47) \text {, plasma } \\
\text { MMA }(p=0.67) \text {, or plasma total Hcys ( } p \\
=0.16) \text {. }\end{array}$ \\
\hline $\begin{array}{l}\text { (Ford, et al., } \\
\text { 2008) } \\
\text { Australia }\end{array}$ & $\begin{array}{l}\text { Randomized, double-blind, } \\
\text { placebo-controlled trial of } \\
\text { vitamins } B_{12}, B_{6} \text {, and folate on } \\
\text { incidence of depression. } \\
299 \text { hypertensive, men } \geq 75 y \text {, } \\
\text { free of depression at } \\
\text { recruitment. }\end{array}$ & $\begin{array}{l}\text { 1) Folic acid }(2000 \mathrm{mcg})+\mathrm{B}_{12} \\
(400 \mathrm{mcg})+\mathrm{B}_{6}(25 \mathrm{mg}) \text { per day }(\mathrm{N} \\
=150) \\
\text { 2) Placebo }(\mathrm{N}=149) \\
\text { Daily for } 2 \text { years. }\end{array}$ & $\begin{array}{l}\text { Depression incidence } \\
\text { (BDI scores } \geq 10 \text { ) } \\
\text { assessed at baseline, } 6 \text {, } \\
12,18, \text { and } 24 \text { months. }\end{array}$ & $\begin{array}{l}\text { - Likelihood of remaining free of } \\
\text { depression during the trial did not differ } \\
\text { between groups ( } 95 \% \mathrm{Cl} 0.68 \text { to } 2.28) \text {. }\end{array}$ \\
\hline
\end{tabular}




\begin{tabular}{|c|c|c|c|c|}
\hline $\begin{array}{l}\text { Author, } \\
\text { Country }\end{array}$ & $\begin{array}{l}\text { Study design } \\
\text { Participants }\end{array}$ & Intervention & Outcome & Main Findings and comments \\
\hline $\begin{array}{l}\text { (Almeida, et } \\
\text { al., 2010) } \\
\text { Australia }\end{array}$ & $\begin{array}{l}\text { Randomized, double-blind, } \\
\text { placebo-controlled trial of tHcy- } \\
\text { lowering treatment. } \\
273 \text { stroke survivors (age } 63.0 \\
\pm 11.4 y \text { ). }\end{array}$ & $\begin{array}{l}\text { 1) Folic acid }(2000 \mathrm{mcg})+B_{12} \\
(500 \mathrm{mcg})+B_{6}(25 \mathrm{mg}) \\
(\mathrm{n}=136) ; \\
\text { 2) placebo }(\mathrm{n}=137) \\
\text { Daily for } 1 \text { to } 10.5 \mathrm{y}(7.1 \pm 2.1 \mathrm{y})\end{array}$ & $\begin{array}{l}\text { Incidence of depression } \\
\text { (MINI every } 6 \text { mo.) after } \\
\text { randomization and } \\
\text { prevalence at the end of } \\
\text { treatment. }\end{array}$ & $\begin{array}{l}\text { - Assignment to B-vitamins was associated } \\
\text { with a lower hazard of major depression } \\
\text { compared with placebo ( } 18.4 \% \text { vs } 23.3 \% \text {, } \\
\text { adjusted HR } 0.48,95 \% \mathrm{Cl} 0.31-0.76) \text {. } \\
\text { - A non-significant trend toward a lower } \\
\text { odds of major or minor depression at the } \\
\text { end of the trial compared with placebo } \\
(19.1 \% \text { vs } 27.7 \% \text {, adjusted OR } 0.58 \text {, } \\
95 \% \mathrm{Cl} 0.31-1.09) \text {. }\end{array}$ \\
\hline $\begin{array}{c}\text { (Walker, et al., } \\
\text { 2010) } \\
\text { Australia }\end{array}$ & $\begin{array}{l}\text { Randomized, double-blind, } \\
\text { placebo-controlled trial of } \\
\text { mental health literacy, physical } \\
\text { activity, or folic acid ( } 400 \text { mcg) } \\
+B_{12}(100 \text { mcg), on depression } \\
\text { symptoms. } \\
909 \text { community-dwelling adults } \\
\text { aged } 60-74 y \text { with elevated } \\
\text { psychological distress (K10 } \\
\text { scores) }\end{array}$ & $\begin{array}{l}\text { 1) Folic acid + } \mathrm{B}_{12} \text {, PA promotion, } \\
\text { mental health literacy; } \\
\text { 2) Folic acid + } \mathrm{B}_{12} \text {, PA promotion, } \\
\text { pain information; } \\
\text { 3) Folic acid + } \mathrm{B}_{12} \text {, nutrition } \\
\text { promotion, mental health literacy; } \\
\text { 4) Folic acid + } \mathrm{B}_{12} \text {, nutrition } \\
\text { promotion, pain information; } \\
\text { 5) Placebo, PA promotion, mental } \\
\text { health literacy; } \\
\text { 6) Placebo, PA promotion, pain } \\
\text { information; } \\
\text { 7) Placebo, nutrition promotion, } \\
\text { mental health literacy; } \\
\text { 8) Placebo, nutrition promotion, } \\
\text { pain information. } \\
\text { Daily for } 2 \text { years. }\end{array}$ & $\begin{array}{l}\text { Depressive symptoms on } \\
\text { the PHQ- } 9 \text {, measured at } \\
\text { baseline, } 6 \text { wks., } 6 \text { mo., } \\
12 \text { mo., and } 24 \text { mo. }\end{array}$ & $\begin{array}{l}\text { - Neither folic acid }+\mathrm{B}_{12} \text { nor physical } \\
\text { activity were effective in reducing } \\
\text { depressive symptoms. } \\
\text { - Mental health literacy had a transient } \\
\text { effect on depressive symptoms. Other } \\
\text { than this, none of the interventions } \\
\text { significantly reduced symptoms relative } \\
\text { to their comparator at } 6 \text { weeks or } \\
\text { subsequently. } \\
\text { Comments: With the exception of the folic } \\
\text { acid + vitamin B } 12 \text { and placebo groups, all } \\
\text { interventions involved } 5 \text { modules of } \\
\text { information delivered by mail in weeks } 1-5 \text {, } \\
\text { followed by further } 5 \text { modules at } 4,8,13 \text {, } \\
18 \text { and } 22 \text { months, with telephone tracking } \\
\text { calls at these same time points. }\end{array}$ \\
\hline
\end{tabular}

(continued on the next page) 


\begin{tabular}{|c|c|c|c|c|}
\hline $\begin{array}{l}\text { Author, } \\
\text { Country }\end{array}$ & $\begin{array}{c}\text { Study design } \\
\text { Participants }\end{array}$ & Intervention & Outcome & Main Findings and comments \\
\hline $\begin{array}{l}\quad(\mathrm{H} . \\
\text { Christensen, } \\
\text { et al., 2011) } \\
\text { Australia }\end{array}$ & $\begin{array}{l}\text { Randomized, double-blind, } \\
\text { placebo-controlled trial of } \\
\text { potentiation of antidepressants } \\
\text { by folic acid + vitamin } \mathrm{B}_{12 .} \text {. } \\
900 \text { community-dwelling older } \\
\text { adults ( } 60-74 y, 358 \text { males and } \\
542 \text { females) with elevated } \\
\text { psychological distress (K10 } \\
\text { scores). }\end{array}$ & $\begin{array}{l}8 \text { groups as in Walker et al. } 2010 \text {, } \\
\text { but separated into } 4 \text { groups: } \\
\text { 1) Folic acid ( } 400 \text { mcg) }+B_{12}(100 \\
\text { mcg) with reported } \\
\text { antidepressants ( } n=100) \text {; } \\
\text { 2) Folic acid + } B_{12} \text {, no reported } \\
\text { antidepressants ( } n=353) \text {; } \\
\text { 3) No folic acid + } B_{12} \text { with } \\
\text { antidepressants }(n=109) \text {; } \\
\text { 4) Control (No folic acid }+B_{12} \text { and } \\
\text { no reported antidepressants, } \\
n=338) \text {. } \\
\text { Daily for } 2 \text { years. }\end{array}$ & $\begin{array}{l}\text { Depressive symptoms on } \\
\text { the PHQ-9, measured at } \\
\text { baseline, } 6 \text { wks., } 6 \text { mo., } \\
12 \text { mo., and } 24 \text { mo. }\end{array}$ & $\begin{array}{l}\text { - Participants reporting antidepressant } \\
\text { medication either at baseline or during } \\
\text { the trial and treated with folic acid + } \\
\text { vitamin } \mathrm{B}_{12} \text { did not experienced greater } \\
\text { reductions in depressive symptoms } \\
\text { compared to users of antidepressants not } \\
\text { treated with folic acid + vitamin } \mathrm{B}_{12} \text {. } \\
\text { - Participants treated with folic acid + } \\
\text { vitamin } \mathrm{B}_{12} \text { but NO reporting of } \\
\text { antidepressant medication did not } \\
\text { experience greater reductions in } \\
\text { depressive symptoms compared to } \\
\text { controls. }\end{array}$ \\
\hline
\end{tabular}

\footnotetext{
a Outcome measures and Findings columns contain only information relevant to this thesis and exclude other unrelated variables such as cognitive outcomes. Mandatory fortification of flour with folic acid since 2007-2009. No mandatory fortification policies to date. Acronyms: BDI = Beck Depression Inventory; CES-D = Center for Epidemiologic Studies Depression Scale; $\mathrm{Cl}=$ Confidence Interval; FFQ $=$ Food frequency questionnaire; Hcys = Homocysteine; HR = Hazards ratio; K10 = Kessler Psychological Distress Scale; MDI = Major Depression Inventory; MINI = Mini-International Neuropsychiatric Interview; MMA = methylmalonic acid (biomarker of $\mathrm{B}_{12}$ deficiency); OR = Odds ratio; PA = Physical Activity; POMS = Profile of Mood States Questionnaire; PHQ-9 = Patient Health Questionnaire-9.
} 
While trials offer strong evidence on the effect of supplementation on the outcome (depression), they cannot shed light on the hypothesis that nutrient intakes from food could have different effects on health, particularly considering that supplement use may signal either a healthier lifestyle and higher nutrient intake or a compensation for a poor diet (Payette \& Shatenstein, 2005). Moreover, even when trials are available, longitudinal studies can broaden the applicability of those specific trials, which, in our case, have been done essentially with people with important illnesses, and provide better information about the disease process, assessment techniques, subject selection criteria, and the effect of potential interventions (Guralnik \& Kritchevsky, 2010). In our second study, we aimed to shed light on the hypothesized protection of higher intakes from food alone and from food+supplements (total) on depression risk among generally healthy, community-dwelling older Canadians.

\subsection{Reverse Causality: Effects of depression on diet}

As much as diet is hypothesized to have a role in the development of depression, depression itself can affect nutrient intake or status due to the very nature of the disease (Reynolds, 2002). As described earlier in this chapter, one of the possible symptoms of depression is change in appetite and body weight. The social withdrawnness, another symptom of depression, can further decrease 
dietary intake, particularly among older adults (Alexopoulos, 2005; Donini, et al., 2003). Stressful life events, such as bereavement, are a risk factor for depression (Cole \& Dendukuri, 2003) and can also have negative repercussions in food intake (Johnson, 2002).

As pointed out previously, most of the evidence on dietary intakes, particularly B-vitamins, and their association with depression in late life comes from cross-sectional studies, from which the direction of this association cannot be inferred (Gilbody, et al., 2007). It is not clear whether lower nutrient intakes increase the risk of depression or depression increases the risk of lower nutrient intakes.

One study by Stewart et al. (2009) objectively investigated the directionality of the depression-inflammation relationship to shed light on the mechanisms through which depression contributes to cardiovascular disease risk. In the Pittsburgh Healthy Heart Project cohort, 263 healthy, community-dwelling adults aged 50-70 years had markers of inflammation [interleukine-6 (IL-6) and Creactive protein (CRP)] and depression (Beck Depression Inventory-II scores) measured at baseline and six years later. According to the authors, baseline IL-6 did not predict 6-year change in depression scores, but baseline depression scores was the second best predictor of IL- 6 change, even after adjustmentsinterestingly, body mass index was the strongest predictor of change in both IL- 6 
$(\beta=0.18, p=0.01)$ and $\operatorname{CRP}(\beta=0.14, p=0.03)$. The authors concluded that depressive symptoms may precede and augment some inflammatory processes relevant to coronary artery disease in this population, not the opposite (Stewart, et al., 2009).

Kendrick et al. (2008) studied red cell folate levels and the subsequent risk of incident depressive symptoms in a large cohort of women aged 20 to 34 years in the Southampton Women's Survey. Low blood folate levels were associated with prevalent depression at baseline $(n=5051)$ but not with incident depression $(n=2732)$ over the two years of follow-up. According to the authors, lower blood folate levels may be a consequence rather than a cause of depressive symptoms in women at child-bearing age (Kendrick, et al., 2008). We could not find, however, a population-based longitudinal study that objectively investigated the effect of depression on nutrient intake, demonstrating the paucity of evidence on the topic. Sensitivity and ancillary analyses seem the most common way to test the reverse causality effect of depression on diet (Akbaraly, et al., 2009; Chocano-Bedoya, et al., 2013; Kim, et al., 2008; Le Port, et al., 2012; Rienks, et al., 2013; Sanchez-Villegas, Delgado-Rodriguez, et al., 2009). In these analyses, researchers excluded or controlled baseline depression (Chocano-Bedoya, et al., 2013; Le Port, et al., 2012; Rienks, et al., 2013; Sanchez-Villegas, DelgadoRodriguez, et al., 2009), or they simply discussed the low likelihood of a reverse 
causality in the study based on the intrinsic longitudinal design (Astorg, et al., 2008; Hodge, et al., 2013; Tolmunen, Hintikka, Ruusunen, et al., 2004). Le Port and colleagues (2012), for example, conducted a sensitivity analysis on the longitudinal association between several dietary patterns and depressive symptoms assessed repeatedly over 10 years among middle-aged GAZEL cohort participants in France. The pattern labelled as "healthy diet," loaded high in raw and cooked vegetables, no longer predicted depression when subjects depressed at baseline were excluded from the analysis. According to the authors, the attenuation of the results was probably due to a reverse causality effect: Participants depressed at baseline could be less likely to have a healthy food pattern due to the disease itself, strengthening the pattern's protective effect when they were considered in the analysis (Le Port, et al., 2012).

In a cohort of 521 community-dwelling Korean adults aged 65 and older followed for two years, incident depression was not only predicted by baseline low serum folate (adjusted OR $1.30,95 \% \mathrm{Cl} 1.06-1.60$ per quintile change) and vitamin $\mathrm{B}_{12}$ levels (adjusted OR 1.31, 95\% Cl 1.08-1.59), but also associated with increased declines in $\mathrm{B}_{12}$ levels (adjusted OR 1.38, 95\% Cl 1.01-1.88, per quintile change) over follow-up years (Kim, et al., 2008). Although this finding generally supports the notion that a depressive state may affect vitamin blood levels, the authors could not establish a temporal relationship because the 
outcome continued to be cases of incident depression, so the decline could have preceded depression.

Taken together, despite being a common concern, the reverse causality hypothesis has not yet been explicitly investigated, so its effect on intakes is largely unknown.

\subsection{Conclusions}

Given that depression can negatively impact health and quality of life of community-dwelling older adults, that most of the evidence on the potential protective effect of dietary patterns and B-vitamin intakes on depression risk comes from cross-sectional studies in middle-aged adults, and that the evidence on the reverse causality effect of depression on diet is practically nonexistent, these outstanding questions remain:

- What dietary patterns exist among community-dwelling older Canadians? Would some of these patterns be protective of depression incidence?

- Given the importance of B vitamins in depressive states, would community-dwelling older Canadians with higher intakes of these vitamins from food and from supplements be less likely to develop depression?

- In the short term, do intakes of some key nutrients decline more in seniors with probable depression than in those without depression?

The following chapters of this dissertation attempt to answer these questions. 


\section{CHAPTER 3. METHODOLOGY}

In this chapter, we expand on the manuscripts' methods section and provide further details on the procedures for data preparation and analysis required to adequately answer the research questions posed in this dissertation.

\subsection{Study setting and description}

The data for this study have been obtained from the Quebec Longitudinal Study on Nutrition and Aging (NuAge) cohort, a 4-year observational study of 1,793 independently-living men and women aged 68 to 82 years at baseline from Sherbrooke and Laval/ Montreal, QC, CA. The NuAge sample recruitment stratified participants into three age categories, 68-72 years, 73-77 years, and 78-82 years, with equivalent numbers of men and women in each group. The older age groups were intentionally oversampled so as to have good precision in all age groups. Names of those meeting desired age-sex criteria were obtained from a random sample within each age-sex stratum from the Quebec health insurance registry (Régie de l'assurance maladie du Québec, RAMQ). Only community-dwelling people were contacted. Potential subjects were sent an invitation letter. Inclusion and exclusion criteria were assessed in two phases: a telephone screening survey followed by a clinical examination conducted by a registered nurse. 
Seniors included in the NuAge study were community-dwelling men and women aged 68-82 years, French or English speaking, willing to commit for a 5year period, able to walk without help (cane acceptable), free of disabilities in activities of daily living, no cognitive impairment [Modified Mini-Mental State (3MS or MMMS) examination score > 79], able to walk at least one block (100 meters) or to climb one flight of stairs without rest and both able and willing to sign an informed consent.

Excluded were people suffering from class II heart failure, chronic obstructive pulmonary disease requiring home oxygen therapy or oral steroids, inflammatory digestive diseases or cancer treated by radiation therapy, chemotherapy or surgery in the 5 years prior to enrollment (with the exception of skin baso-cellular carcinoma).

\subsection{Samples}

In this secondary data analysis, participants of the NuAge cohorts were further excluded by baseline depression $(n=271)$, i.e. scores in the 30 -item Geriatric Depression Scale (GDS) $\geq 11$ or antidepressant medication use, invalid or missing GDS scores at baseline $(n=14)$ or at all follow-up assessments $(n=181)$, and invalid or missing dietary information $(n=103$, manuscripts 1 and 2$)$.

For the third study (reverse causality), the sample was dependant on dietary data 
available for follow-up years, limiting the potential participant pool. From the 170 seniors deemed depressed at some point of follow-up in the first two studies, 158 had dietary data available both for the year of depression diagnosis (as per GDS score and antidepressant use) and the year prior. The same limitation was imposed on the random selection of age-sex matched controls, composed of seniors not meeting the depression criteria set for the study at any year of followup. Although sample sizes were limited by the available data, the minimum detectable differences in intake can be considered clinically significant (e.g. 108 to $180 \mathrm{kcal} /$ day in total energy for the first and the second study, respectively).

In Canada $5.0 \%$ of the population is between ages $65-70$ and only $2.1 \%$ between $80-85$ y (Statistics Canada, 2013a). The NuAge sample is, however, age stratified to ensure that the truly older Canadians were included. At the inception of the cohort, the age range was between $68 \mathrm{y}$ and $82 \mathrm{y}$, which was chosen based on three equally sized samples of $70 \pm 2 y, 75 \pm 2$ y and $80 \pm 2 y$. Should the cohort have been based on sampling proportional to the population, the majority would have been the "young" old-the cohort was not intended to be representative of all older Canadians. Despite obtaining access to the Quebec Medicare database, which is representative of all Quebecers, NuAge did not include anyone living in any sort of residence for seniors, its sample's age 
structure was different, and those with serious chronic conditions were not included. The study participants reported common problems, such as hypertension (47\%), diabetes (11.1\%), or arthritis (53.9\%), but did not have any serious impediments to active living — to illustrate, diabetes affects 20.7 to $25.2 \%$ of older Canadians (Public Health Agency of Canada, 2011), and hypertension had been reported by $56 \%$ of seniors, being more common than heart disease (22\%) and diabetes (21\%) (The Chief Public Health Officer's Report on the State of Public Health in Canada, 2010). Moreover, as indicated by the inclusion criteria of the NuAge study, participants lived in the community with minimal or no assistance and good overall health both physically and mentally at recruitment. The research findings should be interpreted with caution and cannot be generalized to seniors who are frail, in long-term care, institutionalized, and/or with serious health conditions or disabilities.

Before data requisition, the research protocol for this study has been approved by the Research and Ethics Board from McGill University (Faculty of Agricultural and Environmental Sciences). 


\subsection{Measurements}

The three main variables were depression incidence (outcome), dietary information, and the various covariates used to control for potential confounders of the diet-depression relationship. Each study had its own applicable set of confounders, which are described in the next sub-sections.

\subsubsection{Health outcome: Depression incidence}

Incident depression was identified on the basis of GDS scores $\geq 11$ or new use of antidepressant medication at any year of follow-up, being the vast majority considered in the range of mild depression, as described below. The 30-item GDS (Yesavage, et al., 1983) is an inventory with a yes/no format in which each response indicating depressive symptom contributes one point to a total of 30 points (Appendix 1). It is considered a reliable and valid measurement tool to screen the presence of depressive symptoms in an older adult population (Brink, et al., 1982; McDowell, 2006; Yesavage, et al., 1983). At a cut-off score of $\geq 11$, the tool has demonstrated $84 \%$ sensitivity and $95 \%$ specificity for clinically diagnosed major depression (Brink, et al., 1982). Subjects with scores $\leq 10$ are considered not depressed. Only three subjects presented scores $\geq 21$, which is classified as moderate to severe depression. Medications with the therapeutic classification name according to the American Hospital Formulary System 
(AHFS) as "antidepressants," "miscellaneous antidepressants," "selectiveserotonin reuptake inhibitors," and "serotonin modulators" were also used to define depression and encompass the most common drugs prescribed for depression. Although benzodiazepine can be prescribed in cases of anxiety or depressed mood, they are often mis- and/or overprescribed by physicians, particularly in geriatric populations in and outside of Quebec (Straand \& Rokstad, 1997; Tamblyn et al., 1994). It was, therefore, not included in the criteria of probable depression cases.

\subsubsection{Exposure of interest: Diet}

Energy and nutrient intakes at baseline and every follow-up year were obtained from three non-consecutive 24-hour dietary recalls, including one during a weekend day. A 24-hour recall consists of a detailed description of all food items and beverages consumed during the previous day, including cooking methods, recipes, and brand names. The 24-hour recall method (single or multiple) cannot accurately estimate individual's usual intakes (Basiotis, Welsh, Cronin, Kelsay, \& Mertz, 1987), but it is an acceptable tool for assessing mean usual intake of groups, provided all days of the week are equally represented (Gibson, 2005a; Thompson \& Subar, 2013). In their classical paper, Nelson and colleagues (1989) used data from 18 studies to calculate the number of days 
required to estimate individuals' true intake with an accuracy of $r=0.9$ - "the value of ' $r$ ' can be interpreted in terms of the proportion of subjects correctly classified in the top or bottom segments of the distribution of intakes (thirds, quarters, fifths, etc.)" (Nelson, et al., 1989). Interestingly, most nutrients required more than 7 days of diet record to estimate true individual intake, regardless of age and gender (Nelson, et al., 1989). Nutrients with greater variability need greater number of days recorded; hence, the concern lies particularly with the estimation of micronutrients. According to their study, the number of days of diet record in adults required to ensure that $r \geq 0.9$ for $B_{6}$ would be 9 for males, 15 for females, for $B_{12}$ is 35 and 34 , respectively, and for folic acid is 10 and 13 , respectively (Nelson, et al., 1989). Data from a Canadian study showed that folate could be estimated with $r=0.8$ using 3 days of diet record—other nutrients of interest were not studied (Palaniappan, Cue, Payette, \& Gray-Donald, 2003). For nutrients consumed daily (e.g. macronutrients), it is suggested that 3 days can provide a valid estimate for both males and females (Palaniappan, et al., 2003). Although the three days of intake may not reliably estimate individual's usual intakes, the dietary method used in this study can be adequately capture mean intakes sufficiently to be classified in the correct tertile of intake, as it is commonly done with food frequency data, and to assess changes in intakes, 
which were done in our studies (Basiotis, et al., 1987; Illner, Nöthlings, Wagner, Ward, \& Boeing, 2010; Nelson, et al., 1989).

Recall bias has been suggested as a potential concern in cases when memory or cognition is impaired (Thompson \& Subar, 2013), but it should not be a limitation in our study, as participants had good cognitive health, according to the inclusion criteria and the high scores from cognitive tests.

The recalls in NuAge were obtained by registered dietitians who received a rigorous10-day training period for data collection procedures, then coded for entry and analyzed using the CANDAT software (Godin and Assoc., London ON) with the 2007b Canadian Nutrient File database (Health Canada, 2007) plus a database of $>1200$ additional foods that had been developed on site (JohnsonDown, Ritter, Starkey, \& Gray-Donald, 2006). The completeness of the Canadian Nutrient File database for dietary folate equivalents is $88 \%$, vitamin $\mathrm{B}_{6}, 90 \%$, and $B_{12}, 93.5 \%$ (Health Canada, 2007). Portion models aided participants in the estimation of portion sizes.

Supplement use was recorded and entered based on drug identification numbers (DIN) whenever possible, and its exact composition was used, but, in some cases, a default value of the most common supplement of that type (e.g. $50 \mathrm{mg}$ or mcg for most B-vitamin complex supplements) was used (Troppmann, Johns, \& Gray-Donald, 2002). 
For the testing of the reverse causality hypothesis (manuscript 3), dietary data from 24-hour recalls for the follow-up years one (T2) and three (T4) were thoroughly accessed by the candidate (L.G.) for potential data entry errors and aberrant outliers. The candidate cross-checked each participant's recall data (e.g. energy, calcium, vitamin D, folate) using CANDAT software.

\subsubsection{Potential confounders of the relationship}

As mentioned in chapter 2, innumerous health and lifestyle factors can affect both diet and depression incidence and become, therefore, confounding factors, e.g. physical activity and cognition. For the adequate control of potential confounders, several health, social and psychological measurements were explored in initial models and then selected for the final models based on their contribution to the explained variance and/or association with the outcome. Covariates for the study of dietary patterns (manuscript 1) and B-vitamins (manuscript 2) were baseline measurements. In the reverse causality study (manuscript 3), percent changes in physical activity and in functional autonomy from the year of depression diagnosis and the year prior were calculated. The measurement tool and procedure was the same at all time points as described below. 


\subsubsection{Sociodemographic variables}

These variables consisted of age (years), sex, marital status (married/other), and education (years of schooling), obtained through the general questionnaire developed for the NuAge study (Gaudreau et al., 2007) and based on several previously published questionnaires.

Overall, $94.7 \%$ of all seniors in this study felt that their income was sufficient for their needs, indicating very little variation in ability to purchase foods or pay for housing, for example. No detailed information on actual income from work, pensions and savings was collected.

\subsubsection{Health behaviors}

Physical activity was assessed by the Physical Activity Scale for the Elderly (PASE) (Washburn, McAuley, Katula, Mihalko, \& Boileau, 1999; Washburn, Smith, Jette, \& Janney, 1993), a 10-item instrument specifically designed and validated to assess physical activity levels in large samples of older adults over a 1-week period. The PASE questionnaire combines physical activity information from several domains, including leisure, household, and occupational activity. A total PASE score is calculated by multiplying the average number of hours per day spent in these activities and the PASE weight for that item and summing 
these products. Higher PASE scores indicate higher activity levels (range 0-364 in our sample).

Smoking status was obtained from the general questionnaire. To be included in the logistic regression models, responses were transformed into a dichotomous variable (currently smoking/ not currently smoking) from a four level response ("no" and "no, but I have smoked previously" considered as "not currently smoking," and "yes, occasionally" and "yes, regularly," as "currently smoking").

\subsubsection{Health status}

Measures of health status included body mass index (BMI), self-reported hypertension, physical functioning, and cognitive functioning. Other measures were not found to be significantly associated with either the outcome or the exposure in this sample, including diabetes and osteoporosis, for example.

BMI was calculated as weight $(\mathrm{kg}) /$ height $\left(\mathrm{m}^{2}\right)$ where standing height and weight were measured with subjects dressed in indoor clothing without shoes, using a stadiometer and a beam balance.

Presence of hypertension was measured by part A (Multidimensional Functional Assessment Questionnaire) of the Older Americans Resources and Services (OARS) Multidimensional Functional Assessment Questionnaire 
(OMFAQ) with four levels of response ("no," "yes, but it does not interfere at all," "yes, it interferes a little," and "yes, it interferes a great deal") (Fillenbaum, 1988; Fillenbaum \& Smyer, 1981). For easiness of interpretation, it was transformed into a dichotomous variable ("no" for the first response, and "yes" for the other three).

Functional autonomy status was assessed by the Functional Autonomy Measuring System (SMAF, Système de Mesure de l'Autonomie Fonctionnelle), a 29-item rating scale to record functional disabilities and the available material and social resources that could compensate for the disabilities. It assesses present and actual performance—rather than potential—in activities of daily living (7 items), mobility (6 items), communication (3 items), mental function (5 items), and instrumental activities of daily living (8 items) (Desrosiers, Bravo, Hébert, \& Dubuc, 1995; Hébert, Carrier, \& Bilodeau, 1988). For each item, disability is rated on a scale ranging from independent to dependent on assistance. Scores range from 0 to a maximum of 87 , with higher scores meaning higher levels of dependence.

Cognitive functioning was assessed through the Modified Mini-Mental State (MMMS or 3MS) examination test (Teng \& Chui, 1987), which screens cognitive status through assessment of attention, concentration, orientation to time and place, long- and short-term memory, language ability, constructional praxis, and 
abstract thinking. Higher scores indicate better cognitive status, and the maximum score is 100 points (or $100 \%$ ).

\subsubsection{Social functioning status}

Stressful life events were assessed through the question, "Have you recently suffered a stressful life event (e.g., personal illness / death of a loved one)?" present in the Elderly Nutrition Screening tool (ENS॰) (Payette, Guigoz, \& Vellas, 1999).

Social activities in the preceding month were assessed with the Social Activities Questionnaire (social portion of the Elderly Activity Inventory Questionnaire, MAS) (Lefrançois, Leclerc, Dubé, Hamel, \& Gaulin, 2001). It evaluates participation in 19 types of valued activities such as shopping, attending cultural events, traveling, and participating in community organizations, to a maximum score of 21 -higher scores indicate more social activities.

\subsection{Statistical analysis}

Here, we describe the advanced statistical procedures used in the studies of diet and depression, such as factor analysis (manuscript 1), multivariate logistic regression modelling (manuscripts 1 and 2), treatment of missing data 
through multiple imputation method (manuscript 3 ), and mixed model analysis of covariance (manuscript 3).

\subsubsection{Manuscript 1: Dietary patterns and odds ratio}

Principal Component Analysis (PCA), a form of factor analysis, groups observed variables that belong together under their respective latent variable (Munro, 2005). In regards to eating habits, it is common sense that certain food items tend to be eaten together, in some sort of pattern. To illustrate, eating a hamburger is often accompanied by chips and soft drink, salads are often accompanied by salad dressings, and bread can be accompanied by butter, ham or cheese. These are only assumptions from anecdotal observations, but statistical techniques such as factor analysis can help confirm these observations through adequate mathematical modelling.

First, each food consumed is categorized so that more meaningful patterns can be created $(\mathrm{Hu}, 2002)$. In our initial and exploratory analyses, each food item present in the 24-hour dietary recalls was classified into 40 food categories based on their nutrient profile and culinary use and on the scientific literature (Akbaraly, et al., 2009). PCA on these 40 categories was not sufficiently meaningful because several of them were not included in any component or did not help to explain the variance, likely due to a very low consumption in these 
categories. Hence, we decided to merge some of the categories that contained similar food items according to the same criteria of nutrient profile and culinary use (Supplementary Table 1 - Appendix 2).

The weight (in grams) of food items from the same category was summed and averaged over the three days, yielding a mean intake for each food category for each person. Research has indicated that weights seem to yield a better pattern in PCA than other types of data, such as daily number of portions (Hearty \& Gibney, 2009; Smith, Emmett, Newby, \& Northstone, 2013). Mean weights were then used in PCA with varimax rotation to maintain uncorrelated components and greater interpretability. After an exploratory PCA, we retained three components (i.e. patterns) based on the diagram of eigenvalue (>1.0), scree plot (before a "plateau" was reached), interpretability of the components, and percentage of variance explained by the components. The factor loadings, generated from the confirmatory PCA with three components, represent correlation coefficients between each of the 32 food categories and each of the three components (i.e. patterns) (Supplementary Table 2 - Appendix 2). As an example, Figure 2 illustrates the link between the food categories with high factor loadings (or correlations) on the first principal component, which was then labelled "varied diet." According to general consensus, food categories with factor loadings higher than $|0.2|$ or $|0.3|$ can be considered correlated with that 
component (Munro, 2005). The mean intakes (in grams) of food categories weighted by the factor loadings yield each individual's factor scores in each dietary pattern. Therefore, all individuals have scores in all three components (or patterns), and the higher the person scores on a component, the greater is that person's adherence to that component (or dietary pattern). Factor scores were categorized into tertiles for greater interpretability of the results from logistic regression models.

Logistic regression models on tertiles of factor scores yield an odds ratio that can be interpreted as the likelihood of developing the disease (i.e. depression) compared to a reference group, in our case, the first tertile of factor scores-composed of people considered to have the lowest adherence to that pattern. Separate regression models were run for each pattern to avoid overcontrolling for dietary factors. Before the final models were chosen, we undertook several exploratory ones to test for relevant confounders of the diet-depression relationship.

To test for differences in participants' characteristics in bivariate analyses, we used Mantel-Haenszel $\chi^{2}$-test for categorical variables and independent ttests for continuous variables between depressed and non-depressed groups; and Pearson's $\chi^{2}$-test for categorical variables and one-way ANOVA for continuous variables across tertiles of dietary pattern score. 


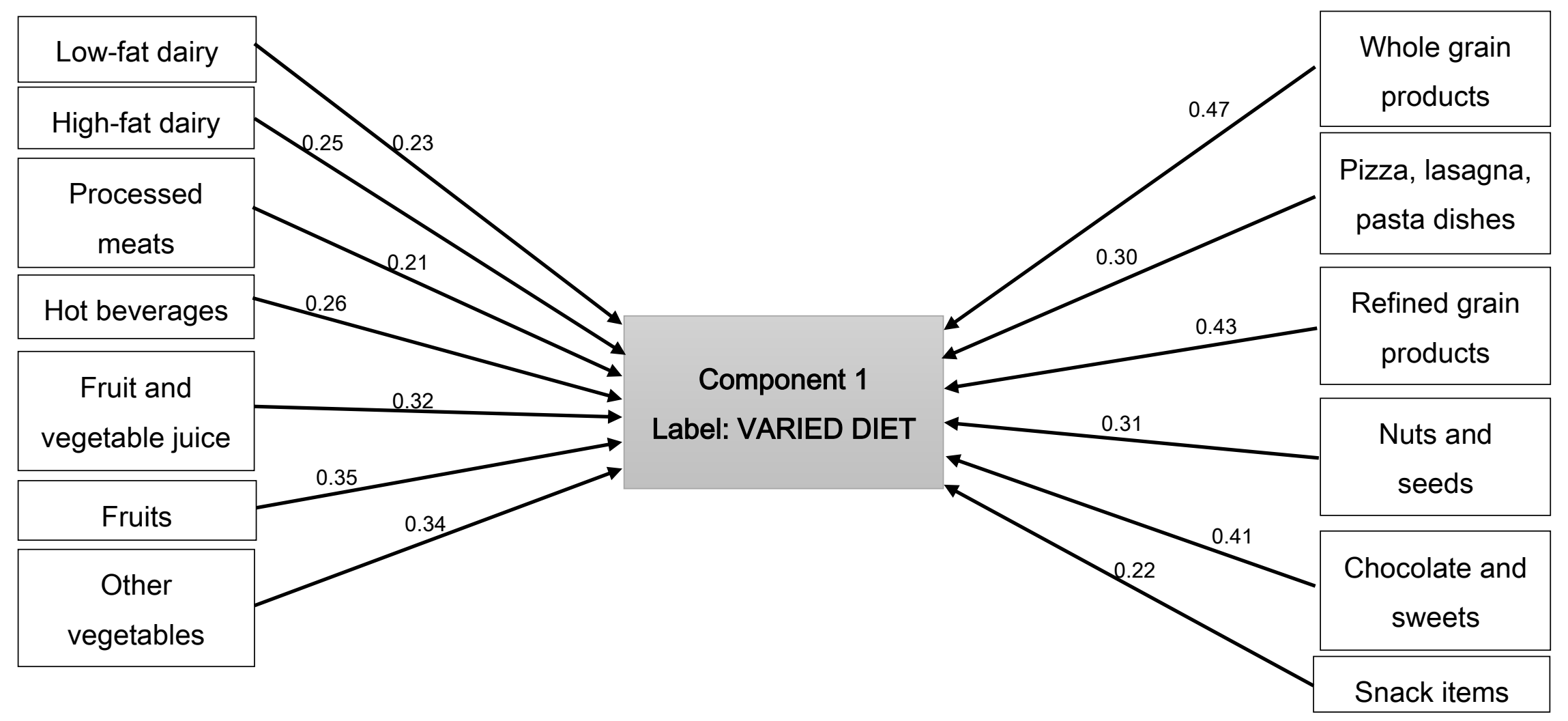

Figure 2: Schematic illustration of the correlation between the food categories with high factor loadings $(\geq 0.2)$ (indicated above each respective arrow) on component 1 (labeled, hence, "varied diet"). The other two components from the principal component analysis have a similar scheme of factor loadings (correlations) but with other food categories (as indicated in the Supplementary Table 2, Appendix 2). 


\subsubsection{Manuscript 2: B-vitamins and odds ratio}

Statistical analyses were conducted separately for men and women due to reported gender differences in both nutrient intakes, mostly due to differences in energy, and depression incidence, which is higher among women. Therefore, tertiles of intakes of each B-vitamin studied were categorized into tertiles with the first tertile as the reference group on logistic regression models of depression incidence. The sex-specific approach reduced the sample size for each regression model, consequently decreasing power. To compensate for loss of statistical power, we had to be parsimonious in the choice of the number of confounders to be controlled. The general consensus is that the number of cases (i.e. depression) be at least 10 times the number of covariates in the full model (Munro, 2005). Therefore, because there were 63 cases of probable depression among men, we could have up to six confounding variables in the final modelwe chose five after some preliminary and exploratory modelling, which is described in more detailed in the methods section of the manuscript. The last model included energy intake as means to compare "crude" vs. energy-adjusted intakes of the vitamins.

To test for differences in participants' characteristics in bivariate analyses, we used Fisher's exact test for categorical variables and independent t-tests for continuous variables between depressed and non-depressed groups. 


\subsubsection{Manuscript 3: Reverse causality of diet-depression relationship}

In this particular study, missing data in one of the predictors (or independent variables) would prompt the statistical software to exclude that person entirely, voiding the pairing of cases and controls, as well as introducing bias and a substantial loss of precision and power (Schafer, 1999; Sterne et al., 2009). To address this problem, we used the multiple imputation approach, a statistical technique that creates several different plausible imputed datasets, and each of them has the missing values suitably imputed. Imputed values are sampled from their predictive distribution based on the observed data. Then, each complete dataset is analyzed independently. Estimates of parameters of interest are averaged across the copies to give a single, pooled estimate (Royston, 2004;

Sterne, et al., 2009). This approach was deemed adequate for several reasons. First, the inferences (e.g. standard errors, p-values, etc.) obtained from multiple imputations are generally valid because the technique injects appropriate variability into the multiple imputed values, allowing to fully account for all uncertainty in predicting the missing values_of which the true value will never be known. Second, one set of " $x$ " number of imputations may be used for a variety of analyses, with no need to reimpute when a new analysis is performed. Third, it can be highly efficient even for small sets of imputations—often 3 to 5 imputations are sufficient to obtain superior results (Schafer \& Olsen, 1998; 
Sterne, et al., 2009). Finally, it works in conjunction with standard complete-data methods and software, including SPSS.

Before carrying out the multiple imputation procedure, sensitivity analyses should be conducted to examine whether the data are missing at random or not, which should be true so that the technique can be used reliably (Schafer \& Olsen, 1998; Sterne, et al., 2009). This sensitivity analysis, available in SPSS software, produces a series of patterns for the missing data, which guide the researcher's decision. In our study, data were missing at random, and, therefore, the use of multiple imputation was further proved adequate. To treat these missing values, we used the automatic multiple imputation method in SPSS (version 17.0, SPSS Inc., Chicago, IL): fully conditional specification method with 10 iterations and 5 imputations using linear regression.

We then undertook a $2 \times 2 \times 2$ (depression group $\times$ stressful event $\times$ time), full factorial, mixed model analysis of covariance (ANCOVA) on the multiple imputed datasets to test the reverse causality hypothesis. Mixed model ANCOVA allowed the incorporation of the temporal design (similar to a "pre-/post-test" design) and control for the most important confounders as seen in the preliminary tests and the other two studies: physical activity and functional autonomy. Due to the categorical nature of the stressful life event variable, it was included in the 
model as a between-factor term. Energy intake was not significant either in bivariate analysis or in the results from hypothesis testing; therefore, nutrient intakes (except saturated fat) were not energy-adjusted in subsequent ANCOVA models. Saturated fat as percent from total energy was maintained for easiness of interpretation. Continuous covariates were transformed into percent of change as to account for the importance of the change.

To test for differences in participants' characteristics in bivariate analyses, we used Fisher's exact test for categorical variables and independent t-tests for continuous variables between depressed and non-depressed groups; and dependent t-tests between the two time points. 


\section{Bridge 1}

As laid out in the literature review, little is known about dietary patterns in ambulatory, healthy, community-dwelling elderly in North America, particularly in Canada. Patterns of diet change over the life span and differ between geographical locations. Therefore, it is important to recognize patterns existent among these Canadian seniors and study their potential health outcomes, including affective health. No study to date has been conducted on the associations of patterns of eating and depression among elderly Canadians, which makes ours a unique contribution to the literature.

The population-based NuAge cohort aimed at examining nutrition as a determinant of successful aging. The dietary, anthropometric, physical performance and other socio-demographic measurements collected at baseline and annually for four years provided the adequate setting to answer the research questions set for this dissertation.

Health promotion through the encouragement of certain dietary habits are easier to incorporate into intervention programs and to be followed by the target audience (K. Young, et al., 2011). 


\section{CHAPTER 4. MANUSCRIPT 1}

Journal of Health, Nutrition, and Aging, in press

\section{Dietary patterns and incidence of depression in a cohort of community-dwelling older Canadians}

Laura Gougeon, M.Sc.1; Hélène Payette, Ph.D.2,3; José Morais, M.D.4; Pierrette Gaudreau, Ph.D.5,6; Bryna Shatenstein, Ph.D.7,8; Katherine Gray-Donald, Ph.D. ${ }^{1}$

Author affiliation:

1 School of Dietetics and Human Nutrition, McGill University

2 Research Center on Aging, Health and Social Services Centre - University Institute of Geriatrics of Sherbrooke

${ }^{3}$ Faculty of Medicine and Health Sciences, University of Sherbrooke

4 Division of Geriatric Medicine, Faculty of Medicine, McGill University

${ }^{5}$ Centre Hospitalier de l'Université de Montréal Research Center

6 Department of Medicine, University of Montreal

7 Department of Nutrition, University of Montreal

8 Institut Universitaire de Gériatrie de Montréal Research Centre

Corresponding author:

Dr. Katherine Gray-Donald, School of Dietetics and Human Nutrition, MacdonaldStewart Building MS 2-035, McGill University, 21111 Lakeshore Road, Ste-Annede-Bellevue, Quebec, Canada, H9X 3V9. Tel.: 514-398-7677, Fax: 398-7739, Email: katherine.gray-donald@mcgill.ca. 


\subsection{Abstract}

Objectives: To investigate the association of dietary patterns with a 3-year incidence of depression among healthy older adults. Design: Multiple logistic regression models adjusted for age, sex, marital status, smoking, education, total energy intake, physical activity, body mass index, hypertension, functional autonomy, cognitive functioning, social activities, and stressful life events. Energy and macronutrient intakes were also analyzed as potential predictors of depression. Setting: Cities of Montréal, Laval, and Sherbrooke in Quebec, CA. Participants: Community-dwelling older adults, free of depression at baseline ( $N=1,358,67-84 y)$, followed for 3y in the Québec Longitudinal Study on Nutrition and Aging (NuAge). Measurements: Dietary patterns derived from principal components analysis of three 24-h recalls at baseline, and depression incidence as measured by the 30-item Geriatric Depression Scale $(>10)$ and/or use of antidepressants at follow-up years. Results: $12.5 \%$ (170 people, $63 \%$ women) became depressed over the 3 years, mostly mild cases. Seniors in the highest tertile of "varied diet" had lower risk of depression before adjustment (OR 0.58, $98 \% \mathrm{Cl} 0.38-0.86)$ but not significant once age and sex were accounted for. No other dietary pattern was associated with the incidence of depression. The highest tertile of energy intake was associated with lower depression incidence after controlling for all confounders (fully adjusted OR $0.55,95 \% \mathrm{Cl} 0.34-0.87$ ). 
Conclusion: Among healthy older adults, dietary patterns do not appear to be related to depression. Those who eat less, however, possibly reflecting declining health, are at higher risk of becoming depressed.

Keywords: dietary patterns; older adults; depression; longitudinal; principal component analysis

\subsection{Introduction}

Depression is one of the most prevalent and costly of all mental health disorders and a leading cause of disability (Stanner, et al., 2009). Reports on the prevalence of clinically significant depressive symptoms among healthy older adults range from approximately $8 \%$ to $16 \%$ (Blazer, 2003). By 2020 , depression may become second only to heart diseases in its contribution to the global burden of disease as measured by disability-adjusted life years (Murray \& Lopez, 1996). In addition, depression in old age is linked with high morbidity and mortality rates (Blazer, 2003; Hamer, et al., 2011) and increased risk for cognitive decline, stroke, low bone mineral density, fractures, loss of appetite, poor quality of life, physical disability, and impairments in activities of daily living (Donini, et al., 2003; Galimanis, Mono, Arnold, Nedeltchev, \& Mattle, 2009; Mezuk, et al., 2008; Palsson \& Skoog, 1997; Penninx, et al., 1999). 
Diet and physical activity are two modifiable factors that are associated with depression in the general population (Bodnar \& Wisner, 2005; Cassidy, et al., 2004; Kohatsu, 2005) and in late-life (Blake, et al., 2009; Bridle, et al., 2012). Nutritional studies on depression have focused mainly on fish, long chain $n-3$ PUFAs, folate, and other B vitamins (Murakami \& Sasaki, 2010), however. Increasingly, dietary pattern analysis is seen as complimentary to traditional analysis of nutrients (Hu, 2002). In longitudinal (Akbaraly, et al., 2009; Le Port, et al., 2012; Rienks, et al., 2013) and cross-sectional (Jacka, et al., 2011; Samieri, et al., 2008) studies of middle-aged adults, dietary patterns were associated with depression or depressive symptoms. Our study is, to our knowledge, the first to explore this relationship longitudinally in older men and women. Therefore, our primary objective was to examine the associations of dietary patterns from principal component analysis, and, secondarily, to examine energy and macronutrient intakes, in relation to the incidence of depression over a three-year follow-up period in a large cohort of initially healthy older adults.

\subsection{Methods}

\subsubsection{Study population}

The Québec Longitudinal Study on Nutrition and Aging (NuAge) is a 4-year observational study of 1,793 men and women, free of disabilities in activities of 
daily living, and without functional or cognitive impairment at recruitment living in Montreal, Laval and Sherbrooke (QC, CA). Detailed information on the study population was published elsewhere (Gaudreau, et al., 2007). Baseline data collection occurred between December 2003 and March 2005. Participants provided informed consent. Ethics was approved by the Geriatric University Institutes of Montréal and Sherbrooke.

Participants with depression [Geriatric Depression Scale (GDS) scores $\geq 11$ or antidepressant medication use] at baseline ( $n=271)$, missing/invalid GDS scores at baseline or at all three follow-up assessments $(n=195)$, and invalid or missing dietary information at baseline $(n=103)$ were excluded. The final sample size for this study was 1,358 individuals ( $50.4 \%$ women, mean age \pm SD $74 \pm 4$ years). Follow-up data were available for 3 y for $79 \%, 2$ y $15 \%$, and 1 y $6 \%$.

\subsubsection{Dietary assessment and dietary patterns at baseline}

Mean energy and nutrient intakes at baseline were obtained from three nonconsecutive 24-hour dietary recalls, including one during a weekend day, by research dietitians and analyzed using the CANDAT software and the 2007b Canadian Nutrient File (Health Canada, 2007). For nutrients consumed daily (e.g. macronutrients), it is suggested that 3 days can reliably estimate and rank group's intakes for both males and females (Palaniappan, et al., 2003). 
Each food item in the dietary recalls was categorized into one of the 32 categories created according to nutrient profile, culinary use, and existing research (Akbaraly, et al., 2009) (Supplementary Table 1 - Appendix 2). Dietary patterns were identified using principal component analysis. Components were rotated by orthogonal transformation (varimax rotation). The eigenvalue, scree plot, interpretability of the components, and percentage of variance explained by the components were used to determine the number of dietary patterns to be retained. Factor loadings represent correlation coefficients between the food categories and the dietary pattern. The sum of intakes (in grams) weighted by the category's factor loading yields factor scores for each individual in all three patterns - the higher the person's factor score in a patterns, the greater is the person's adherence to that pattern.

\subsubsection{Main outcome measure: Depression incidence}

Depression incidence was identified on the basis of scores on the 30 -item Geriatric Depression Scale (GDS) $\geq 11$ (Brink, et al., 1982) or new use of antidepressant medication at any year of follow-up. Only three subjects presented scores $\geq 21$, classified as severe depression. At a cut-off score of $\geq 11$, the tool has $84 \%$ sensitivity and $95 \%$ specificity for clinically diagnosed major depression (Brink, et al., 1982). Medications with the therapeutic classification 
name, according to the American Hospital Formulary System, as "antidepressants," "miscellaneous antidepressants," "selective-serotonin reuptake inhibitors," and "serotonin modulators" were also used to define depression—benzodiazepine was not included.

\subsubsection{Confounders at baseline}

Sociodemographic variables are age (years), sex, marital status (married/other), and education (years of schooling). Physical activity was assessed by the Physical Activity Scale for the Elderly (PASE) (Washburn, et al., 1999), designed and validated to assess physical activity levels over 1-week. Higher PASE scores indicate higher activity levels (range 0-793). Smoking status at baseline was measured as smoker/non-smoker.

Health status measures included self-reported hypertension (yes/no), body mass index (BMI, $\left.\mathrm{kg} / \mathrm{m}^{2}\right)$, functional status [Functional Autonomy Measuring System (SMAF) scores] (Desrosiers, et al., 1995), and cognition [Modified MiniMental State (3MS) examination] (Teng \& Chui, 1987).

Measurements of social functioning status included reporting of stressful life events, through the question "Have you recently suffered a stressful life event (e.g., personal illness / death of a loved one)?' in the Elderly Nutrition Screening tool (ENS $\left.{ }^{\odot}\right)$ (Payette, et al., 1999), and social activities in the preceding month, 
assessed with the Social Activities Questionnaire (social portion of the Elderly Activity Inventory Questionnaire) (Lefrançois, et al., 2001).

\subsubsection{Statistical analyses}

Difference in proportions and means of covariates according to depressive symptoms was assessed using Mantel-Haenszel $\chi^{2}$-test for categorical variables and independent t-tests for continuous variables. Trend association across tertile categories of each dietary pattern was assessed using Pearson's $\chi^{2}$-test for categorical variables and one-way ANOVA for continuous variables.

Factor scores from principal component analysis were categorized into tertiles. Multiple logistic regression models were used to test for associations between the tertiles of dietary patterns and depression, with the lowest tertile as reference. No sex interactions were found between dietary patterns or energy intake and depression. Model 1 was controlled for age and sex. Model 2 was further adjusted for energy intake, marital status, education, smoking status, and physical activity. Model 3 was further adjusted for BMI, hypertension, functional autonomy and cognition, and the final model, for social activities and stressful life events. Separate tests were run for each dietary pattern. 
Two-sided $p$-values less than 0.05 were considered as statistically

significant. All statistical analyses were conducted using SPSS software package for Windows version 19.0 (IBM SPSS Inc., Chicago, IL).

\subsection{Results}

\subsubsection{Incidence of depression}

Among the 1,358 participants, 170 (12.5\%) developed depression at some point during follow-up-36 were identified on the basis of antidepressant medication use alone. Seventy six were first detected on year 1 of follow-up, 59 in year 2 , and 35 in year 3.

\subsubsection{Dietary patterns}

Three dietary patterns were retained from principal component analysis (Supplementary Table 2 - Appendix 2), accounting for $14.3 \%$ of the total variance explained and total initial eigenvalue of 1.36 . The first pattern, labelled "varied diet," was heavily loaded by high intakes of fruit, fruit juice and vegetable juice, other vegetables, nuts and seeds, refined and whole grain products, pizza, pasta dishes, chocolate and sweets, snacks items, hot beverages, processed meats, and high-fat dairy. The second pattern, labelled "traditional diet," was heavily loaded by high intake of red meat, butter and fats, alcoholic beverages, 
potatoes, tubers and starchy vegetables, soups, peas and legumes, desserts, processed meats, high-fat dairy, and low intake of low-fat dairy. The third pattern, labelled "convenience diet," was heavily loaded by high intake of sugar beverages, fried foods, fast foods, mixed dishes, and low intake of fish and seafood, margarine, oils, salad dressings, and leafy vegetables.

\subsubsection{Population characteristics at baseline}

Table 4 presents the baseline characteristics across tertiles of dietary pattern scores. Participants scoring high (tertile 3 ) in each of the dietary patterns were mostly men. Those with high adherence (tertile 3) to the "varied" pattern had lower rates of hypertension and more years of schooling, while the opposite was observed among those with high adherence to the "traditional" pattern. Physical activity was significantly higher among people in the highest tertile for "varied" and "traditional" patterns, but not for "convenience" pattern. As the adherence to a dietary pattern increased, energy intake also increased significantly $(p<0.001)$.

Those who developed depression at follow-up were more likely to be female, slightly older $(75.2 \pm 4.0 \mathrm{vs} .74 .2 \pm 4.2$ years $)$, and with lower physical activity scores $(90.3 \pm 45.7$ vs. $106.0 \pm 52.8)$ (Table 5). 


\subsubsection{Dietary patterns and depression incidence}

The association between the three dietary pattern scores at baseline and incidence of depression in the three years of follow-up is shown in Table 6. Compared to the first tertile participants with the highest score for the "varied diet" (tertile 3 ) were less likely to develop depression (OR 0.58, 95\% Cl 0.380.86). However, this association was no longer significant once confounders were controlled. None of the other dietary patterns were associated with depression in this population. Two baseline factors were significantly associated with developing depression in all three patterns: functional autonomy (fully adjusted models, tertile 3 OR 1.08, 95\% Cl 1.02-1.14), and stressful life events (fully adjusted models, tertile 3 OR 1.87, 95\% Cl1.33-2.63) (data not shown).

\subsubsection{Macronutrient intake and depression incidence}

Tertiles of energy as a measure of total intake and energy adjusted macronutrients as a measure of diet quality were examined in relation to incidence of depression. A multivariate logistic regression analysis indicated a strong protective effect of higher energy intakes (Table 7). Those in the top tertile of energy ( $\geq 2035 \mathrm{kcal}$ ) were almost $50 \%$ less likely to develop depressive symptoms over the three years of follow-up even after controlling for confounding variables. Modeling with energy intake as a continuous variable in increments of 
$100 \mathrm{kcal}$ yielded similar results in a fully adjusted model. There was no significant association between depression incidence and protein or fat intakes as a percent of energy (data not shown).

\subsection{Discussion}

In this longitudinal study, dietary patterns are not associated with the incidence of late-life depression over three years of follow-up in a large cohort of generally healthy older Canadians. Having good daily energy intake ( $\geq 2035 \mathrm{kcal}$ ), however, was strongly and independently protective against developing depression. Diet was measured rigorously using three $24 \mathrm{~h}$ recalls for each participant, and analyses were controlled for several important potential confounders.

The observed lack of association between dietary patterns and late-life depression incidence could have a number of explanations. Dietary patterns may not play a role due to insufficient variation in diet in this population. Small variations in patterns of food consumption among older individuals were also observed by other similar studies (Chocano-Bedoya, et al., 2013; Samieri, et al., 2008). The quality of the diet appears to be less important than consuming sufficient energy and nutrients contained in these foods. 
Our findings corroborate with those from the Nurses' Health Study in the US (Chocano-Bedoya, et al., 2013). Among the 50,605 female nurses (50-77 y) free of depression at baseline followed for over $12 \mathrm{y}$, no significant longitudinal associations between incident depression and either "Prudent" or "Western" dietary patterns after controlling for social, health, and dietary confounders were observed (Chocano-Bedoya, et al., 2013). It seems the association of healthy diets (i.e. high in fruits, vegetables, and whole-grains) with lower risk of depression is not clear even among middle-aged adults. In UK, (Akbaraly, et al., 2009) a "whole food" pattern, obtained through factor analysis, was not protective of depression five years later once participants depressed at baseline were excluded. Le Port et al. (Le Port, et al., 2012) followed 12,404 public sector employees in France aged 45 to 60 for 10 years and, also using factor analysis to identify dietary patterns, observed that the "healthy diet" pattern was not protective in either men or women who were not initially depressed. In the Australian Longitudinal Study on Women's Health ( $n=7,588,50-55 y)$, six dietary patterns were identified through factor analysis. Two, the "Mediterranean-like" and "fruit" dietary patterns, were associated with lower risks of depression three years later when adjusting for confounders, but the latter became just marginally associated $(p=0.03)$ after further adjustment for baseline depressive symptoms (Rienks, et al., 2013). In contrast, among 8,660 generally healthy men and 
women born in Australia, aged 50-69 years and followed for 12 years, the "Australian Dietary Pattern," but not the "Mediterranean Dietary Pattern," was protective for depression risk after controlling for several confounders (Hodge, et al., 2013). The study did not explore depression incidence, however, as baseline depressive symptoms were not available and, hence, not controlled.

Longitudinal evidence to date suggests that dietary patterns may not be a strong predictor of incident depression. The potential association of depression with dietary patterns may be due to existing depression history, which predicts the subsequent depression (Alexopoulos, 2005). Moreover, with respect to latelife depression, although protecting against dietary deficiencies and excesses is important, the intake of certain food items may not be more protective than just an adequate overall intake. Among participants of the Chicago Health and Aging Project, for instance, researchers reported an energy intake of 1,500 $\pm 573 \mathrm{kcal}$ in the lowest tertile of Mediterranean Diet Score (MedDietScore) and 1,945 \pm 578 kcal in the upper tertile, which had lower annual depression rates (Skarupski, et al., 2013). A 3-month clinical trial testing the effects of fasting and moderate calorie restriction in 32 healthy Malay men, aged 50 to 70 years, found no significant differences in depression scores (Hussin, Shahar, Teng, Ngah, \& Das, 2013). The higher overall energy intakes in our study may reflect a higher energy expenditure, possibly due to higher physical activity potentially due to better 
health (J. J. Anderson, Suchindran, Kritchevsky, \& Barrett-Connor, 2004; de Castro \& Stroebele, 2002). Higher activity levels are associated with better overall health and lower risk for several diseases including depression (Fox, 1999; Schuit, 2006). In NuAge, those in the highest tertiles of "varied" and "traditional" diets had indeed a higher physical activity level, and, as in other studies (Djernes, 2006; Hamer, et al., 2011; Ostbye et al., 2005), lower functional autonomy was associated with depression. Thus, good overall intake may also reflect better physical capacity. Energy intake was, however, a strong predictor of depression independently of functional limitations and physical activity. Persistent low energy intakes can lead to malnutrition, which is associated with elevated depression risk (Hickson, 2006). It is possible that, while aging, eating patterns somewhat lose their importance as compared to other biological, psychosocial, or health factors. Alexopoulos (2005) contends that depressive symptoms in the elderly are more likely to be caused by serious diseases, including cancer, cerebrovascular disease, chronic medical illness, disease complications, cognitive impairment and disability.

\subsection{Conclusion}

Dietary patterns were not associated with a 3-y depression incidence in healthy, community-dwelling older adults. Longitudinal studies should investigate 
potential associations longer than 3 years. Continuing to eat a sufficient quantity may be more protective than small variations in quality, independent of other health indicators such as physical activity and functional autonomy.

\subsection{Acknowledgments and conflict of interest disclosure}

The authors wish to thank the men and women of the NuAge cohort for their generous participation in the study, and the study personnel for their highly professional and devoted work. The NuAge study was supported by the Canadian Institute of Health Research (CIHR), Grant No. MOP-62842, the Fonds de la Recherche en Santé du Québec (FRSQ), and the Québec Network for Research on Aging.

None of the authors have conflicts of interest to disclose.

This research was presented as a poster at the $4^{\text {th }}$ Annual Scientific Meeting of the Canadian Nutrition Society, held in Québec City, QC, Canada, from May $30^{\text {th }}$ to June $2^{\text {nd }}, 2013$. Title: Dietary patterns are not associated with a 3-year incidence of depression among healthy elderly Quebecers: the NuAge Study. Authors: Gougeon L; Gray-Donald K; Morais, JA; Payette H. Abstracts were published in the special edition of the Applied Physiology, Nutrition and Metabolism (APNM) journal [2013, 38(4): 433-476, 10.1139/apnm-2013-0099]. 


\subsection{References}

Refer to the dissertation's bibliography. 


\subsection{Tables}

Table 4: Participants' baseline characteristics according to tertiles of dietary pattern scores $(\mathrm{N}=1,358)^{\mathrm{a}}$

\begin{tabular}{|c|c|c|c|c|c|c|c|c|c|c|c|c|}
\hline \multirow[b]{2}{*}{ Variables } & \multicolumn{4}{|c|}{ Varied Diet } & \multicolumn{4}{|c|}{ Traditional Diet } & \multicolumn{4}{|c|}{ Convenience Diet } \\
\hline & $\begin{array}{c}\text { Tertile } 1 \\
\text { (low) }\end{array}$ & Tertile 2 & $\begin{array}{c}\text { Tertile } 3 \\
\text { (high) }\end{array}$ & $p$ & $\begin{array}{c}\text { Tertile } 1 \\
\text { (low) }\end{array}$ & Tertile 2 & $\begin{array}{c}\text { Tertile } 3 \\
\text { (high) }\end{array}$ & $p$ & $\begin{array}{c}\text { Tertile } 1 \\
\text { (low) }\end{array}$ & Tertile 2 & $\begin{array}{c}\text { Tertile } 3 \\
\text { (high) }\end{array}$ & $p$ \\
\hline $\mathrm{n}$ & 453 & 452 & 453 & & 452 & 453 & 453 & & 453 & 453 & 452 & \\
\hline Female & $\begin{array}{c}281 \\
(62 \%)\end{array}$ & $\begin{array}{c}233 \\
(52 \%)\end{array}$ & $\begin{array}{c}171 \\
(38 \%)\end{array}$ & $<0.001$ & $\begin{array}{c}283 \\
(63 \%)\end{array}$ & $\begin{array}{c}251 \\
(55 \%)\end{array}$ & $\begin{array}{c}151 \\
(33 \%)\end{array}$ & $<0.001$ & $\begin{array}{c}236 \\
(52 \%)\end{array}$ & $\begin{array}{c}260 \\
(57 \%)\end{array}$ & $\begin{array}{c}189 \\
(42 \%)\end{array}$ & $<0.001$ \\
\hline Married & $\begin{array}{c}269 \\
(59 \%)\end{array}$ & $\begin{array}{c}267 \\
(59 \%)\end{array}$ & $\begin{array}{c}284 \\
(63 \%)\end{array}$ & 0.470 & $\begin{array}{c}244 \\
(54 \%)\end{array}$ & $\begin{array}{c}266 \\
(59 \%)\end{array}$ & $\begin{array}{c}310 \\
(68 \%)\end{array}$ & $<0.001$ & $\begin{array}{c}265 \\
(59 \%)\end{array}$ & $\begin{array}{c}277 \\
(61 \%)\end{array}$ & $\begin{array}{c}278 \\
(62 \%)\end{array}$ & 0.600 \\
\hline Smokers & $20(4 \%)$ & $28(6 \%)$ & $37(8 \%)$ & 0.070 & $20(4 \%)$ & $29(6 \%)$ & $36(8 \%)$ & 0.090 & $25(6 \%)$ & $21(5 \%)$ & $39(9 \%)$ & 0.034 \\
\hline Hypertension & $\begin{array}{c}233 \\
(51 \%)\end{array}$ & $\begin{array}{c}215 \\
(48 \%)\end{array}$ & $\begin{array}{c}195 \\
(43 \%)\end{array}$ & 0.040 & $\begin{array}{c}205 \\
(45 \%)\end{array}$ & $\begin{array}{c}216 \\
(48 \%)\end{array}$ & $\begin{array}{c}222 \\
(49 \%)\end{array}$ & 0.540 & $\begin{array}{c}200 \\
(44 \%)\end{array}$ & $\begin{array}{c}227 \\
(50 \%)\end{array}$ & $\begin{array}{c}216 \\
(48 \%)\end{array}$ & 0.194 \\
\hline $\begin{array}{l}\text { Stressful life event } \\
\text { (yes) }\end{array}$ & $\begin{array}{c}167 \\
(37 \%)\end{array}$ & $\begin{array}{c}157 \\
(35 \%)\end{array}$ & $\begin{array}{c}152 \\
(34 \%)\end{array}$ & 0.571 & $\begin{array}{c}159 \\
(35 \%)\end{array}$ & $\begin{array}{c}173 \\
(38 \%)\end{array}$ & $\begin{array}{c}144 \\
(32 \%)\end{array}$ & 0.130 & $\begin{array}{c}151 \\
(33 \%)\end{array}$ & $\begin{array}{c}169 \\
(37 \%)\end{array}$ & $\begin{array}{c}156 \\
(35 \%)\end{array}$ & 0.437 \\
\hline Age, years & $\begin{array}{c}75.0 \pm \\
4.2\end{array}$ & $\begin{array}{c}74.3 \pm \\
4.2\end{array}$ & $\begin{array}{c}73.6 \pm \\
4.1\end{array}$ & $<0.001$ & $\begin{array}{c}74.4 \pm \\
4.1\end{array}$ & $\begin{array}{c}74.7 \pm \\
4.4\end{array}$ & $\begin{array}{c}73.7 \pm \\
4.1\end{array}$ & 0.002 & $\begin{array}{c}74.2 \pm \\
4.1\end{array}$ & $\begin{array}{c}74.5 \pm \\
4.2\end{array}$ & $\begin{array}{c}74.2 \pm \\
4.2\end{array}$ & 0.561 \\
\hline Education, years & $\begin{array}{c}11.0 \pm \\
4.3\end{array}$ & $\begin{array}{c}11.6 \pm \\
4.3\end{array}$ & $\begin{array}{c}12.5 \pm \\
4.8\end{array}$ & $<0.001$ & $\begin{array}{c}12.3 \pm \\
4.4\end{array}$ & $\begin{array}{c}12.0 \pm \\
4.8\end{array}$ & $\begin{array}{c}10.8 \pm \\
4.3\end{array}$ & $<0.001$ & $\begin{array}{c}12.0 \pm \\
4.4\end{array}$ & $\begin{array}{c}11.6 \pm \\
4.6\end{array}$ & $\begin{array}{c}11.6 \pm \\
4.6\end{array}$ & 0.302 \\
\hline BMI, $\mathrm{kg} / \mathrm{m}^{2}$ & $\begin{array}{c}27.9 \pm \\
4.7\end{array}$ & $\begin{array}{c}27.9 \pm \\
4.3\end{array}$ & $\begin{array}{c}27.7 \pm \\
4.3\end{array}$ & 0.600 & $\begin{array}{c}27.5 \pm \\
4.5\end{array}$ & $\begin{array}{c}27.8 \pm \\
4.4\end{array}$ & $\begin{array}{c}28.3 \pm \\
4.4\end{array}$ & 0.022 & $\begin{array}{c}27.5 \pm \\
4.3\end{array}$ & $\begin{array}{c}27.9 \pm \\
4.6\end{array}$ & $\begin{array}{c}28.1 \pm \\
4.4\end{array}$ & 0.168 \\
\hline $\begin{array}{l}\text { Level of physical } \\
\text { activity }\end{array}$ & $\begin{array}{c}100.8 \pm \\
53.3\end{array}$ & $\begin{array}{c}101.5 \pm \\
50.2\end{array}$ & $\begin{array}{c}109.8 \pm \\
52.7\end{array}$ & 0.020 & $\begin{array}{c}98.6 \pm \\
47.7\end{array}$ & $\begin{array}{c}101.5 \pm \\
53.8\end{array}$ & $\begin{array}{c}112.1 \pm \\
54.1\end{array}$ & $<0.001$ & $\begin{array}{c}103.2 \pm \\
50.8\end{array}$ & $\begin{array}{c}103.5 \pm \\
52.9\end{array}$ & $\begin{array}{c}105.5 \pm \\
53.1\end{array}$ & 0.770 \\
\hline Social activity score & $7.1 \pm 2.6$ & $6.9 \pm 2.6$ & $7.0 \pm 2.9$ & 0.444 & $6.9 \pm 2.8$ & $7.2 \pm 2.6$ & $6.9 \pm 2.6$ & 0.085 & $7.1 \pm 2.6$ & $7.1 \pm 2.7$ & $6.9 \pm 2.7$ & 0.339 \\
\hline $\begin{array}{l}\text { Total energy intake, } \\
\text { kcal/day }\end{array}$ & $\begin{array}{c}1603 \pm \\
418\end{array}$ & $\begin{array}{c}1865 \pm \\
439\end{array}$ & $\begin{array}{c}2126 \pm \\
532\end{array}$ & $<0.001$ & $\begin{array}{c}1705 \pm \\
484\end{array}$ & $\begin{array}{c}1772 \pm \\
445\end{array}$ & $\begin{array}{c}2121 \pm \\
507\end{array}$ & $<0.001$ & $\begin{array}{c}1838 \pm \\
490\end{array}$ & $\begin{array}{c}1805 \pm \\
510\end{array}$ & $\begin{array}{c}1955 \pm \\
524\end{array}$ & $<0.001$ \\
\hline
\end{tabular}

a Categorical variables are presented as $\mathrm{n}(\%)$, and continuous variables as mean \pm standard deviation. One-way ANOVA was used for continuous variables and Person's $\chi^{2}$-test, for categorical variables. P-value for trend ( $\alpha$-level $=0.05$ ). BMI = Body mass index; Level of physical activity = scores in the Physical Activity Scale for the Elderly; Social activity score = scores in the Social Activities Questionnaire from the Elderly Activity Inventory Questionnaire. 
Table 5: Participants' baseline characteristics according to the incidence of depression over three-years of follow-up $(N=1,358)^{\text {a }}$

Depression Incidence

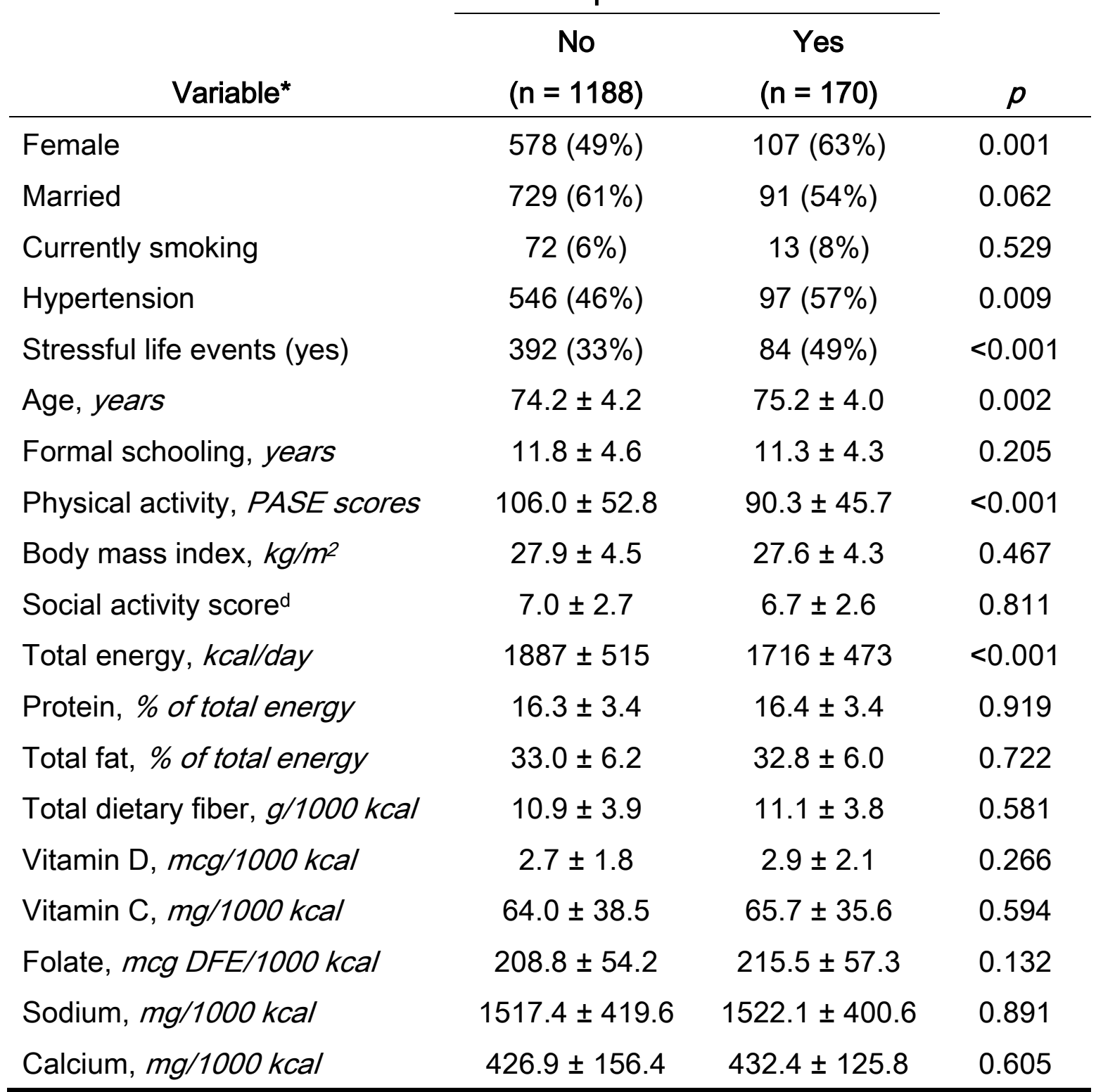

a Counts of depression on the basis of 30 -item Geriatric Depression Scale scores $\geq 11$ or use of antidepressant medication at any time of follow-up. Categorical variables are presented as $n(\%)$, and continuous variables as mean \pm standard deviation. Dietary intakes are means from three non-consecutive 24-hour recalls. Independent t-tests were used for continuous variables and Mantel-Haenszel's $\chi^{2}$-test, for categorical variables. P-value for trend $(\alpha$-level $=0.05)$. PASE $=$ Physical Activity Scale for the Elderly. Social activity score $=$ scores in the Social Activities Questionnaire from the Elderly Activity Inventory Questionnaire. 
Table 6: Associations between tertiles of dietary pattern scores at baseline and incidence of depression over three years of follow-up $(\mathrm{N}=1,358)^{\text {a }}$

\begin{tabular}{|c|c|c|c|c|c|}
\hline \multirow[b]{2}{*}{ Dietary Pattern } & \multirow{2}{*}{$\begin{array}{c}\text { Tertile } 1 \text { (low } \\
\text { adherence) } \\
\text { Reference }\end{array}$} & \multicolumn{2}{|c|}{ Tertile 2} & \multicolumn{2}{|c|}{ Tertile 3 (high adherence) } \\
\hline & & OR (95\% C.I.) & $p$ & OR (95\% C.I.) & $p$ \\
\hline \multicolumn{6}{|l|}{ Varied Diet } \\
\hline Unadjusted model & 1.00 & $0.79(0.54-1.15)$ & 0.217 & $0.58(0.38-0.86)$ & 0.007 \\
\hline Model 1 & 1.00 & 0.87 (0.59-1.27) & 0.462 & $0.70(0.46-1.07)$ & 0.096 \\
\hline Model 2 & 1.00 & $0.92(0.62-1.37)$ & 0.691 & $0.82(0.52-1.29)$ & 0.388 \\
\hline Model 3 & 1.00 & $0.94(0.63-1.41)$ & 0.779 & $0.86(0.55-1.36)$ & 0.527 \\
\hline Model 4 & 1.00 & $0.95(0.63-1.42)$ & 0.802 & $0.86(0.54-1.37)$ & 0.533 \\
\hline \multicolumn{6}{|l|}{ Traditional Diet } \\
\hline Unadjusted model & 1.00 & $0.98(0.67-1.43)$ & 0.979 & $0.73(0.48-1.09)$ & 0.121 \\
\hline Model 1 & 1.00 & $1.00(0.68-1.46)$ & 0.982 & $0.88(0.58-1.35)$ & 0.564 \\
\hline Model 2 & 1.00 & $1.02(0.69-1.50)$ & 0.939 & $1.00(0.64-1.56)$ & 0.999 \\
\hline Model 3 & 1.00 & $0.96(0.65-1.42)$ & 0.820 & $0.97(0.62-1.52)$ & 0.894 \\
\hline Model 4 & 1.00 & $0.92(0.62-1.37)$ & 0.675 & $0.96(0.61-1.52)$ & 0.876 \\
\hline \multicolumn{6}{|l|}{ Convenience Diet } \\
\hline Unadjusted model & 1.00 & $0.80(0.71-1.55)$ & 0.796 & $0.90(0.60-1.35)$ & 0.609 \\
\hline Model 1 & 1.00 & $1.01(0.68-1.49)$ & 0.963 & $0.95(0.63-1.43)$ & 0.811 \\
\hline Model 2 & 1.00 & $1.02(0.69-1.51)$ & 0.930 & $0.97(0.64-1.46)$ & 0.874 \\
\hline Model 3 & 1.00 & $1.01(0.68-1.50)$ & 0.975 & $0.91(0.60-1.38)$ & 0.668 \\
\hline Model 4 & 1.00 & $1.00(0.67-1.48)$ & 0.979 & $0.89(0.59-1.35)$ & 0.579 \\
\hline
\end{tabular}


Table 7: Associations between total energy intake at baseline and incidence of depression over three years of follow-up $(\mathrm{N}=1,335)^{\mathrm{a}}$

\begin{tabular}{|c|c|c|c|c|c|c|}
\hline \multirow[b]{2}{*}{ Model } & & \multirow{2}{*}{$\begin{array}{c}\text { Tertile } 1 \\
\text { ( } \leq 1611 \text { kcal) } \\
\text { Reference }\end{array}$} & \multicolumn{2}{|c|}{$\begin{array}{c}\text { Tertile } 2 \\
(1612-2034 \text { kcal })\end{array}$} & \multicolumn{2}{|c|}{$\begin{array}{c}\text { Tertile } 3 \\
(\geq 2035 \mathrm{kcal})\end{array}$} \\
\hline & & & OR (95\% C.I.) & $p$ & OR (95\% C.I.) & $p$ \\
\hline & $\mathrm{n}$ & 448 & 443 & & 444 & \\
\hline Unadjusted & & 1.00 & $0.68(0.47-0.99)$ & 0.046 & $0.44(0.29-0.66)$ & $<0.001$ \\
\hline Model 1 & & 1.00 & $0.77(0.53-1.13)$ & 0.182 & $0.56(0.36-0.88)$ & 0.012 \\
\hline Model 2 & & 1.00 & $0.77(0.53-1.14)$ & 0.192 & $0.56(0.36-0.89)$ & 0.013 \\
\hline Model 3 & & 1.00 & $0.73(0.49-1.08)$ & 0.115 & $0.54(0.34-0.86)$ & 0.009 \\
\hline Model 4 & & 1.00 & $0.72(0.49-1.07)$ & 0.108 & $0.55(0.34-0.87)$ & 0.012 \\
\hline
\end{tabular}

a Values are Odds Ratio (95\% Confidence Interval) from multiple logistic regression models. Model 1: Adjusted for age and sex. Model 2: Model 1 plus adjustment for marital status, smoking status, education, and physical activity. Model 3: Model 2 plus adjustment for body mass index, hypertension, physical functioning, and cognitive functioning. Model 4: Model 3 plus adjustment for social activities and stressful life events. Pvalue for trend $(\alpha-$ level $=0.05)$. 


\section{Bridge 2}

We were intrigued by the findings that dietary patterns were not predictive of a 3-year depression incidence in these seniors. As previously mentioned, biological factors might play a greater role in the aetiology of the disease in the elderly population compared to other psychosocial factors (Alexopoulos, 2005). Hence, the supposition of a potential longitudinal association at the nutrient level began to emerge.

B vitamins play an essential role in brain reactions, such as neurotransmitter synthesis and the one-carbon metabolism. Moreover, in crosssectional studies, mental health patients seemed more likely to have low B vitamin status (Coppen \& Bolander-Gouaille, 2005), and dietary intakes of these vitamins have direct effect on status (e.g. Garcia, et al., 2008). We further explored depression risk as a function of the observed quantile levels of mean usual intakes of vitamin $\mathrm{B}_{6}, \mathrm{~B}_{12}$, and folate among older men and women. 


\title{
CHAPTER 5. MANUSCRIPT 2
}

To be submitted for publication

\section{Vitamin $B_{6}$ and $B_{12}$ from food, but not folate, are protective of depression in a cohort of healthy community-dwelling older Canadians}

\begin{abstract}
Laura Gougeon, M.Sc. ${ }^{1}$; Hélène Payette, Ph.D.2,3; José Morais, M.D.4; Katherine Gray-Donald, Ph.D. ${ }^{1}$
\end{abstract}

\begin{abstract}
Author affiliation:
1 School of Dietetics and Human Nutrition, McGill University

2 Research Center on Aging, Health and Social Services Centre - University Institute of Geriatrics of Sherbrooke

3 Faculty of Medicine and Health Sciences, University of Sherbrooke

4 Division of Geriatric Medicine, Faculty of Medicine, McGill University
\end{abstract}

Corresponding author:

Dr. Katherine Gray-Donald, School of Dietetics and Human Nutrition, MacdonaldStewart Building MS 2-035, McGill University, 21111 Lakeshore Road, Ste-Annede-Bellevue, Quebec, Canada, H9X 3V9. Tel.: 514-398-7677, Fax: 398-7739, Email: katherine.gray-donald@mcgill.ca.

\subsection{Abstract}

This study investigates the role of dietary intake of folate $\left(B_{9}\right)$, vitamin $B_{6}$, and $\mathrm{B}_{12}$ in predicting the incidence of depression among healthy, communitydwelling older adults over 3 years of follow-up. Participants $(N=1,368 ; 74 \pm 4$ 
years old; 691 women, and 677 men) were followed annually in the Québec Longitudinal Study on Nutrition and Aging (NuAge) and were free of depression and cognitive impairment ( $3 \mathrm{MS}>79$ ) at baseline. Tertiles of nutrient intakes were obtained from the mean of three non-consecutive 24-hour recalls at baseline. Incident depression was assessed by the 30-item Geriatric Depression Scale ( $\geq 11)$ or antidepressant medication use during follow-up. Sex-stratified multiple logistic regression models were adjusted for age, physical activity, physical functioning, stressful life events, and total energy intake. There were $170(12.5 \%)$ new cases of depression over 3 years, mostly mild. Women in the highest tertile of crude intake of $B_{6}$ from food were 43 percent less likely to become depressed (multivariate OR $0.57,95 \% \mathrm{Cl} 0.39-0.96$ ), but the protective effect disappeared after further adjustment for energy intake. Dietary $\mathrm{B}_{12}$ lowered depression risk in men after controlling for all confounders (multivariate OR $0.42,95 \% \mathrm{Cl} 0.20$ 0.90). Total intake (diet+supplements) of each B-vitamin or folate was not associated with depression. This study provides limited support to the hypothesis that higher dietary intakes of certain B-vitamins (but not supplementation) can be protective of late-life depression among generally healthy seniors living in the community.

Keywords: B vitamins; intake; depression; older adults; community-dwelling 


\subsection{Introduction}

A growing body of literature links diet with mental health, including depression (Kohatsu, 2005). The interest in low folate, $B_{6}$, and $B_{12}$ status being associated with psychiatric disorders comes from their role in the neurotransmitter synthesis (norepinephrine, serotonin, and dopamine) (Fava \& Mischoulon, 2009) and from their participation in the one-carbon metabolism as methyl donors for methyl transferases involved in monoamine metabolism and re-methylation of homocysteine (Hcys) (Folstein, et al., 2007; Selhub, 2002). Low B vitamin levels lead to accumulation of circulating Hcys, whose oxidized derivates have been shown to be toxic to brain cells and the vascular endothelium, causing an inflammation-like state, which, in turn, cause depression of mood (Bhat, 2009; Folstein, et al., 2007; Kim, et al., 2008). Whether the role of these vitamins on mental health goes beyond frank vitamin deficiency; in other words, whether higher intakes might in fact be associated with lower risks of developing depression is not clear (Alpert, et al., 2000; Reynolds, 2006).

Four Australian randomized, double-blind, placebo-controlled trials with durations ranging from 35 days (Bryan, et al., 2002) to two years $(H$. Christensen, et al., 2011; Ford, et al., 2008; Walker, et al., 2010) examined the association of B vitamins supplementation with the incidence of depression in older adults aged $\geq 60 y$ living in the community. They found no evidence of 
benefits from vitamin supplementation on measures of depression. Observational studies that found significant associations between B vitamins and depressive symptoms in older adults have been limited to cross-sectional designs with measures of blood levels (Dimopoulos, et al., 2007; Merete, et al., 2008; Ng, Feng, et al., 2009; Robinson, et al., 2011; Tiemeier, et al., 2002), not dietary intakes. Whether diet predicts depression or depression affects dietary intake in these studies is unclear (Gilbody, et al., 2007). To our knowledge, the only longitudinal evidence on depression and B-vitamin intakes among communitydwelling older adults comes from the Chicago Health and Aging Project (CHAP) in approximately 3,500 US older adults ( $\geq 65 \mathrm{y}$ ) followed for 7 years (Skarupski, et al., 2010). It showed a significant decrease in depressive symptoms with higher total intakes (food + supplements from food frequency questionnaires) of $B_{12}$ and $\mathrm{B}_{6}$, but not from food alone. In middle-aged adults, Astorg et al. (2008) did not observe a significant association among a large cohort of French men and women aged 35-60y followed for 8 years, whereas Tolmunen et al. (2004) found that Finish men aged $42-60 y$ followed for 13 years in the lowest third of energyadjusted dietary folate intake had a higher risk of being depressed compared to the highest tertile.

It is also unclear whether higher intakes of B vitamins, as well as whether the source of the vitamin (food vs. supplement), is protective of depression 
incidence in community-living older adults. Hence, in this study, we examined the hypothesis that higher intakes of $\mathrm{B}$-vitamins, more specifically, folate, $\mathrm{B}_{6}$ and $\mathrm{B}_{12}$, either from food alone (i.e. dietary intake) or from food+supplements (i.e. total intake) may be protective of incident depression in late-life in a cohort of initially healthy, community-dwelling older Canadian adults followed for three years.

\subsection{Methods}

\subsubsection{Study population}

The Québec Longitudinal Study on Nutrition and Aging (NuAge) is a 4year observational study of 1,793 men and women in good general health at recruitment, described in detail elsewhere (Gaudreau, et al., 2007). In summary, the sample was drawn from a random sample obtained from the Québec Medicare database for the regions of Montreal, Laval and Sherbrooke (QC, CA) and stratified by age and sex. Community-dwelling men and women were included if they spoke French or English, were free of disabilities in activities of daily living, were without cognitive impairment (scores in the Modified MiniMental State (3MS) Examination >79), able to walk one block or to climb one flight of stairs without rest and willing to commit to a 5-year study period. Those who had heart failure $\geq$ class II, chronic obstructive pulmonary disease requiring oxygen therapy or oral steroids, inflammatory digestive diseases or cancer 
treated either by radiation therapy, chemotherapy or surgery in the past five years were excluded. The number of participants recruited into each age stratum were as follows: 68-72 years: $337 \mathrm{~F}, 329 \mathrm{M}$; 73-77 years: $305 \mathrm{~F}, 289 \mathrm{M} ; \geq 78$ years: 298 F, 235 M. Data were collected by trained research dietitians and nurses using computer-assisted personal interview methodology (William ${ }^{\mathrm{MD}}$, CMultispectra, 1997-2004 data capture software) following rigorous standardized procedures. Baseline data collection for this study occurred between December 2003 and March 2005. Participants were then examined annually using a series of nutritional, functional, medical, biological and social measurements.

All participants signed an informed consent approved by the Ethics committees of both of the Geriatric University Institutes of Montréal (Institut Universitaire de Gériatrie de Montréal - IUGM) and Sherbrooke (Institut Universitaire de Gériatrie de Sherbrooke - IUGS).

For this study, we limited the analysis to participants deemed free of depression at baseline, as defined by scores on the 30-item Geriatric Depression Scale $\geq 11(n=183)$ or antidepressant medication use $(n=78)$-details in the next section. Excluded were those with invalid or missing GDS scores at baseline $(n=14)$, with no GDS scores for follow-up years $(n=141)$, and with invalid or missing dietary information at baseline $(n=9)$. The final sample size for this 
study was 1,368 individuals aged 67-84y: 691 women (74.5 $\pm 4.3 y)$, and 677 men $(74.1 \pm 4.3 y)$.

\subsubsection{Dietary assessment at baseline}

Mean nutrient intakes at baseline were obtained from three non-consecutive 24-hour dietary recalls, including one for a weekend day. According to studies on the reliability of diet records, the three $24 \mathrm{~h}$-recalls can reliably estimate group's mean intakes and allowed for adequate ranking (Basiotis, et al., 1987; IIIner, et al., 2010; Palaniappan, et al., 2003; Thompson \& Subar, 2013).

The dietary intake data were recorded by research dieticians, coded for entry by the trained dietician or assistant, and analyzed using the CANDAT software and the 2007b Canadian Nutrient File (Health Canada, 2007). The dietary data were carefully checked with the initial paper record of the intake when variation between days exceeded $1000 \mathrm{kcal}$. Outliers in nutrient intake were verified following a thorough data cleaning protocol.

Supplement use was recorded and analyzed using the Natural Product Number (NPN) or Homeopathic Medicine Number (DIN-HM) which is associated with the nutrient levels. "Total intakes" represent the three-day average intakes of B vitamins coming from both food and supplements (food+supplement). 


\subsubsection{Main outcome measure: Incident depression}

Incident depression was identified on the basis of the 30 -item Geriatric Depression Scale (GDS) scores $\geq 11$ or new use of antidepressant medication at any annual follow-up. The GDS (Yesavage, et al., 1983) is an inventory with a yes/no format in which each affirmative response contributes one point to a total of 30 points. It is considered a reliable and valid measurement and screening tool, indicating the presence of depressive symptoms in an older adult population (Brink, et al., 1982; McDowell, 2006; Yesavage, et al., 1983). At a cut-off score of $\geq 11$, the tool has $84 \%$ sensitivity and $95 \%$ specificity for clinically diagnosed major depression (Brink, et al., 1982). Subjects with scores $\leq 10$ are considered not-depressed. Only three subjects presented scores $\geq 21$, deemed as severe depression. Medications with the therapeutic classification name, according to the American Hospital Formulary System (AHFS), as "antidepressants," "miscellaneous antidepressants," "selective-serotonin reuptake inhibitors," and "serotonin modulators" were also used to define cases of depressionbenzodiazepine was not included.

\subsubsection{Baseline confounders}

Preliminary analyses tested several health, social, and life-style confounders including years of schooling, marital status, smoking status, self- 
reported hypertension, body mass index, and measures of social activities.

However, due to the low incidence of depression, we were parsimonious in the choice of confounders and restricted the choice of covariates to the following baseline characteristics shown to differ between participants deemed depressed and not-depressed. Overall, $94.7 \%$ of all seniors in this study felt that their income was sufficient for their needs, indicating very little variation in ability to purchase foods or pay for housing, for example. No detailed information on actual income from work, pensions and savings was collected.

Physical activity was measured by the Physical Activity Scale for the Elderly (PASE) (Washburn, et al., 1999; Washburn, et al., 1993), a 10-item instrument specifically designed and validated to assess physical activity levels in large samples of older adults over a 1-week time period. A total PASE score is calculated by multiplying the average number of hours per day spent in these activities and a PASE weight for that item and summing these products. Higher PASE scores indicate higher activity levels.

Functional autonomy status was assessed by the Functional Autonomy Measuring System (SMAF, Système de Mesure de l'Autonomie Fonctionnelle) (Desrosiers, et al., 1995; Hébert, et al., 1988), a 29-item rating scale to record functional disabilities and the available material and social resources that could compensate for the disabilities. It assesses present and actual performance- 
rather than potential—in activities of daily living (7 items), mobility (6 items), communication ( 3 items), mental function ( 5 items), and instrumental activities of daily living (8 items). For each item, disability is rated on a scale ranging from independent to dependent on assistance. Scores range from 0 to 87 , with higher scores indicating greater dependence.

Finally, stressful life events were measured through the question, "Have you recently suffered a stressful life event (e.g., personal illness / death of a loved one)?' in the Elderly Nutrition Screening tool (ENS ${ }^{\odot}$ ) (Payette, et al., 1999).

\subsubsection{Statistical analyses}

Continuous variables are presented as means \pm standard deviation (SD). Before hypothesis testing, the distributions for all variables were examined for violations of assumptions of normality. Tests for skewness and kurtosis revealed that vitamins $\mathrm{B}_{6}$ and folate from diet alone had approximately normal distributions, while $B_{12}$ was highly skewed and kurtotic. Distribution for total intakes (food+supplements) did not approximate normality. Baseline dietary and total intakes of the B9-6-12 vitamins were categorized into sex-specific tertiles based on their distribution, allowing a robust estimation of risk of depression across levels of intakes without a strong influence of extreme values. Group differences according to the incidence of depression were assessed using 
Fisher's exact test for categorical variables and independent t-tests for continuous variables.

Most of the continuous variables were not normally distributed. Data for these variables were transformed using logarithmic (base 10) transformations, but subsequent analyses on transformed and untransformed scores produced comparable results. Therefore, untransformed scores were used in all analyses. Moreover, the sample size of the study makes it quite robust against normality violations.

Due to differences in rates of depression (Djernes, 2006) and nutrient intakes among men and women, sex-stratified multiple logistic regression models were undertaken to test for associations between the tertiles of intakes and depression. The lowest tertile group was taken as the reference, providing an estimated odds ratio (OR) and 95\% confidence interval. We tested three models. The unadjusted model includes only the tertiles of absolute ("crude" or nonenergy adjusted) intake. Adjusted model 1 includes the tertiles of absolute intakes and controls for age, physical activity, physical functioning, and stressful life event. Adjusted model 2 includes the same variables as in model 1 plus total energy intake in kilocalories and, hence, tests for tertiles of B-vitamin intake relative to energy consumption. Two-sided $p$-values less than 0.05 were considered as statistically significant. All statistical analyses were conducted 
using SPSS software package for Windows version 19.0 (IBM SPSS Inc., Chicago, IL).

\subsection{Results}

Compared to those included in the study at baseline, the 425 excluded participants were mostly women $[58.6 \%$ vs. $50.5 \%$, excluded vs. included sample, respectively, $\left.\chi^{2}(1)=8.481, p=0.004\right]$, have had a stressful life event [48.8\% vs. $\left.34.9 \%, \chi^{2}(1)=26.065, p<0.001\right]$, had lower physical activity scores [PASE $88.8 \pm 48.2$ vs. $104.1 \pm 52.2, t(1779)=-5.307, p<0.001]$, higher depression scores [GDS $9.1 \pm 5.4$ vs. $3.8 \pm 2.7, t(472.8)=19.011, p<0.001$ ], lower functional autonomy [SMAF scores $4.7 \pm 4.2$ vs. $3.8 \pm 3.3, \mathrm{t}(585.974)=$ $3.883, p<0.001]$ and lower energy intake $[1765 \pm 495$ vs. $1865 \pm 510, t(1776)=-$ 3.498, $p<0.001]$. Data not shown.

\subsubsection{Incidence of depression}

Among the 1,368 participants, 170 (12.5\%) developed depression (GDS $\geq 11$ and or started antidepressant use) at some point of follow-up (63\% women). Among these 170 people designated with depression, 36 were identified on the basis of antidepressant medication use alone (i.e. they did not have GDS scores $\geq 11$ at available follow-ups but reported use of antidepressant medication). 


\subsubsection{Baseline characteristics between depressed and not-depressed}

Table 8 shows the baseline characteristics for participants deemed depressed and not-depressed. Men who developed depression were older, less physically active, had lower physical functioning and lower energy intake compared with those who did not develop depression. Women deemed depressed have lower physical functioning and lower energy intake. Depressed men and women were more likely to have reported a stressful life event at baseline. Overall, only $14 \%$ of men and $21 \%$ of women took supplements containing B-vitamins.

We cannot assert intake adequacy as within-person variability was not accounted for, but, notably, when compared to the Estimated Average Requirements (EAR) for the sex and age group (Institute of Medicine, 2006), the recommended intake is found below the median value for all three B-vitamins, except folate in depressed women (Figures 3 to 5 ).

\subsubsection{Associations between B vitamins and depression incidence}

The odds ratio $(\mathrm{OR})$ and $95 \%$ confidence interval $(\mathrm{Cl})$ for the association between tertiles of vitamin $B_{6}, B_{12}$, and folate intakes and depression incidence are presented in Table 9. Models with tertiles of total intakes (i.e. from food + 
supplement) for each of the B vitamins yielded no significant associations and are not shown.

When considering the crude intake of dietary $\mathrm{B}_{6}$ and controlling for age, physical activity, physical functioning, and stressful life events, women in the highest tertile ( $\geq 1.71 \mathrm{mg} /$ day) were 43 percent less likely to develop depression in the three years of follow-up when controlling for health and lifestyle factors (multivariate OR $0.57,95 \% \mathrm{Cl} 0.39-0.96$ ) compared to women in the lowest tertile ( $\leq 1.33 \mathrm{mg} /$ day). This protective association was no longer significant after total energy intake was controlled (multivariate OR $0.70,95 \% \mathrm{Cl} 0.37-1.30$ ). In Spearman Correlation analyses, $\mathrm{B}_{6}$ intake and energy among women had the highest correlation coefficient $(\rho=0.602)$, and, although "tolerance" values showed no collinearity, eigenvalue for energy was above 15 , indicating a potential mutlicollinearity. In men, there was no association of $B_{6}$ intake and depression (Table 9).

Men in the highest tertile of dietary $B_{12}$ intake $(\geq 4.79 \mu \mathrm{g} /$ day $)$ were approximately 60 percent less likely to become depressed in comparison to men in the lowest tertile $(\leq 3.16 \mu \mathrm{g} / \mathrm{day})$ after controlling for all confounding factors, including energy intake (multivariate OR $0.42,95 \% \mathrm{Cl} 0.20-0.90$ ). $\mathrm{B}_{12}$ intakes were not associated with incidence of depression in women. 
In unadjusted models, depression risk was lower among women in the highest tertile of dietary folate [ $\geq 390 \mu \mathrm{g} /$ day as Dietary Folate Equivalent (DFE)] (unadjusted OR $0.60,95 \% \mathrm{Cl} 0.36-0.99$ ), but the effect was no longer significant once confounders were controlled. No association of folate and depression in men was observed.

\subsection{Discussion}

This study of the association of $\mathrm{B}_{6-9-12}$ intakes and the 3-y depression incidence in a large cohort of healthy older Canadians indicates a lower likelihood of depression among senior women with higher intakes of $B_{6}$ from food and among men with higher energy-adjusted intakes of $B_{12}$ from food, when compared to peers at lower rankings of intakes. Total intakes (food + supplement) had no detectable benefits, possibly due to the very low proportion of supplement use, increasing the variability in overall intakes.

To date, most studies with community-dwelling elderly have a crosssectional design and use blood levels (Beydoun, et al., 2010; Bjelland, et al., 2003; Dimopoulos, et al., 2007; Lee, Wing, \& Fong, 1998; Lindeman et al., 2000; Ng, Feng, et al., 2009; Ramos, Allen, Haan, Green, \& Miller, 2004; Robinson, et al., 2011) to investigate these vitamins. Randomized, placebo-controlled trials with older adults found no significant effect of B-vitamin supplements on their 
affective health (Bryan, et al., 2002; H. Christensen, et al., 2011; Ford, et al., 2008; Walker, et al., 2010). Our longitudinal observation of the relationship B vitamin supplements and depression corroborates these findings. In contrast, findings from the longitudinal Chicago Health and Aging Project (CHAP) (Skarupski, et al., 2010) showed a significant decrease in depressive symptoms with higher energy-adjusted intakes of total $B_{12}$ and $B_{6}$ (food + supplements), but not from food alone.

Researchers hypothesize that stronger associations are seen when there is lower adequacy or status (Astorg, et al., 2008; Lee, et al., 1998; Murakami et al., 2008; Penninx et al., 2000; Sanchez-Villegas, Doreste, et al., 2009; Tolmunen, Hintikka, Ruusunen, et al., 2004; Tolmunen et al., 2003). A threshold, as proposed by Sanchez-Villegas et al. (2009), is plausible, "Once a minimal level is attained, further increases in intake do not lead to further reduction in depression risk." It is noteworthy that most of the studies that found depression to be associated with low folate levels (blood or intakes) were conducted in countries where folate fortification was not mandatory at least at the time of the study, e.g. Finland (Tolmunen, Hintikka, Ruusunen, et al., 2004; Tolmunen, et al., 2003), France (Astorg, et al., 2008), Greece (Dimopoulos, et al., 2007), Japan (Murakami, et al., 2008; Nanri, Mizoue, et al., 2010) Norway (Bjelland, et al., 2003), Singapore (Ng, Niti, Zaw, \& Kua, 2009), Spain (Sanchez-Villegas, 
Doreste, et al., 2009; Sanchez-Villegas, et al., 2006), and Australia before 2009 (Almeida, et al., 2010; Sachdev et al., 2005). Fortification of flour with folic acid may have attenuated the effect of folate, which corroborates the aforementioned hypothesis that lower vitamin status may be more strongly associated with depression compared to higher vitamin status due to mandatory fortification. In unadjusted models, we observed a protective effect of folate from food among women, but not with supplementation.

Despite vitamins $\mathrm{B}_{6-9-12}$ playing a role in the one-carbon metabolism, each vitamin seems to have different underlying mechanisms (Tiemeier, et al., 2002). In our study, the effect of $B_{6}$ in women is dependent on total energy intake, which is positively correlated with $\mathrm{B}_{6}$ intakes. We postulate that $\mathrm{B}_{6}$ intake can be a marker of other health or lifestyle behaviours associated with better mental and affective health. Dietary sources of $\mathrm{B}_{6}$ include fortified, ready-to-eat cereals, fish, meat, poultry, yeast, certain seeds, bran, white potato and other starchy vegetables, and non-citrus fruits (Gibson, 2005b; Institute of Medicine, 2006), which compose a varied diet. In another study from our group, however, the principal component that most resembled a "varied diet" pattern, which did include many of those food items, was not protective of depression incidence when controlling for health and social confounders, but higher total energy intake was (Gougeon et al., in press). 
The protective effect of higher intakes of $B_{12}$ from food in men was independent of energy and other confounding factors. As the main sources of that vitamin are foods of animal origin (Institute of Medicine, 2006), we postulate that $B_{12}$ may have a direct effect on the risk of depression or it may be a proxy for social eating behaviours. Although, in preliminary analysis, measures of social activity was not associated with depression in this cohort, the reduced OR for higher intakes of $\mathrm{B}_{12}$ in men in a fully adjusted model coupled with the lack of association among women deserves further study as to whether there is a true diet effect or it is a reflection of social engagement.

It is interesting to note that these older adults may have generally good intakes of B vitamins. The estimated average requirements (EARs) for those aged $>51 \mathrm{y}$ are $1.3 \mathrm{mg} / \mathrm{day}$ of $\mathrm{B}_{6}$ for females and $1.4 \mathrm{mg} /$ day for males, 2.0 $\mathrm{mcg} /$ day of $\mathrm{B}_{12}$ for both sexes, and $320 \mathrm{mcg} /$ day of dietary folate equivalent for both sexes (Institute of Medicine, 2006); values all contained in the first tertiles of dietary intake. This raises the concern of lack of power, particularly in studies where the protective effect is fairly small (Beydoun, et al., 2010). Hence, we undertook a minimum detectable alternative of independent t-tests in nutrient intake between depressed and non-depressed participants using Power and Sample Size Calculations (PS) software v.3.0.2 (Dupont \& Plummer, 1990) with the following parameters: 1) alpha $=0.05$ and power $(\beta)=0.80 ; 2) \mathrm{N}=63$ for men 
and 107 for women; 3) the highest standard deviation (Table 8); and 4) the ratio of non-depressed to depressed participants $(9.75: 1$ for males and $5.46: 1$ for females). The detectable alternatives for men are $0.09 \mathrm{mg} / 1000 \mathrm{kcal}$ for dietary $\mathrm{B}_{6}, 1.15 \mathrm{mcg} / 1000 \mathrm{kcal}$ for dietary $\mathrm{B}_{12}$, and $20.78 \mathrm{DFE} \mathrm{mcg} / 1000 \mathrm{kcal}$ for dietary folate. The detectable alternatives for women are $0.07 \mathrm{mg} / 1000 \mathrm{kcal}$ for dietary $\mathrm{B}_{6}, 1.15 \mathrm{mcg} / 1000 \mathrm{kcal}$ for dietary $\mathrm{B}_{12}$, and $17.11 \mathrm{DFE} \mathrm{mcg} / 1000 \mathrm{kcal}$ for dietary folate. Differences smaller than these values are unlikely to be clinically relevant. Both depressed and non-depressed older adults in the NuAge study seemed to have fairly similar intakes of dietary $\mathrm{B}_{6-9-12}$ at baseline.

We advise to use caution when interpreting these findings, as they may not be applicable to the general geriatric population. Seniors included in the study tended to differ in several important demographic and health characteristics compared to those not included.

\subsection{Conclusion}

This 4-year longitudinal study on B-vitamin intake and depression risk among healthy, community-dwelling older adults provides some evidence that intakes of $B_{6}$ for women and $B_{12}$ for men from food sources show protective associations with incidence of depression. Folate had no detectable effect on the risk of depression incidence. Given the significant associations, the protective 
effect of vitamin $B_{6}$ in women was likely related to caloric intake and overall good diet, while the $B_{12}$ in men may reflect either a true effect of diet or social engagement. While maintaining an adequate consumption in quantity and quality of foods source of these vitamins may play a role in protecting generally healthy older adults from becoming depressed, these associations warrant further investigation.

\subsection{Acknowledgements and conflict of interest disclosure}

The authors wish to thank the men and women of the NuAge cohort for their generous participation in the study, and the study personnel for their highly professional and devoted work. The NuAge study was supported by the Canadian Institute of Health Research (CIHR), Grant No. MOP-62842, the Fonds de la Recherche en Santé du Québec (FRSQ), and the Québec Network for Research on Aging.

None of the authors have conflicts of interest to disclose.

This research was presented as a poster at the $42^{\text {nd }}$ Annual Scientific and Educational Meeting of the Canadian Association on Gerontology, Halifax, NS, October 17-19, 2013. Title: Dietary $\mathrm{B}_{6}$ and $\mathrm{B}_{12}$, but not folate, are associated with a 3-year incidence of depression among healthy elderly Quebecers. The NuAge Study. Authors: Gougeon L; Gray-Donald K; Morais, JA; Payette H. 


\subsection{References}

Refer to the dissertation's bibliography. 


\subsection{Tables and Figures}

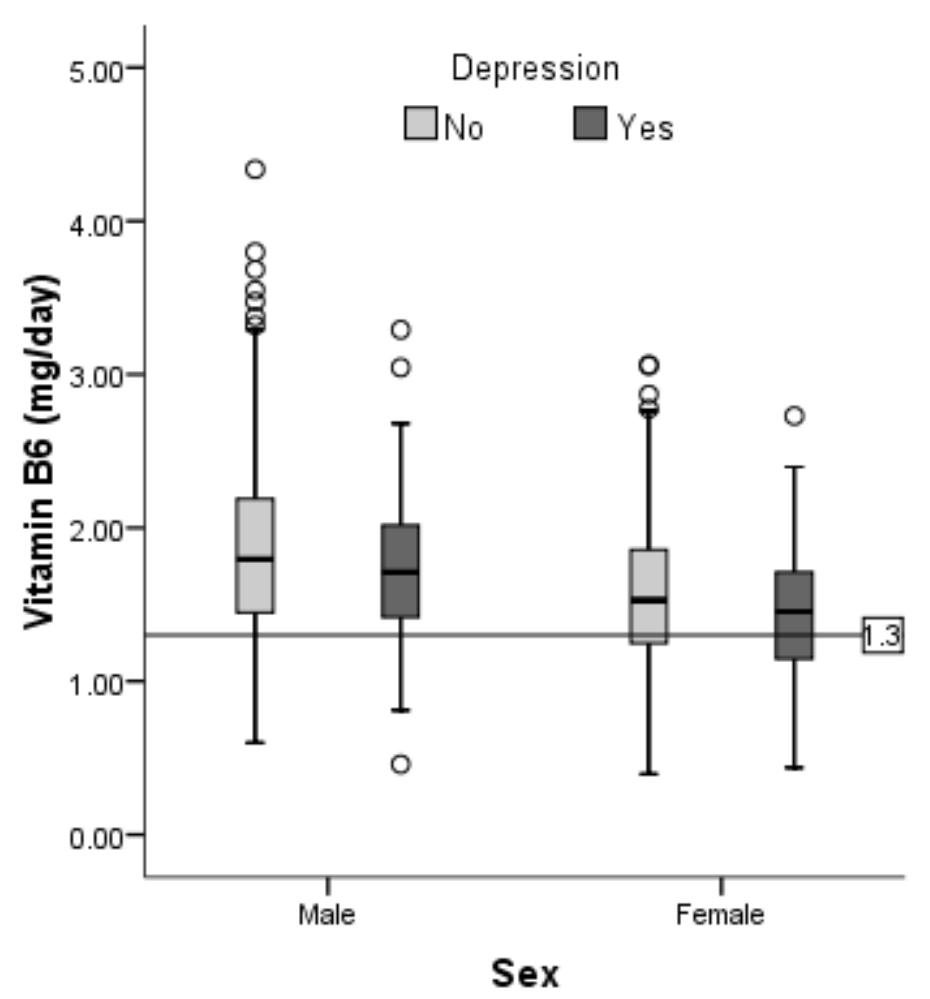

Figure 3: Box plot showing the distribution of $\mathrm{B}_{6}$ intake from diet according to sex and depression incidence (as per GDS scores $\geq 11$ and/or antidepressant use). The horizontal line indicates the Estimated Average Requirements (EAR) for women aged $\geq 51 \mathrm{y}$ (for men, the EAR is $1.4 \mathrm{mg} / \mathrm{day}$ ) and is for informative purposes only, as intakes are mean from three non-consecutive 24-hour recalls and does not account for within-person variability. Legend: o outliers farther than 1.5 interquartile and closer than 3 interquartile ranges, $\star$ outliers farther than 3 interquartile ranges. 


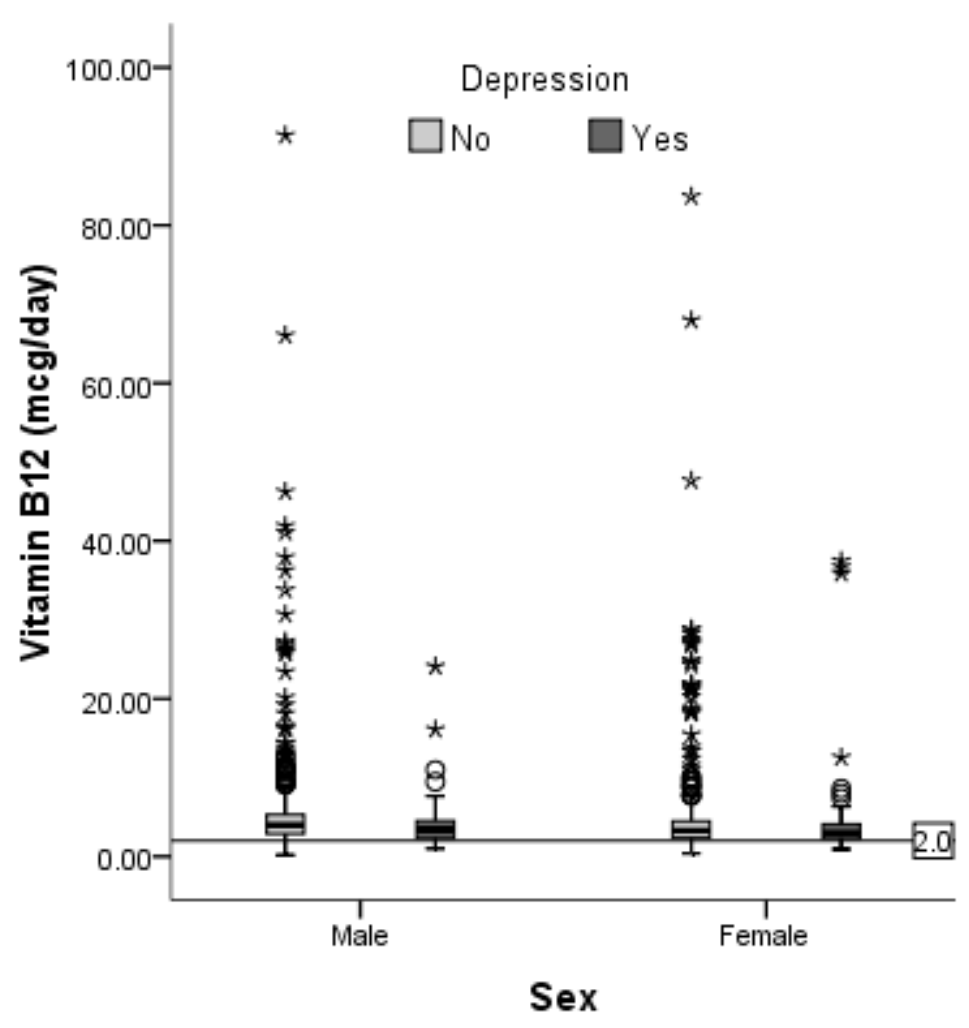

Figure 4: Box plot showing the distribution of $\mathrm{B}_{12}$ intake from diet according to sex and depression incidence (as per GDS scores $\geq 11$ and/or antidepressant use). The horizontal line indicates the Estimated Average Requirements for men and women aged $\geq 51 \mathrm{y}$ and is for informative purposes only, as intakes are mean from three non-consecutive 24-hour recalls and does not account for within-person variability. Legend: $\circ$ outliers farther than 1.5 interquartile and closer than 3 interquartile ranges, $\star$ outliers farther than 3 interquartile ranges. 


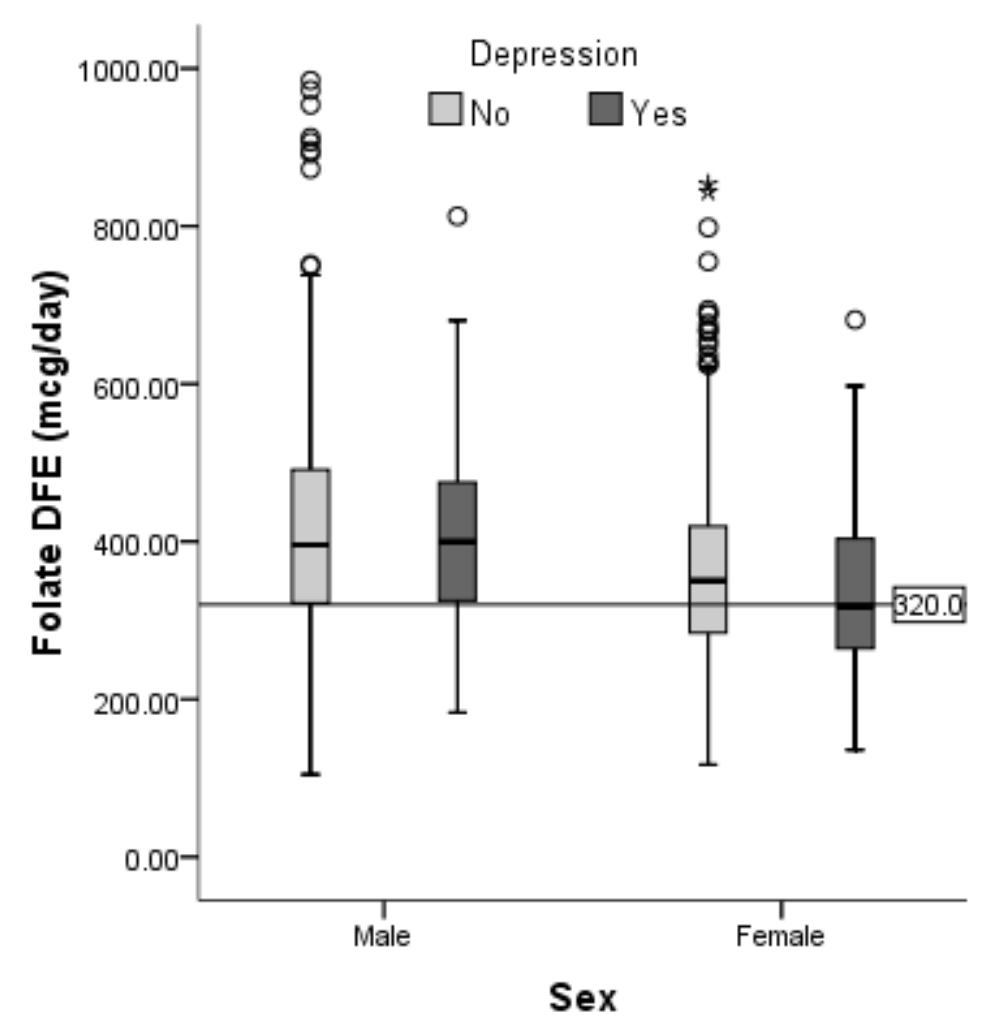

Figure 5: Box plot showing the distribution of folate intake (as dietary folate equivalent [DFE]) from diet according to sex and depression incidence (as per GDS scores $\geq 11$ and/or antidepressant use). The horizontal line indicates the Estimated Average Requirements for men and women aged $\geq 51 \mathrm{y}$ and is for informative purposes only, as intakes are mean from three non-consecutive 24-hour recalls and does not account for within-person variability. Legend: $\circ$ outliers farther than 1.5 interquartile and closer than 3 interquartile ranges, $\star$ outliers farther than 3 interquartile ranges. 
Table 8: Baseline characteristics according to the incidence of depression over three years of follow-upa

\begin{tabular}{|c|c|c|c|c|c|c|}
\hline \multirow[b]{2}{*}{ Baseline characteristics ${ }^{b}$} & \multicolumn{3}{|c|}{ Men $(n=677)$} & \multicolumn{3}{|c|}{ Women $(n=691)$} \\
\hline & $\begin{array}{c}\text { No } \\
(n=614)\end{array}$ & $\begin{array}{c}\text { Yes } \\
(n=63)\end{array}$ & $\mathrm{P}$ & $\begin{array}{c}\text { No } \\
(n=584)\end{array}$ & $\begin{array}{c}\text { Yes } \\
(n=107)\end{array}$ & $\mathrm{P}$ \\
\hline Age, years & $74.0 \pm 4.1$ & $75.3 \pm 4.1$ & 0.024 & $74.4 \pm 4.3$ & $75.2 \pm 4.0$ & 0.062 \\
\hline Education, years & $12.2 \pm 5.1$ & $11.1 \pm 4.6$ & 0.135 & $11.4 \pm 3.9$ & $11.4 \pm 4.1$ & 0.923 \\
\hline Married, $n(\%)$ & $475(77 \%)$ & $47(75 \%)$ & 0.637 & $261(45 \%)$ & $44(41 \%)$ & 0.526 \\
\hline Smoking, $n(\%)$ & $50(8 \%)$ & $4(6 \%)$ & 0.808 & $22(4 \%)$ & $9(8 \%)$ & 0.042 \\
\hline Hypertension, $n(\%)$ & $259(42 \%)$ & $34(54 \%)$ & 0.084 & $287(49 \%)$ & $63(59 \%)$ & 0.092 \\
\hline Body mass index, $\mathrm{kg} / \mathrm{m}^{2}$ & $28.0 \pm 4.0$ & $28.2 \pm 4.5$ & 0.730 & $27.8 \pm 4.9$ & $27.3 \pm 4.2$ & 0.362 \\
\hline Use of supplements with B-vitamins, $n$ (\%) & $81(13 \%)$ & $13(21 \%)$ & 0.797 & $123(21 \%)$ & $21(20 \%)$ & 0.425 \\
\hline Level of physical activity, PASE scores & $118 \pm 56$ & $96 \pm 53$ & 0.003 & $93.1 \pm 45.5$ & $87.0 \pm 40.4$ & 0.195 \\
\hline Stressful life event, $n(\%)$ & $158(26 \%)$ & $29(46 \%)$ & 0.001 & $236(40 \%)$ & $55(51 \%)$ & 0.043 \\
\hline Functional autonomy, SMAF scores & $4.2 \pm 3.6$ & $5.5 \pm 3.2$ & 0.006 & $3.3 \pm 2.9$ & $3.9 \pm 2.8$ & 0.040 \\
\hline Total energy intake, kcal/day & $2089 \pm 524$ & $1939 \pm 496$ & 0.030 & $1674 \pm 405$ & $1580 \pm 384$ & 0.027 \\
\hline Dietary $\mathrm{B}_{6}$ intake, $\mathrm{mg} / 1000 \mathrm{kcal}$ & $0.9 \pm 0.2$ & $0.9 \pm 0.2$ & 0.946 & $0.9 \pm 0.2$ & $0.9 \pm 0.2$ & 0.860 \\
\hline Dietary $\mathrm{B}_{12}$ intake, $\mathrm{mcg} / 1000 \mathrm{kcal}$ & $2.6 \pm 3.1$ & $2.2 \pm 1.9$ & 0.327 & $2.8 \pm 3.6$ & $2.8 \pm 3.9$ & 0.965 \\
\hline Dietary folate (DFE), $\mathrm{mcg} / 1000 \mathrm{kcal}$ & $200.4 \pm 51.5$ & $213.5 \pm 55.9$ & 0.057 & $217.3 \pm 55.3$ & $216.5 \pm 57.7$ & 0.895 \\
\hline
\end{tabular}

a Depression cases on the basis of 30-item Geriatric Depression Scale scores $\geq 11$ or use of antidepressant medication. Nutrient intakes from diet only (without supplements) from the mean of three non-consecutive 24-hour recalls. Abbreviations: PASE = Physical Activity Scale for the Elderly (range 0-793); SMAF = Functional Autonomy Measuring System (87-0, high to low dependence); DFE = Dietary Folate Equivalent. P-value: independent t-test (continuous variables) and Fisher's exact test (categorical variables), $\alpha$-level $=0.05$. 
Table 9: Associations between $B_{6}, B_{12}$, and folate intakes from food at baseline and incidence of depression over three years of follow-upa

\begin{tabular}{|c|c|c|c|c|c|c|c|c|c|}
\hline \multicolumn{10}{|c|}{$\operatorname{Men}(n=677)$} \\
\hline & \multicolumn{3}{|c|}{ Vitamin $B_{6}$ (mg/day) } & \multicolumn{3}{|c|}{ Vitamin $B_{12}$ (mcg/day) } & \multicolumn{3}{|c|}{ Folate (DFE mcg/day) } \\
\hline Model & $\begin{array}{c}\text { Tertile } 1 \\
\leq 1.56 \\
\end{array}$ & $\begin{array}{c}\text { Tertile } 2 \\
1.57-2.01 \\
\end{array}$ & $\begin{array}{c}\text { Tertile } 3 \\
\geq 2.02\end{array}$ & $\begin{array}{c}\text { Tertile } 1 \\
\leq 3.16\end{array}$ & $\begin{array}{c}\text { Tertile } 2 \\
3.17-4.78\end{array}$ & $\begin{array}{c}\text { Tertile } 3 \\
\geq 4.79\end{array}$ & $\begin{array}{c}\text { Tertile } 1 \\
\leq 346\end{array}$ & $\begin{array}{l}\text { Tertile } 2 \\
347-453\end{array}$ & $\begin{array}{c}\text { Tertile } 3 \\
\geq 454\end{array}$ \\
\hline Unadjusted & 1.00 & $\begin{array}{c}0.85 \\
(0.46,1.55)\end{array}$ & $\begin{array}{c}0.61 \\
(0.31,1.17)\end{array}$ & 1.00 & $\begin{array}{c}0.66 \\
(0.37,1.20)\end{array}$ & $\begin{array}{c}0.37 \dagger \\
(0.19,0.75)\end{array}$ & 1.00 & $\begin{array}{c}1.11 \\
(0.60,2.07)\end{array}$ & $\begin{array}{c}0.90 \\
(0.47,1.73)\end{array}$ \\
\hline Model 1 & 1.00 & $\begin{array}{c}0.86 \\
(0.46,1.60)\end{array}$ & $\begin{array}{c}0.63 \\
(0.32,1.23)\end{array}$ & 1.00 & $\begin{array}{c}0.61 \\
(0.33,1.12)\end{array}$ & $\begin{array}{c}0.37 \dagger \\
(0.18,0.75)\end{array}$ & 1.00 & $\begin{array}{c}1.21 \\
(0.64,2.30)\end{array}$ & $\begin{array}{c}1.05 \\
(0.54,2.05)\end{array}$ \\
\hline Model 2 & 1.00 & $\begin{array}{c}1.00 \\
(0.52,1.92) \\
\end{array}$ & $\begin{array}{c}0.83 \\
(0.38,1.80) \\
\end{array}$ & 1.00 & $\begin{array}{c}0.68 \\
(0.35,1.29) \\
\end{array}$ & $\begin{array}{c}0.42 \dagger \\
(0.20,0.90) \\
\end{array}$ & 1.00 & $\begin{array}{c}1.53 \\
(0.78,3.00) \\
\end{array}$ & $\begin{array}{c}1.68 \\
(0.77,3.66) \\
\end{array}$ \\
\hline \multicolumn{10}{|c|}{ Women $(n=691)$} \\
\hline & \multicolumn{3}{|c|}{ Vitamin $B_{6}$ (mg/day) } & \multicolumn{3}{|c|}{ Vitamin $\mathrm{B}_{12}$ (mcg/day) } & \multicolumn{3}{|c|}{ Folate (DFE mcg/day) } \\
\hline Model $^{\mathrm{b}}$ & $\begin{array}{c}\text { Tertile } 1 \\
\leq 1.33 \\
\end{array}$ & $\begin{array}{c}\text { Tertile } 2 \\
1.34-1.70 \\
\end{array}$ & $\begin{array}{c}\text { Tertile } 3 \\
\geq 1.71 \\
\end{array}$ & $\begin{array}{c}\text { Tertile } 1 \\
\leq 2.59 \\
\end{array}$ & $\begin{array}{c}\text { Tertile } 2 \\
2.60-3.92 \\
\end{array}$ & $\begin{array}{c}\text { Tertile } 3 \\
\geq 3.93 \\
\end{array}$ & $\begin{array}{c}\text { Tertile } 1 \\
\leq 239 \\
\end{array}$ & $\begin{array}{c}\text { Tertile } 2 \\
240-389 \\
\end{array}$ & $\begin{array}{c}\text { Tertile } 3 \\
\geq 390 \\
\end{array}$ \\
\hline Unadjusted & 1.00 & $\begin{array}{c}0.75 \\
(0.46,1.23)\end{array}$ & $\begin{array}{c}0.58 \dagger \\
(0.35,0.97)\end{array}$ & 1.00 & $\begin{array}{c}1.01 \\
(0.62,1.64)\end{array}$ & $\begin{array}{c}0.70 \\
(0.41,1.18)\end{array}$ & 1.00 & $\begin{array}{c}0.62 \\
(0.38,1.01)\end{array}$ & $\begin{array}{c}0.60 \dagger \\
(0.36,0.99)\end{array}$ \\
\hline Model 1 & 1.00 & $\begin{array}{c}0.74 \\
(0.45,1.21)\end{array}$ & $\begin{array}{c}0.57 \dagger \\
(0.39,0.96)\end{array}$ & 1.00 & $\begin{array}{c}1.03 \\
(0.63,1.68)\end{array}$ & $\begin{array}{c}0.73 \\
(0.43,1.23)\end{array}$ & 1.00 & $\begin{array}{c}0.66 \\
(0.40,1.09)\end{array}$ & $\begin{array}{c}0.66 \\
(0.39,1.09)\end{array}$ \\
\hline Model 2 & 1.00 & $\begin{array}{c}0.83 \\
(0.49,1.41)\end{array}$ & $\begin{array}{c}0.70 \\
(0.37,1.30)\end{array}$ & 1.00 & $\begin{array}{c}1.16 \\
(0.70,1.92)\end{array}$ & $\begin{array}{c}0.90 \\
(0.51,1.60)\end{array}$ & 1.00 & $\begin{array}{c}0.75 \\
(0.44,1.27)\end{array}$ & $\begin{array}{c}0.84 \\
(0.46,1.55)\end{array}$ \\
\hline
\end{tabular}

a Values are odds ratio (95\% Confidence Interval) from logistic regression models with Tertile 1 as reference. For better visualization, $p$-values and total intakes (food + supplements) are not shown (data available upon request). DFE $=$ dietary folate equivalent. Model 1: Adjusted for baseline age (years), physical activity (scores in the Physical Activity Scale for the Elderly), functional autonomy (SMAF dependence scores), and stressful life events (no/yes). Model 2: Model 1 plus adjustment for total energy intake (kcal). tStatistically significant with $p<0.05$. 


\section{Bridge 3}

The first study suggested a decreased depression risk from higher energy intakes at baseline. This second study suggested that high baseline vitamin $\mathrm{B}_{6}$ intake in women and $B_{12}$ in men are also associated with decreased depression risk in these healthy seniors. Given that the majority of the evidence on the nutrient-depression relationship comes from cross-sectional studies, we question whether depression would lead to significant declines in the nutrient intakes of depressed seniors compared to non-depressed counterparts. Hence, we carried out a reverse causality study to shed light on the directionality of the relationship and to estimate the magnitude of the effect incident depression can have on seniors' short-term nutrient intake. 


\title{
CHAPTER 6. MANUSCRIPT 3
}

To be submitted for publication

\begin{abstract}
A prospective evaluation of the depression-nutrient intake relationship among healthy community-dwelling older Canadians: The reverse causality hypothesis
\end{abstract}

Laura Gougeon, M.Sc. ${ }^{1}$; Hélène Payette, Ph.D. 2,3; José Morais, M.D.4; Katherine Gray-Donald, Ph.D. ${ }^{1}$

Author affiliation:

1 School of Dietetics and Human Nutrition, McGill University

2 Research Center on Aging, Health and Social Services Centre - University Institute of Geriatrics of Sherbrooke ${ }^{3}$ Faculty of Medicine and Health Sciences, University of Sherbrooke

${ }^{4}$ Division of Geriatric Medicine, Faculty of Medicine, McGill University

Corresponding author:

Dr. Katherine Gray-Donald, School of Dietetics and Human Nutrition, MacdonaldStewart Building MS 2-035, McGill University, 21111 Lakeshore Road, Ste-Annede-Bellevue, Quebec, Canada, H9X 3V9. Tel.: 514-398-7677, Fax: 398-7739, Email: katherine.gray-donald@mcgill.ca.

\subsection{Abstract}

Purpose: This study investigates whether incident depression results in changes in nutrient intakes in late-life, widely known as the reverse causality hypothesis of depression. Methods: Case-control nested within the Québec Longitudinal Study 
on Nutrition and Aging (NuAge). Participants were community-dwelling older adults ( $\geq 67 \mathrm{y}$ ) followed annually for 4 years, free of depression and cognitive impairment at baseline. Participants $(n=158,75.1 \pm 4.0 y, 61 \%$ female) who became depressed over follow-up (Geriatric Depression Scale $\geq 11$ or antidepressant medication) were matched by age group and sex with nondepressed participants. We compared mean nutrient intake from the year depression was detected with intake one year prior between depressed and nondepressed participants. GLM mixed models were adjusted for percent changes in physical activity and functional autonomy, and stressful life events reported at diagnosis. Results: A significant interaction of timexdepression $(p=0.033)$ was observed only for vitamin $\mathrm{B}_{12}$ : Intakes among depressed elderly participants declined more over time than among those not depressed. Intakes of energy, protein, saturated fat, total dietary fibre, vitamin $B_{6}$, and folate were not significantly affected over time in the depressed group compared to those not depressed. Conclusion: Despite newly reported depression, participants maintained a consistent diet with reduced levels of $\mathrm{B}_{12}$.

Keywords: reverse causality; diet; depression; older adults; community-dwelling 


\subsection{Introduction}

Depression in late-life is a predisposing factor for chronic diseases and low functional status, consequently affecting older people's quality of life and perceptions of aging healthily (Aguilar-Navarro \& Avila-Funes, 2007; Alexopoulos, 2005; Jeste et al., 2013). Diet is a modifiable factors that can potentially affect mood and mental health, including depressive symptoms (Akhondzadeh, et al., 2013; Bhat, 2009; L. Christensen, 2001). One of the symptoms of depression, however, is altered appetite and increased seclusion and avoidance behaviour, which can, in turn, influence depressed people's food intake (American Psychiatric Association, 2000). This effect is often referred to as the reverse causality hypothesis of depression and diet, whereby having a poor diet maybe one of the consequences of depression (Akbaraly, et al., 2009; Astorg, et al., 2008;

Chocano-Bedoya, et al., 2013; Gilbody, et al., 2007; Kim, et al., 2008; Rienks, et al., 2013; Sanchez-Villegas, Delgado-Rodriguez, et al., 2009). Although deficiencies and dietary changes can be widely regarded as a secondary consequence of psychiatric illness, nutritional studies have not confirmed this view (Gilbody, et al., 2007; Reynolds, 2002).

Three cohort studies indicated the potential existence of a reverse causality effect in their findings. In a large cohort of women aged 20 to 34 years in the Southampton Women's Survey, Kendrick et al. (2008) observed that low blood 
folate levels were associated with prevalent depression at baseline $(n=5051)$ but not with incident depression ( $\mathrm{n}=2732$ ) over the two years of follow-up suggesting that lower blood folate levels may be a consequence, rather than a cause, of depressive symptoms in women at child-bearing age(Kendrick, et al., 2008).

This view was not supported by a similar study of the elderly (Kim, et al., 2008), in which a cohort of 521 community-dwelling Korean adults aged 65 and older were followed for two years. Incident depression not only was predicted by lower serum folate levels and vitamin $B_{12}$ levels at baseline, but was also associated with greater declines in $\mathrm{B}_{12}$ serum levels over follow-up (Kim, et al., 2008). Their finding generally supports the notion that a depressive state may affect $B_{12}$ serum levels.

To test the reverse causality hypothesis, cohort studies often conducted some sensitivity analysis by excluding or controlling baseline depression (Chocano-Bedoya, et al., 2013; Le Port, et al., 2012; Rienks, et al., 2013; Sanchez-Villegas, Delgado-Rodriguez, et al., 2009). Others only briefly discussed that the possibility of depression influencing participants' food intakes in their study was unlikely due to some intrinsic design factors, such as no inclusion of baseline depression or the distant follow-up (Astorg, et al., 2008; Hodge, et al., 2013; Tolmunen, Hintikka, Ruusunen, et al., 2004). 
Taken together, despite being a common concern, the reverse causality has not yet been explicitly investigated, so its effect on intakes is largely unknown, particularly among vulnerable groups such as older adults. We could not find a study that investigates the influence of depression on short-term nutrient intakes in older adults living in the community. Therefore, we aim to explore whether depression is associated with significant declines in intakes of total energy, protein, saturated fat, dietary fibre, and vitamins $B_{6}, B_{12}$, and folate in a group of initially healthy, community-dwelling older adults who became depressed at some point of follow-up.

\subsection{Material and methods}

\subsubsection{Study population}

The Québec Longitudinal Study on Nutrition and Aging (NuAge) is a 4-year observational study of 1,793 men and women in good general health at recruitment, described in detail elsewhere (Gaudreau, et al., 2007). In summary, the sample was randomly drawn from the Québec Medicare database for the regions of Montreal, Laval, and Sherbrooke (QC, CA) and stratified by age and sex. Community-dwelling men and women were included if they spoke French or English, were free of disabilities in activities of daily living, were without cognitive impairment (scores in the Modified Mini-Mental State (3MS) Examination >79), 
able to walk one block or to climb one flight of stairs without rest and willing to commit to a 5-year study period. Those who had heart failure $\geq$ class II, chronic obstructive pulmonary disease requiring oxygen therapy or oral steroids, inflammatory digestive diseases or cancer treated either by radiation therapy, chemotherapy or surgery in the past five years were excluded. Participants were recruited between December 2003 and March 2005 and examined annually using a series of nutritional, functional, medical, biological and social measurements. Data were collected by trained research dieticians and nurses using computerassisted personal interview methodology (William ${ }^{\text {TM }}$, OMultispectra, 1997-2004 data capture software) following rigorous standardized procedures. The number of participants recruited into each age group was as follows: 68-72 years: 337 females, 329 males; 73-77 years: 305 females, 289 males; $\geq 78$ years: 298 females, 235 males.

All participants signed an informed consent approved by the Ethics committees of both of the Geriatric University Institutes of Montréal (Institut Universitaire de Gériatrie de Montréal - IUGM) and Sherbrooke (Institut Universitaire de Gériatrie de Sherbrooke - IUGS).

To answer our research question on the reverse causality of diet and depression, we conducted a case-control study nested within the NuAge cohort. 
We limited the analysis to participants deemed free of depression at NuAge baseline, i.e. scores on the 30-item Geriatric Depression Scale (GDS) $\geq 11$ ( $n=183)$ or antidepressant medication use $(n=78)$. Excluded were those with invalid or missing GDS scores at baseline $(n=14)$, with no GDS scores for all three years of follow-up ( $n=141)$, and with invalid or missing dietary information at baseline $(n=9)$. Among the remaining 1,368 individuals, those who developed depression at some time of follow-up $(n=170)$ were screened for available dietary information at the time point depression was detected (henceforth referred to as T.1) and at the year prior to detection (henceforth referred to as T.0), to a final sample size of 158 for probable depression cases. Each subject was then randomly matched by sex and baseline age group with a non-depressed participant whose dietary data was available for the same time points as their depressed counterparts $(n=158)$.

\subsubsection{Dietary assessment}

Average nutrient intakes at T.0 and T.1, excluding intakes from supplements, were obtained from three non-consecutive 24-hour dietary recalls, including one for a weekend day, ensuring that all days of the week were equally represented. While the three days of intake were below the number suggested by Nelson et al. (1989) to reliably measure individuals usual intakes, they can estimate group's 
mean intakes within acceptable precision and can allow for comparison of dietary change in those who did and did not become depressed (Basiotis, et al., 1987; Illner, et al., 2010; Nelson, et al., 1989; Palaniappan, et al., 2003; Thompson \& Subar, 2013).

The dietary intake data were recorded by research dietitians, coded for entry by the trained dietitian or assistant, and analyzed using the CANDAT software and the 2007b Canadian Nutrient File (Health Canada, 2007). The dietary data were carefully checked with the initial paper record of the intake when variation between days exceeded $1000 \mathrm{kcal}$. Outliers in nutrient intake were verified following a thorough data cleaning protocol.

To minimize type I error, we had to be parsimonious in the choice of outcome nutrients. Therefore, we limited the analysis to the following macronutrients: energy (kcal), body-weight adjusted protein (grams per kilogram of body weight), saturated fat (percent of total energy), and total dietary fibre (grams). We were also interested in the intakes of vitamins $B_{6}, B_{12}$ and folate as they have been previously shown to be associated with incident depression risk (Gougeon, Payette, Morais, \& Gray-Donald, in preparation). Diet quality scores were not explored because existing indexes do not predict health outcomes significantly better than individual dietary factors (Waijers, et al., 2007), and, in this 
study, we were not interested in changes to guideline adherence over time, but nutrient intakes per se.

\subsubsection{Depression cases}

Probable depression cases were identified on the basis of the 30 -item Geriatric Depression Scale (GDS) scores $\geq 11$ or new use of antidepressant medication at point of follow-up. The GDS (Yesavage, et al., 1983) is an inventory with a yes/no answer format in which each response indicating depression contributes one point to a total of 30 points. It is considered a reliable and valid measurement and screening tool, indicating the presence of depressive symptoms in an older adult population (Brink, et al., 1982; McDowell, 2006; Yesavage, et al., 1983). At a cut-off score of $\geq 11$, the tool has $84 \%$ sensitivity and 95\% specificity for major depression according to the Research Diagnostic Criteria (Brink, et al., 1982). Subjects with scores $\leq 10$ are considered not-depressed. Medications with the therapeutic classification name, according to the American Hospital Formulary System (AHFS), as "antidepressants," "miscellaneous antidepressants," "selective-serotonin reuptake inhibitors," and "serotonin modulators" were also used to define cases of depression—benzodiazepine was not included. 


\subsubsection{Potential confounders}

Preliminary linear regression models of changes in intakes controlling for baseline nutrient intake level explored several potential health, social, and lifestyle confounders including years of schooling, marital status, smoking status, selfreported hypertension, body mass index $\left[\left(\mathrm{BMI}, \mathrm{kg} / \mathrm{m}^{2}\right)\right.$ using weight and height measured on-site], and measures of social activities. Two variables repeatedly showed significant associations $(p<0.05)$ with the dependent variables tested: physical activity, functional autonomy, and stressful life event measured at the time of depression (T.1), and, hence, used in the final analysis. Overall, $94.7 \%$ of all seniors in this study felt that their income was sufficient for their needs, indicating very little variation in ability to purchase foods or pay for housing, for example. No detailed information on actual income from work, pensions and savings was collected.

Physical activity was measured by the Physical Activity Scale for the Elderly (PASE) (Washburn, et al., 1999; Washburn, et al., 1993), a 10-item instrument specifically designed and validated to assess physical activity levels in large samples of older adults over a 1-week time period. A total PASE score is calculated by multiplying the average number of hours per day spent in these 
activities and a PASE weight for that item and summing these products. Higher PASE scores indicate higher activity levels.

Functional status was assessed by the Functional Autonomy Measuring System (SMAF, Système de Mesure de l'Autonomie Fonctionnelle) (Desrosiers, et al., 1995; Hébert, et al., 1988), a 29-item rating scale to record functional disabilities and the available material and social resources that could compensate for the disabilities. It assesses present and actual performance-rather than potential—in activities of daily living (7 items), mobility (6 items), communication (3 items), mental function (5 items), and instrumental activities of daily living (8 items). For each item, disability is rated on a scale ranging from independent to dependent on assistance. Scores range from 0 to 87 , with higher scores indicating greater dependence.

Finally, stressful life events were measured through the question, "Have you recently suffered a stressful life event (e.g., personal illness / death of a loved one)?' in the Elderly Nutrition Screening tool (ENS $\left.{ }^{\odot}\right)$ (Payette, et al., 1999).

\subsubsection{Treatment of missing data}

We analyzed patterns of missing data for the independent variables there were potentially associated with the dependent variables (nutrient intake) and were used to describe the study groups at both time points (T.0 and T.1): stressful 
life event, cognitive status (Modified Mini Mental State examination [3MS]), functional status (SMAF), BMI, and physical activity (PASE). Overall, a total of 66 unique values $(2.1 \%)$ were missing, and 39 subjects $(12.3 \%)$ out of the 316 had at least one missing value for at least one of those variables. PASE at T.1 had the highest proportion of missing values (5.4\%), followed by BMI at T.1 (4.1\%), stressful life event at T.1 (2.8\%), 3MS scores at T.1 (1.9\%), PASE at T.0 and SMAF at T.1 (both with 1.6\%), stressful life event at T.0 (0.6\%) and, finally, SMAF and $3 \mathrm{MS}$ at T.0 (both with $0.3 \%$ ). Although these are fairly small proportions, one missing value would lead to the exclusion of the person, which would void the age-sex pairing of the groups, introduce bias, and decrease preciseness and power (Schafer \& Olsen, 1998). Therefore, to treat these missing values, we used the automatic multiple imputation method in SPSS (version 17.0, SPSS Inc., Chicago, IL): fully conditional specification method with 10 iterations and 5 imputations using linear regression. The use of multiple imputation was also judged adequate because preliminary sensitivity analysis, also available in the SPSS software, demonstrated that data were missing at random, an assumption necessary for the reliability of the procedure (Sterne, et al., 2009). 


\subsubsection{Statistical analysis}

Bivariate analyses. At recruitment, we used Fisher's exact test (categorical variables) and independent t-tests (continuous variables) to test for group differences in sex (men/women), marital status (married/other), smoker (yes/no), hypertension (yes/no), age (years), and formal schooling (years). Independent ttests were used to test for differences between groups at the same time point (e.g. depressed vs. non-depressed at T.0), and paired t-tests to test within groups at different time points (e.g. T.0 vs. T.1 among depressed group) on the following variables: cognitive function (scores in the 3MS), functional autonomy scores (SMAF), BMI, and physical activity scores (PASE). Continuous variables are presented as pooled means \pm standard deviation (SD), unless otherwise stated. We tested differences in the "stressful life event" variable (yes/no) using McNemar's chi-square test for proportions within each subject group (nonparametric test for repeated measures with continuity correction) and Fisher's exact test for proportions between groups.

Normality assumption. Before hypothesis testing, normality assumption was tested for all dependent variables using skewness, kurtosis, and visual analysis of histogram with normal curve. Vitamin $B_{6}, B_{12}$ and folate were not normally distributed. Natural logarithmic (Ln) transformations showed a more approximately 
normal distribution and were used in the final analyses. Covariates had an approximate normal distribution and no transformation was necessary.

Multivariate analyses. A $2 \times 2 \times 2$ (time $\times$ group $\times$ stress), full factorial, mixed model analysis of covariance (ANCOVA) was used for hypothesis testing through the General Linear Model (GLM) repeated measures function in SPSS statistical package for Windows (version 17.0, SPSS Inc., Chicago, IL). Percent change in PASE and in SMAF scores from T.0 to T.1 were calculated, as to take into account the magnitude of the change, and entered as covariates in the models. Separate models were run for each nutrient of interest. Because energy intake did not differ significantly in exploratory or final analyses either within or between groups, intakes of protein, fibre, and B vitamins were not energy adjusted. Group (non-depressed vs. depressed) and stressful life events at T.1 (no vs. yes) were entered as between-subject effects, and time (T.0 vs. T.1), as within-subject effect. Due to the choice of five imputations to treat missing data, GLM mixed models yield results for six models: original data + one for each imputation. Significance-level. Two-sided $p$-values less than 0.05 were considered as statistically significant. Pooled results from multiple imputations were the preferred choice for reporting. 


\subsection{Results}

\subsubsection{Subjects' characteristics}

Of the 158 depressed cases ( $61.4 \%$ women), $47.5 \%$ were detected at first year follow-up, $33.5 \%$, at the second year, and $19 \%$, at the third year (data not shown).

At the time of recruitment, depressed participants' mean age ( \pm SD) was 75 years $( \pm 4.2 \mathrm{y})$. Age, marital status, smoking status, hypertension, and years of formal schooling were identical between depressed and age-sex matched nondepressed participants (Table 10).

The proportion with stressful life events within each group did not differ over time (McNemar's $\chi^{2}=0.679, p=0.410$, not shown). Compared to their nondepressed counterparts, depressed elderly were, however, more likely to report a stressful life event both at the year prior ( $52.6 \%$ vs. $35.4 \%$, depressed vs. nondepressed, Table 11$)$ and at the year of diagnosis ( $56.9 \%$ vs. $39.6 \%$, depressed vs. non-depressed, Table 11). Groups were similar in regard to cognitive functioning, which decreased significantly in both groups from one year to the next (Table 11). Although dependence level (SMAF scores) increased over time within depressed and non-depressed seniors, cases had higher dependence levels when compared to the non-depressed group at each time point (Table 11). Participants with incident depression decreased their physical activity level from 
one year to the next and had lower scores compared to the non-depressed group in each time point (Table 11). Body mass index (BMI) did not differ between the two groups and in any time point (Table 11).

Table 12 shows the mean \pm SD (and quartiles) of nutrient intakes for depressed and non-depressed subjects at both time points.

\subsubsection{Mixed models analyses}

Table 13 details the significant results from the GLM mixed models and their estimated marginal means. Intakes of energy, fibre and protein did not change significantly over time in depressed seniors compared to their non-depressed counterparts (i.e. interaction terms time $\times$ group and timexgroup $\times$ stress had $p$ values $>0.05$ in all models—not shown in the table). There was a significant main effect of time on saturated fat intake (as percent of kcal) in the models with the original $(p=0.018)$ and the multiple imputed data ( $p$-values from 0.023 to 0.029$)$ (Table 13), meaning that both groups increased significantly their saturated fat intake over time.

In respect to micronutrients, the timexgroup interaction for $\mathrm{B}_{12}$ intakes was significant in all five models with imputed data $(\mathrm{N}=316$, $p$-value ranging from 0.033 to 0.035$)$, meaning that intakes of vitamin $B_{12}$ decreased more over time in 
depressed subjects than in non-depressed subjects (Table 13). Although modelling with the original data showed a non-significant timexgroup interaction (non-depressed $n=134$, depressed $n=142, p=0.053$ ), the direction of the effect was identical. The loss of subjects in the model with original data voided the paired design and may have introduced biased in the analyses.

Interestingly, a main effect of group (depressed vs. non-depressed) (Table 13) was observed for all three B-vitamins $(p<0.05)$. In other words, depressed participants had significantly lower intakes compared to non-depressed, independent of time point.

\subsection{Discussion}

In this case-control study nested within the NuAge cohort, communitydwelling seniors deemed depressed over follow-up did not change their intakes of macronutrients compared to their non-depressed, age-sex matched counterparts. Saturated fat showed a significant increase over time in both groups, and, hence, increase cannot be attributed to depression. Only vitamin $B_{12}$ was slightly affected by depression over the one-year period.

The lack of significant timexgroup interactions in this study for most studied nutrients suggests that depression does not strongly affect one-year nutrient 
intakes, demystifying the hypothesis of a reverse causality among older adults living in the community-at least in the short-term. Our conclusion seems to agree with that from longitudinal studies that either conducted some kind of sensitivity analysis (Akbaraly, et al., 2009; Chocano-Bedoya, et al., 2013; Rienks, et al., 2013; Sanchez-Villegas, Delgado-Rodriguez, et al., 2009) or argued a lack of reverse causality to be intrinsic to their design (Astorg, et al., 2008; Hodge, et al., 2013; Tolmunen, Hintikka, Ruusunen, et al., 2004). Kim at el. (2008) observed greater declines in $\mathrm{B}_{12}$ serum levels in Korean elderly deemed depressed at two years of follow-up, with which our findings corroborate. This decline in $\mathrm{B}_{12}$ could be a proxy for changes in other health or lifestyle factors such as physical activity or social engagement; however, physical activity was included in the models and social engagement, in preliminary work, and neither was related to depression. This vitamin is present in foods of animal origin (Institute of Medicine, 2006); items often consumed in social gatherings. It is puzzling, however, that protein intake did not differ between and within groups, so a decreased consumption of meat products does not necessarily explain the observed interaction. Declines in $\mathrm{B}_{12}$ intakes were rather small (from $2.0 \pm 4.7 \mathrm{mcg} /$ day at the year prior to $1.8 \pm 1.4$ $\mathrm{mcg} /$ day at the year of diagnosis) and, therefore, unlikely to put seniors at risk of deficiency. 
It is noteworthy that, although intakes of macronutrients did not differ between groups, B-vitamin intakes were lower at both time points among depressed subjects. This finding could indicate a low nutrient density diet among these seniors, but neither vitamin D nor calcium showed significant differences in bivariate analyses. Fruits, vegetables, and whole-grain products are good sources of B-vitamins (Institute of Medicine, 2006) and also the main sources of dietary fibre (Mozaffarian et al., 2003). Because fibre did not differ between and within groups over time, equivalent intakes of these food items can be expected in both groups, and, hence, does not adequately explain the differences in B vitamins. In a previous study, dietary patterns did not predict incidence of depression (Gougeon, et al., in press); however, $\mathrm{B}_{6}$ in women and $\mathrm{B}_{12}$ in men did predict depression (Gougeon, et al., 2014).

Assessment of inadequate intakes cannot be done because intakes did not account for within-person variability, so we cannot ascertain about the prevalence of inadequate intake, but, notably, participants may have had a good overall diet, regardless of depression when compared to recommendation levels. The Estimated Average Requirement (EAR) (Institute of Medicine, 2006) for the three vitamins can be found within the $25^{\text {th }}$ percentile of intake in both depressed and non-depressed groups for most nutrients. Groups' mean protein intake was above the EAR of $0.66 \mathrm{~g} / \mathrm{kg} /$ day for adults over $50 \mathrm{y}$ of age (Institute of Medicine, 2006) 
and within higher recommendations of $1.0-1.3 \mathrm{~g} / \mathrm{kg} /$ day deemed necessary to maintain nitrogen balance in the healthy elderly, according to other sources (Morais, Chevalier, \& Gougeon, 2006). Total dietary fibre was below the Adequate Intake of $14 \mathrm{~g} / 1000 \mathrm{kcal}$, but still greater than the average for the adult Canadian population (approximately $8 \mathrm{~g} / 1000 \mathrm{kcal}$ for men and $9 \mathrm{~g} / 1000 \mathrm{kcal}$ for women) (Langlois, Garriguet, \& Findlay, 2009).

Over the one-year period, these seniors had no significant changes in practically all studied nutrients in spite of adversities—depression or having had a stressful life event. We postulate that these community-dwelling seniors would have personality traits associated with better mental health, more precisely, "hardiness" or "resilience" (van Kessel, 2013). The concept of resilience in older people has been defined as the ability to bounce back and recover physical and psychological health in the face of adversity (van Kessel, 2013). This notion of resilience can be applied to the diet, in which people develop and use adaptive strategies to maintain an adequate diet despite facing dietary challenges (Vesnaver, Keller, Payette, \& Shatenstein, 2012). A qualitative study with selected NuAge participants deemed diet resilient revealed some of their strategies and motivations to keep eating healthily, which included prioritizing eating well and getting help when needed (Vesnaver, et al., 2012). Studies using a life course 
perspective approach to food choice suggest that dietary resilience can be reached through exposures to (or the lack of exposure to) a particular critical health threat or benefit over the life span (Devine, 2005). The dietary resilience theory is strengthened by another NuAge sub-study, in which dietary patterns were not positively associated with the residential food environment, as originally expected (Mercille et al., 2012), meaning that these older adults maintained their patterns of intake independently of their proximity to different types of food stores. It would be reasonable to expect that depressed subjects' intakes would be lower due to their decreased physical activity initially and over time, but this expectation did not hold true. The maintenance in intake is unlikely to be due to physiological compensation processes that occur among the young population with low intakes or weight loss, for example, not only because these processes are much weaker in older people (de Castro \& Stroebele, 2002), but also because weight changes were not observed. Therefore, both psychological and dietary resilience may walk along side each other in old age and may be major players in successful aging. Research points out to the critical role low levels of depression and high resilience have on successful aging as defined by seniors themselves, in spite of physical or health limitations (Jeste, et al., 2013). Although we can only propose a resilience theory to explain our findings, they support its potential existence and warrant its further investigation as a factor in healthy aging. 


\section{Final considerations}

Seniors' dietary intakes, very well measured through three non-consecutive $24 \mathrm{~h}$ recalls at each time point, and annual measures allowed for adequate investigation of the reverse causality hypothesis between depression and diet in the short term. The paired design added strength to the study, as other potential confounders (age and sex) were intrinsically controlled. Nonetheless, caution should be used when interpreting these findings. Though all the necessary steps were taken to meet required statistical assumptions, some variables showed very high variance, which can decrease statistical power. The multiple imputation method to treat missing data had the advantage to maintain the strength of a paired design, but also lead to multiple tests, which can increase type I error.

In addition to having an overall good health, living independently in the community, and almost all stating sufficient revenue for their needs, these seniors had only mild levels of depression, which may not have been enough to change dietary habits in any significant way. Changes in nutrient intakes will likely have a different magnitude in seniors with moderate/severe depressive symptoms or in hospital or long-term care settings, for example. Intakes were considered in the short-term (up to one year), so whether greater declines will be seen in the long 
term are still largely unknown. Other well-designed longitudinal studies with longer follow-up should overtly explore the reverse causality effect to shed further light on the nutrient intake of community-dwelling seniors with late onset depression.

\subsection{Acknowledgements and conflict of interest disclosure}

The authors wish to thank the men and women of the NuAge cohort for their generous participation in the study, and the study personnel for their highly professional and devoted work. The NuAge study was supported by the Canadian Institute of Health Research (ClHR), Grant No. MOP-62842, the Fonds de la Recherche en Santé du Québec (FRSQ), and the Québec Network for Research on Aging.

None of the authors have conflicts of interest to disclose.

An abstract on these findings was accepted to be presented at the $67^{\text {th }}$ Annual Scientific Meeting of the Gerontological Society of America, in Washington, DC, November 5-9, 2014, as part of the Symposium entitled, "Nutrition as a Determinant of Healthy Aging: New Results from the NuAge Study," chaired by Dr. Pierrette Gaudreau, under the title, "Diet and late-life depression: A reverse causality study in community-dwelling older adults. The NuAge Study." 


\subsection{References}

Refer to the dissertation's bibliography. 


\subsection{Tables}

Table 10: Participants' demographic characteristics at recruitment

\begin{tabular}{|c|c|c|c|}
\hline \multirow[b]{2}{*}{ Variableb } & \multicolumn{2}{|c|}{ Depression over 3 years of follow-upa } & \multirow[b]{2}{*}{$p^{c}$} \\
\hline & $\begin{array}{c}\text { No } \\
(n=158)\end{array}$ & $\begin{array}{c}\text { Yes } \\
(n=158)\end{array}$ & \\
\hline Female, n (\%) & \multicolumn{2}{|c|}{$97(61.4 \%)$} & - \\
\hline Married, n (\%) & $84(53.2 \%)$ & $87(55.1 \%)$ & 0.821 \\
\hline Smoker, n (\%) & $7(4.4 \%)$ & $12(7.6 \%)$ & 0.344 \\
\hline Hypertension, n (\%) & $75(47.8 \%)$ & $89(56.3 \%)$ & 0.143 \\
\hline Income satisfies needs, n (\%) & $977(94 \%)$ & $131(93.6 \%)$ & 0.472 \\
\hline Age (years) & $74.8 \pm 4.3$ & $75.1 \pm 4.0$ & 0.436 \\
\hline Formal schooling (years) & $11.9 \pm 4.4$ & $11.3 \pm 4.4$ & 0.176 \\
\hline \multicolumn{4}{|c|}{$\begin{array}{l}\text { a Depression detected on the basis of GDS scores } \geq 11 \text { and/or use of antidepressant medication } \\
\text { over three follow-up years. Depressed subjects were matched by sex and age group with } \\
\text { subjects deemed not depressed and whose dietary data were available for the same time points } \\
\text { as the depression cases. Continuous variables shown as mean } \pm \text { standard deviation. } \\
\text { b P-value for trend. Fisher's Exact Test for categorical variables. Independent t-tests for continuous } \\
\text { variables }(\alpha=0.05) \text {. }\end{array}$} \\
\hline
\end{tabular}


Table 11: Demographic characteristics of depressed and non-depressed subjects at the year prior (T.0) and at the year of detection (T.1)a

\begin{tabular}{|c|c|c|c|c|}
\hline \multirow[b]{2}{*}{ Variables $^{b}$} & \multicolumn{2}{|c|}{ Non-Depressed $(n=158)$} & \multicolumn{2}{|c|}{ Depressed $(n=158)$} \\
\hline & $\begin{array}{c}\text { Year prior } \\
(\mathrm{T} .0)\end{array}$ & $\begin{array}{l}\text { Matched } \\
\text { year of } \\
\text { diagnosis } \\
\text { (T.1) }\end{array}$ & $\begin{array}{c}\text { Year prior } \\
(\mathrm{T} .0)\end{array}$ & $\begin{array}{l}\text { Year of } \\
\text { diagnosis } \\
\text { (T.1) }\end{array}$ \\
\hline \multicolumn{5}{|l|}{ Stressful life event, $\mathrm{n}(\%)$} \\
\hline Original & $56(35.4 \%) \dagger \dagger$ & $61(39.6 \%) \dagger \dagger$ & 82 (52.6\%)†† & $87(56.9 \%) \dagger \dagger$ \\
\hline Pooled n & 56 & 62.2 & 83 & 89.2 \\
\hline Cognitive function scores & $93.6 \pm 5.3^{* *}$ & $92.5 \pm 6.5^{* *}$ & $93.2 \pm 5.4^{* *}$ & $92.0 \pm 6.5^{* *}$ \\
\hline $25^{\text {th }}$ percentile & 91.0 & 91.0 & 91.0 & 90.0 \\
\hline $50^{\text {th }}$ percentile & 95.0 & 94.0 & 94.0 & 93.0 \\
\hline $75^{\text {th }}$ percentile & 97.0 & 97.0 & 97.0 & 96.0 \\
\hline Functional autonomy & $4.4 \pm 4.0^{* *}+\dagger$ & $5.3 \pm 4.8^{* *}+\dagger$ & $6.1 \pm 4.1^{* *} \dagger \dagger$ & $8.3 \pm 5.1^{* *} \dagger \dagger$ \\
\hline $25^{\text {th }}$ percentile & 2.0 & 2.0 & 3.0 & 4.5 \\
\hline $50^{\text {th }}$ percentile & 3.5 & 4.0 & 5.0 & 7.5 \\
\hline $75^{\text {th }}$ percentile & 6.5 & 7.0 & 8.5 & 11.5 \\
\hline Body mass index $\left(\mathrm{kg} / \mathrm{m}^{2}\right)$ & $28.0 \pm 6.0$ & $27.8 \pm 4.2$ & $27.4 \pm 4.5$ & $27.4 \pm 4.7$ \\
\hline $25^{\text {th }}$ percentile & 25.0 & 25.1 & 24.4 & 24.5 \\
\hline $50^{\text {th }}$ percentile & 27.4 & 27.4 & 27.3 & 27.2 \\
\hline $75^{\text {th }}$ percentile & 30.5 & 30.0 & 30.0 & 30.0 \\
\hline Physical activity scores & $97 \pm 50 \dagger$ & $95 \pm 50 \dagger \dagger$ & $84 \pm 43^{* *} \dagger$ & $72 \pm 42^{* *} \dagger \dagger$ \\
\hline $25^{\text {th }}$ percentile & 65 & 57 & 51 & 42 \\
\hline $50^{\text {th }}$ percentile & 86 & 89 & 79 & 66 \\
\hline $75^{\text {th }}$ percentile & 122 & 126 & 110 & 93 \\
\hline \multicolumn{5}{|c|}{$\begin{array}{l}\text { a Depression was detected on the basis of GDS scores } \geq 11 \text { and/or use of antidepressant } \\
\text { medication over three years of follow-up. Depressed subjects were matched by sex and age } \\
\text { group with non-depressed subjects. NOTE: Means } \pm \text { standard deviation (SD) for scores are } \\
\text { pooled from five multiple imputations, and quartiles are from original data. }\end{array}$} \\
\hline \multicolumn{5}{|c|}{$\begin{array}{l}\text { b Stressful life events } \mathrm{n}(\%) \text { from original data. Cognitive function scores measured by the Modified } \\
\text { Mini-Mental State examination (range: } 0-100 \%) \text {; Functional autonomy measured by scores in the } \\
\text { Functional Autonomy Measuring System (range 0-87); Physical activity scores measured by the } \\
\text { Physical Activity Scores for the Elderly scale (range 0-793). }\end{array}$} \\
\hline \multicolumn{5}{|c|}{$\begin{array}{l}\text { LEGEND: Difference in within-group means (scores in T.0 vs. in T. } 1 \text { within each group) is } \\
\text { statistically significant with * } p \text {-value }<0.05 \text { and }{ }^{* *} p \text {-value }<0.01 \text { according to dependent t-tests for } \\
\text { continuous variables with five multiple imputations for missing data. Difference in between-group } \\
\text { means (non-depressed vs. depressed at a given time point) is statistically significant with } \dagger p \text { - } \\
\text { value }<0.05 \text {, and } \dagger \dagger p \text {-value }<0.01 \text {, according to independent t-tests for continuous variables and } \\
\text { Fisher's Exact test for categorical variables, with five multiple imputations for missing data. }\end{array}$} \\
\hline
\end{tabular}


Table 12: Dietary intakes of key nutrients for depressed and non-depressed subjects at the year prior (T.0) and at the year of detection (T.1 $)^{\mathrm{a}}$

\begin{tabular}{|c|c|c|c|c|}
\hline \multirow[b]{2}{*}{ Variables $^{b}$} & \multicolumn{2}{|c|}{ Non-Depressed $(n=158)$} & \multicolumn{2}{|c|}{ Depressed $(n=158)$} \\
\hline & $\begin{array}{c}\text { Year prior } \\
(\mathrm{T} .0)\end{array}$ & $\begin{array}{l}\text { Matched } \\
\text { year of } \\
\text { detection } \\
\text { (T.1) }\end{array}$ & $\begin{array}{c}\text { Year prior } \\
(\mathrm{T} .0)\end{array}$ & $\begin{array}{l}\text { Year of } \\
\text { detection } \\
\text { (T.1) }\end{array}$ \\
\hline Energy intake (kcal/day) & $1861 \pm 505$ & $1826 \pm 469$ & $1763 \pm 465$ & $1769 \pm 480$ \\
\hline $25^{\text {th }}$ percentile & 1555 & 1482 & 1457 & 1446 \\
\hline $50^{\text {th }}$ percentile & 1795 & 1822 & 1690 & 1724 \\
\hline $75^{\text {th }}$ percentile & 2144 & 2116 & 2030 & 2008 \\
\hline Protein intake (g/kg body weight) & $1.1 \pm 0.4$ & $1.0 \pm 0.3$ & $1.0 \pm 0.3$ & $1.0 \pm 0.3$ \\
\hline $25^{\text {th }}$ percentile & 0.8 & 0.8 & 0.8 & 0.8 \\
\hline $50^{\text {th }}$ percentile & 1.0 & 1.0 & 1.0 & 1.0 \\
\hline $75^{\text {th }}$ percentile & 1.2 & 1.2 & 1.2 & 1.2 \\
\hline Total dietary fat (\% of total energy) & $33.0 \pm 5.6$ & $34.0 \pm 5.6$ & $33.6 \pm 6.1$ & $34.2 \pm 5.7$ \\
\hline $25^{\text {th }}$ percentile & 29.8 & 16.1 & 30.7 & 30.7 \\
\hline $50^{\text {th }}$ percentile & 34.1 & 21.3 & 34.6 & 34.6 \\
\hline $75^{\text {th }}$ percentile & 37.7 & 27.8 & 37.8 & 37.9 \\
\hline $\begin{array}{l}\text { Total saturated fat ( } \% \text { of total } \\
\text { energy) }\end{array}$ & $11.1 \pm 2.6$ & $11.3 \pm 2.9$ & $11.1 \pm 2.9^{*}$ & $11.5 \pm 2.9^{*}$ \\
\hline $25^{\text {th }}$ percentile & 9.0 & 9.3 & 9.1 & 9.6 \\
\hline $50^{\text {th }}$ percentile & 10.9 & 11.3 & 10.7 & 11.1 \\
\hline $75^{\text {th }}$ percentile & 12.6 & 13.1 & 12.9 & 13.5 \\
\hline Total dietary fibre (g/1000 kcal) & $10.8 \pm 3.4$ & $11.0 \pm 3.2$ & $11.1 \pm 3.4$ & $11.6 \pm 4.2$ \\
\hline $25^{\text {th }}$ percentile & 8.0 & 8.8 & 8.3 & 8.8 \\
\hline $50^{\text {th }}$ percentile & 10.5 & 10.6 & 11.0 & 11.0 \\
\hline $75^{\text {th }}$ percentile & 12.8 & 12.7 & 13.0 & 13.6 \\
\hline Vitamin D (mcg/1000 kcal) & $2.8 \pm 2.1$ & $2.8 \pm 1.9$ & $2.8 \pm 1.9$ & $2.8 \pm 1.6$ \\
\hline $25^{\text {th }}$ percentile & 1.3 & 1.7 & 1.7 & 1.6 \\
\hline $50^{\text {th }}$ percentile & 2.4 & 2.4 & 2.6 & 2.5 \\
\hline $75^{\text {th }}$ percentile & 3.6 & 3.5 & 3.4 & 3.3 \\
\hline Vitamin $\mathrm{B}_{6}(\mathrm{mg} / 1000 \mathrm{kcal})$ & $1.7 \pm 3.8 \dagger \dagger$ & $1.6 \pm 2.2 † \dagger$ & $0.9 \pm 0.2 \dagger \dagger$ & $0.9 \pm 0.2 \dagger \dagger$ \\
\hline $25^{\text {th }}$ percentile & 0.8 & 0.9 & 0.8 & 0.8 \\
\hline $50^{\text {th }}$ percentile & 1.0 & 1.2 & 0.9 & 0.9 \\
\hline $75^{\text {th }}$ percentile & 1.5 & 1.7 & 1.0 & 1.0 \\
\hline Vitamin $\mathrm{B}_{12}(\mathrm{mcg} / 1000 \mathrm{kcal})$ & $6.0 \pm 43.5 \dagger \dagger$ & $9.1 \pm 40.7 \dagger \dagger$ & $2.0 \pm 4.7^{*} \dagger \dagger$ & $1.8 \pm 1.4^{*} \dagger \dagger$ \\
\hline $25^{\text {th }}$ percentile & 1.7 & 1.6 & 1.3 & 1.4 \\
\hline $50^{\text {th }}$ percentile & 2.6 & 8.6 & 1.9 & 1.8 \\
\hline $75^{\text {th }}$ percentile & 33 & 41.3 & 2.4 & 2.3 \\
\hline
\end{tabular}




\begin{tabular}{|c|c|c|c|c|}
\hline \multirow[b]{2}{*}{ Variables $^{b}$} & \multicolumn{2}{|c|}{ Non-Depressed $(n=158)$} & \multicolumn{2}{|c|}{ Depressed $(n=158)$} \\
\hline & $\begin{array}{c}\text { Year prior } \\
\text { (T.0) }\end{array}$ & $\begin{array}{l}\text { Matched } \\
\text { year of } \\
\text { detection } \\
\text { (T.1) }\end{array}$ & $\begin{array}{c}\text { Year prior } \\
(\mathrm{T} .0)\end{array}$ & $\begin{array}{c}\text { Year of } \\
\text { detection } \\
\text { (T.1) }\end{array}$ \\
\hline Folate (DFE mcg/1000 kcal) & $220 \pm 54 †$ & $218 \pm 51 \dagger$ & $212 \pm 55 \dagger$ & $208 \pm 54 \dagger$ \\
\hline $25^{\text {th }}$ percentile & 181 & 181 & 174 & 175 \\
\hline $50^{\text {th }}$ percentile & 215 & 211 & 209 & 198 \\
\hline $75^{\text {th }}$ percentile & 247 & 254 & 255 & 237 \\
\hline Calcium (mg/1000 kcal) & $433 \pm 149$ & $425 \pm 119$ & $420 \pm 133$ & $422 \pm 137$ \\
\hline $25^{\text {th }}$ percentile & 323 & 341 & 325 & 325 \\
\hline $50^{\text {th }}$ percentile & 401 & 418 & 404 & 409 \\
\hline 75 $5^{\text {th }}$ percentile & 516 & 480 & 491 & 496 \\
\hline
\end{tabular}

a Depression was detected on the basis of GDS scores $\geq 11$ and/or use of antidepressant medication over three years of follow-up. Depressed subjects were matched by sex and age group with subjects deemed not depressed and whose dietary data were available for the same time points as the depression cases. NOTE: Intakes are from food only and do not include supplements.

b First row of values are means \pm standard deviation from three non-consecutive 24-hour recalls, (for Vitamin $B_{12}$, the geometric mean is shown). Vitamins $B_{6}, B_{12}$, and folate were transformed to natural log for statistical testing.

LEGEND: Difference in within-group means (scores in T.0 vs. in T.1 within each group) is statistically significant with * $p$-value $<0.05$ and ${ }^{* *} p$-value $<0.01$ according to dependent t-tests. Difference in between-group means (non-depressed vs. depressed at a given time point) is statistically significant with $\dagger p$-value $<0.05$, and $\dagger \dagger p$-value $<0.001$, according to independent ttests. 
Table 13: Mixed-model variables for saturated fat and B-vitamins, with estimates \pm SEM and significance, in community dwelling older Canadiansa

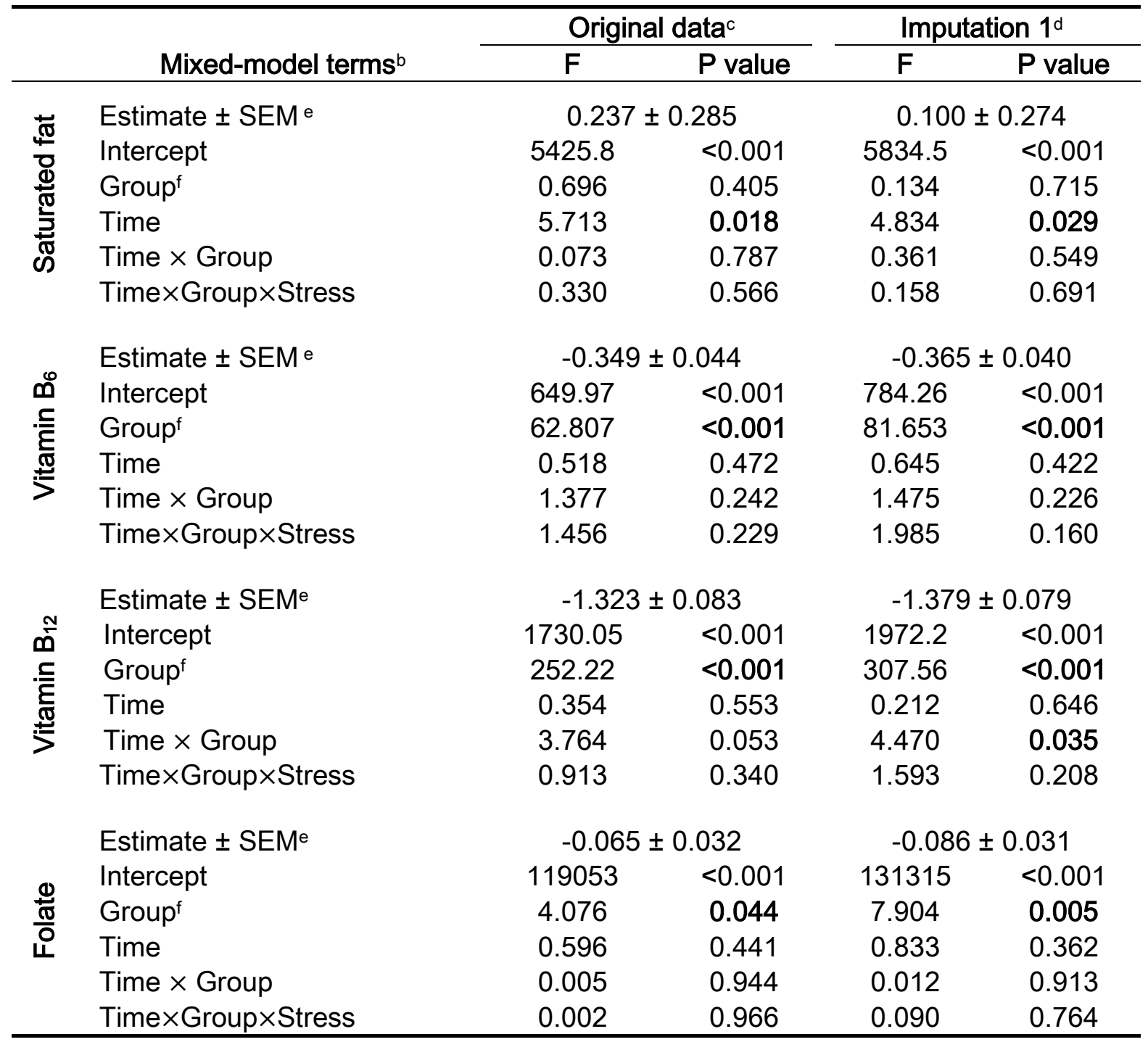

a For simplicity, data shown are restricted to nutrients with significant results from mixed model ANCOVA. Saturated fat measured as percent of total calories (kcal). Vitamins were transformed to natural $\log _{\text {of }} \mathrm{B}_{6}$ as $\mathrm{mg} /$ day; $\mathrm{B}_{12}$ as $\mathrm{mcg} /$ day, and folate as dietary folate equivalent $\mathrm{mcg} / \mathrm{day}$.

b $2 \times 2 \times 2$ (time $\times$ group $\times$ stress), full factorial, mixed model ANCOVA. Only relevant between- and within-factor terms for models using the original data and first set of imputed data are shown (the other four sets of imputed data had similar results and were excluded from the table for simplicity).

c, d Covariates appearing in the model are functional autonomy (\% change SMAF) and physical activity (\% change PASE) and are respectively evaluated at the following values: original data, 70.3814 and 7.5252; imputation 1, 73.0718 and 6.9502. Degrees of freedom of the error term ( $\left.\mathrm{df}_{\text {error }}\right)$ is 270 for original data and 310 for imputed data.

e Mean difference in the estimate between (Depressed - Non-depressed) \pm Standard error of the mean (SEM)

${ }^{\mathrm{f}}$ Group = depressed vs. non-depressed 


\section{CHAPTER 7. OVERALL SUMMARY AND CONCLUSIONS}

The elderly population is growing as the baby-boomer cohorts recently started passing the age of 65 . According to Statistics Canada, it is estimated that $5,379,600$ Canadians (15.3\% of the country's population) were $\geq 65$ years of age on July 1,2013 . In 1960 , the proportion of Canadians at this age was $7.6 \%$ (Statistics Canada, 2013a). With this graying of the population, impacts of eating behaviors are of great importance (Elsner, 2002). Diet is a modifiable factor recurrently associated with chronic disease risk and (un)healthy aging (Peel, McClure, \& Bartlett, 2005; Topp, Fahlman, \& Boardley, 2004), even among older Canadians (Ramage-Morin, Shields, \& Martel, 2010). Depression greatly affects seniors' health and quality of life, and, if its risks can be potentially modified through diet, research can shed light on this relationship to help create more effective preventive measures (Harbottle \& Schonfelder, 2008; Lopresti, et al., 2013).

Numerous population-based studies on diet and depression have a crosssectional design and cannot, therefore, adequately explain the direction and the magnitude of the relationship. This shortcoming is particularly true among older adults, about whom very little research has been conducted. In this work, we shed light on the direction of the diet-depression relationship by using different analytical strategies and different time points in a longitudinal setting. Among the 
healthy, older participants of the NuAge study, a sizable number became depressed over the 3 years of follow-up, which, according to our findings, was more likely due to their decreased overall energy and some B-vitamin intakes than to their specific patterns of eating. In fact, seniors with energy intakes higher than $2000 \mathrm{kcal}$ were, on average, $45 \%$ less likely to develop depression over the 3 follow-up years, independently of age, sex, and other important demographic, health, and social factors.

It could be argued that the strong protection from high energy intakes is possibly a reflection of better health or increased physical activity, which are linked with better food intakes (Donini, et al., 2003). However, we were able to control for these two factors. Residual confounding may have a role, but it appears that, whatever the reasons, maintaining elevated (which does not mean excessive) energy intake in old age is protective for affective health. Higher total energy intakes also mean better intakes of macro- and many micronutrients (Willett, Howe, \& Kushi, 1997). It is well known that decreased food and energy intake are a sign of declining health (Drewnowski \& Shultz, 2001) and can lead to decreased nutritional status, weight loss, and frailty in the long term, which, in turn, significantly increase both morbidity and mortality (Dey, Rothenberg, Sundh, Bosaeus, \& Steen, 2001; Donini, et al., 2003; Payette \& Shatenstein, 2005). Dietary advice to prevent depression in generally healthy seniors should 
emphasize adequate overall intake as opposed to small variations in quality. To illustrate, it may be more important to encourage older people to have a source of good protein, such as meat, in their diet instead of focusing on the differences between red and white meat. It is important to remember that certain chronic disease do bring certain dietary restrictions, which are not the focus of this dissertation. Future research on diet and affective health in older adults should pay close attention to energy intake, a good practice in any epidemiological study (Willett, et al., 1997).

Seniors with initially high $\mathrm{B}_{6}$ (women) and $\mathrm{B}_{12}$ (men) intakes from food, not from supplements, had decreased likelihood of becoming depressed over the next three years of follow-up. The protective effect of $B_{6}$ in women was dependent on total energy intake, which further validates the importance of energy in relation to depression incidence. It is possible that these vitamins are a proxy for associated lifestyle factors or other dietary behaviours that would more strongly affect depression risk. Measures of social engagement, for example, have been associated with lower incidence of depression and better dietary intake in a number of studies (de Castro \& Stroebele, 2002; Isaac, Stewart, Artero, Ancelin, \& Ritchie, 2009; Payette \& Shatenstein, 2005)—but not in ours. Moreover, it is possible that other unmeasured factors may independently 
influence both B-vitamin intakes and depression. These factors could contribute to the apparent B vitamin-depression relationship and yet not reflect a causal relationship between the two.

Evidence on the effect of folate on depression seems highly variable in the elderly. Countries with mandatory folic acid fortification tend to show less in the way of associations of B vitamins and depression, e.g. in the United States (Lindeman, et al., 2000; Skarupski, et al., 2010), compared to countries with voluntary or no fortification policies, e.g. Australia (before 2009) and most countries in Asia and Europe (e.g. Dimopoulos, et al., 2007; Kim, et al., 2008; Nanri et al., 2012; Ng, Feng, et al., 2009; Tolmunen, Hintikka, Ruusunen, et al., 2004). Because folic acid fortification effectively increases serum folate concentrations at the population level (Jacques, Selhub, Bostom, Wilson, \& Rosenberg, 1999; Lawrence, Petitti, Watkins, \& Umekubo, 1999), we agree with other researchers that have proposed the likelihood of a "threshold effect": no further benefits would be seen after a certain status or intake is reached in a given population (Astorg, et al., 2008; Lee, et al., 1998; Murakami, et al., 2008; Penninx, et al., 2000; Sanchez-Villegas, Doreste, et al., 2009; Tolmunen, Hintikka, Ruusunen, et al., 2004; Tolmunen, et al., 2003).

The protective effect observed for $\mathrm{B}_{6}$ and $\mathrm{B}_{12}$ intakes from food only, and not from food+supplement, is also noteworthy and might, once again, support the 
importance of energy intake, as well as the aforementioned "threshold hypothesis." Vitamin intake is directly and positively related to total energy intake (Willett, et al., 1997). Hence, high energy diets will usually be higher in their ability to meet protein and micronutrient requirement (Kant, 1996). Our findings suggest that seniors should have an adequate energy intake, to have better intakes of vitamins $B_{6}$ and $B_{12}$ as well, particularly among women. Furthermore, once intakes from food reach a certain threshold level, supplementation may not bring further benefits for affective health.

Food consumption and, consequently, nutrient intakes can be compromised due to the symptomatic nature of depression. Overall nutrient intakes did not show, however, important declines over the course of the year depression developed. In the NuAge cohort, seniors with probable depression had similar macronutrient intakes compared to non-depressed seniors. Even though intakes of B vitamins were lower among depressed individuals independent of time point-further supporting the findings of our second study—declines over time were not steeper among these depressed participants compared to their nondepressed counterparts. Vitamin $B_{12}$ intake decreased slightly more in depressed subjects over time, but unlikely enough to lead to a deficiency over that period. Once again, it could be suggested that this slight decline in $B_{12}$ intake is 
explained by other depression risk factors, such as social engagement.

Depression increases social isolation and decreases social mealtimes, possibly affecting the consumption of meat products, which are the main source of that nutrient. Unfortunately, we could not find any study on the effects of social mealtimes on vitamin $B_{12}$ intakes to support this theory. In our study, social activities were not found to be associated with changes in $B_{12}$ intake in the preliminary analyses, rendering it an unlikely explanatory variable.

The consistent intakes observed in seniors in this third study, in spite of depression or stressful life events, can be an indication of dietary resilience-at least in the very short-term. Considering that more than half of the participants were married both in the depressed and in the non-depressed group, we can suppose that having a partner may have contributed to the maintenance of dietary intakes. The partner's role in supporting food intake and disease adaptation has been demonstrated in community-living couples experiencing dementia (Atta-Konadu, Keller, \& Daly, 2011; L. Johansson, 2013) and could also be true in depression. Either with the partner's help or by themselves, these depressed seniors may have developed adaptive strategies to maintain an adequate diet despite facing challenges (Vesnaver, et al., 2012). This proposed dietary resilience does not mean, however, these seniors will maintain their resiliency in the long-term should they continue to be depressed; in other words, 
they may not be able to maintain diet quality over time-even though the process of dietary resilience may result in dietary resiliency (Vesnaver, et al., 2012). The dietary resilience hypothesis offers a logical explanation for our findings but cannot be confirmed through our material.

The lack of a significant effect of BMI on affective health is not surprising. Research shows that the traditional BMI classification is not a good predictor of health in the elderly (Heiat, Vaccarino, \& Krumholz, 2001; Janssen \& Mark, 2007). In regard to affective health, data from a national survey in the general US population indicated BMI to be the primary predictor of major depression in the past year (Carpenter, Hasin, Allison, \& Faith, 2000), but gerontological studies do not corroborate this observation. A group of Korean researchers studied depressive symptoms in elderly people with arthritis and noted that BMI was not significantly associated with the disease prevalence, while several other health and social factors were (An \& Tak, 2009). A group of American researchers investigated whether BMI would predict depressive symptoms in the three years of follow-up in a biracial sample of 2,406 community-dwelling older adults (Sachs-Ericsson et al., 2007). The association of a higher BMI with increased depressive symptoms had only a small effect size and seemed a more important 
predictor among African-Americans than white participants (Sachs-Ericsson, et al., 2007).

The median measured BMl of our sample was $27.4 \mathrm{~kg} / \mathrm{m}^{2}$ (mean at 27.8 $\mathrm{kg} / \mathrm{m}^{2}$ )—slightly lower than the average of $28.2 \mathrm{~kg} / \mathrm{m}^{2}$ for the general older Canadian population aged 60 to $79 y$, according to CHMS data (Statistics Canada, 2010). Based on the Health Canada's BMI classification (Health Canada, 2003), only 4 persons were underweight, the vast majority (72.6\%) was either normal weight $(26.0 \%)$ or overweight $(46.6 \%), 20.9 \%$ were obese class I (BMI 30.0 to $\left.34.9 \mathrm{~kg} / \mathrm{m}^{2}\right)$, and only $6.3 \%(\mathrm{n}=85)$, obese class $I I+\left(B M I \geq 35 \mathrm{~kg} / \mathrm{m}^{2}\right)$ at the study's baseline. In a literature review, Heiat et al. (2001) concluded that BMI in the range of 25 to $27 \mathrm{~kg} / \mathrm{m}^{2}$ was not a risk factor for all-cause and cardiovascular mortality in people aged 65 and older and suggested a U-shaped relationship between BMI and mortality, with a large flat bottom, and a right curve that becomes significantly elevated only around a BMI of $31-32 \mathrm{~kg} / \mathrm{m}^{2}$. The authors questioned the existing BMI guidelines for this age group, describing them as "overly restrictive" (Heiat, et al., 2001). Janssen and Mark (2007) corroborated these findings in another systematic review and meta-analysis of the evidence on the impact of an elevated BMI on mortality risk in men and women aged $\geq 65 \mathrm{y}$ and older. Seniors with $\mathrm{BMI}$ in the overweight range did not have increased risk for mortality, and those in the moderately obese range (30- 
$34.9 \mathrm{~kg} / \mathrm{m}^{2}$ ) had only modest increases when compared to the normal weight range (Janssen \& Mark, 2007). A Canadian study of 11,326 respondents aged $\geq 25$ y followed for 12 years in the 1994/1995 National Population Health Survey also found that underweight and obesity class II and III were significant risk factors for mortality, while overweight seemed protective and obesity class I was not associated with an increased risk of mortality, when compared to the normal weight BMI category (Orpana et al., 2010). The aforementioned proportions may be a reflection of the rather healthy NuAge participants, and, therefore, BMI not being significantly associated with depression incidence could be expected.

Another interesting observation is that a study in elderly Quebecers has observed a 12-month rate of incident depression of 3.4\% (Preville, et al., 2010), which would sum up to an approximate rate of $10.2 \%$ over three years-a rate that is close to what was observed in our study $(12.5 \%)$.

Health care providers, policy makers and community programs should not take these results to mean that there is no need to worry about depression in the elderly as not influencing dietary intake, as the follow-up for the study was short and important declines may take longer than a year to appear once depression develops. Moreover, this group of well elderly reported sufficient revenue for their 
needs in their majority, was willing to commit to being part of a cohort, and seemed to have some resilience to adversity. As discussed in the second and third studies, recommended dietary intakes were observed at the first tertiles or quartile of B-vitamin and protein intakes, rendering their diets likely adequate-a potential topic for future research.

The work for this dissertation does not come without limitations. Some are intrinsic to study design, such as the arbitrary aspects of dietary pattern creation or the attrition of depressed participants. As discussed in chapter 3, PCA involves some arbitrary decisions on the food category creation and on the number of principal components to retain. Nevertheless, nutrition research has been increasingly using this technique to derive eating patterns that are relevant to specific populations. Such studies provide both guidance in creating the food categories and a basis for cross-study comparisons. The decisions involving the retaining of components also follow common consensus among statisticians and researchers, much like the $95 \%$ confidence level in hypothesis testing, decreasing the subjectivity of the method.

Another intrinsic limitation pertains to the longitudinal study of depression: the potential loss of participants who may have become depressed at follow-up could introduce a selection bias (Farmer, 1994). Those who did not participate in 
the follow-up examination may differ unfavourably with respect to depressive status, overall health status, or health-related lifestyle and diet compared to those who did. This potential bias could not be fully examined in our work, as information related to non-returning participants in respect to depression was not available.

The cohort size was fixed, so statistical power issues can arise, particularly for nutrients with very high variance. Multiple imputation addressed the missing data in potential confounders and increased statistical power of the study of reverse causality, which presented with the smaller sample size. Overall, differences in energy intake of as low as $150 \mathrm{kcal}$ were detected, as well as small variations in some nutrients such as $0.40 \%$ energy from saturated fat. Certain nutrients were mathematically transformed to address the issue of high variance and non-normal distribution and used in the final analysis when results differ between the original and the transformed scale. As expected, extremely high variances were more commonly seen when supplement use was considered, in which case, the many data transformations did not help normalize the distribution. It is noteworthy that the use of supplements among seniors is controversial, as their use can indicate either better lifestyles and nutrient intakes or a strategy to compensate for the poor diet (Payette \& Shatenstein, 2005; 
Sebastian, et al., 2007). Furthermore, the statistical tests used for hypothesis testing are deemed robust against normality violations.

Strong and precise quantitative methods are needed to capture changes in dietary intake. To undertake the reverse causality study, we had six 24-h recalls on 158 people who became depressed and compared their intakes to controls'. Although the number was not large due to examining incident cases, no study of this phenomenon has been done to date, largely because such precise dietary data have not been collected longitudinally in the elderly.

In our studies, we chose not to control for certain medications that could impair vitamin absorption for a number of reasons. Examples include isoniazid (for tuberculosis) and L-DOPA (for Parkinson's disease) can inhibit the intestinal absorption of $B_{6}$, or very large therapeutic doses (e.g. 3,900 mg/day) of nonsteroidal anti-inflammatory drugs (e.g. aspirin, ibuprofen, and acetaminophen), anticonvulsant drugs, and methotrexate (for rheumatoid arthritis) can interfere the absorption of folate, or proton pump inhibitors or $\mathrm{H}_{2}$-receptor antagonists, of vitamin $B_{12}$ (Institute of Medicine, 2006; Wolters, Ströhle, \& Hahn, 2004). First, we were interested in intakes, not in the status or the bioavailability of these vitamins. Second, even though some of these medications can also affect intake due to other such side effects as anorexia or changes in taste, these side effects would be reflected in people's dietary intakes, if any were present. Third, the 
NuAge seniors are generally healthy and free of major diseases that would require treatment with such medications.

Finally, the results from these studies are not generalizable to all older Canadian adults because, as mentioned earlier, NuAge participants lived in the community, had generally very good health at recruitment (mobile and without cognitive impairment or certain illnesses), agreed to make an effort to come to the study center each year for follow-up or, if it was not possible after the first visit, to have a home visit. Seniors had to be able to communicate in either French or English, and, therefore, small ethnic groups, such as immigrants who moved to Canada late in life, might not have shown the requisite language skills to be enrolled or may have refused participation. Therefore, findings cannot be generalized to other groups of elderly, such as the minorities, frail elderly, residents of long-term care facilities, patients in acute care, or seniors with severe (co-)morbidities. Another aspect that limits generalization pertains to the type of depression and measurement tools, which were restricted to the scores in the GDS screening tool and antidepressant use. This restriction increased the chances of missing or misclassifying depression cases due to potential over- and under-prescription of antidepressant drugs (Freudenstein, Jagger, Arthur, \& Donner-Banzhoff, 2001). Atypical cases of depression that more commonly affect the elderly than the young could also have been missed—although these atypical 
cases are more prevalent among the oldest old and those who are institutionalized (Palsson \& Skoog, 1997).

Although this study was not able to resolve the issue of the uncertainty regarding the association between dietary intakes and depression risk in late life, we contributed to the scientific literature with new and unique longitudinal evidence, particularly in regards to the Canadian population. The longitudinal, population-based design of all three studies offers unparalleled and invaluable evidence on the relationship of diet and depression incidence-as opposed to prevalence (Murakami \& Sasaki, 2010; Vink, et al., 2008)—and on the direction and magnitude of the association. Several psychosocial variables were systematically collected annually for four years, providing singular insights into short-term and long-term relationships and aspects of healthy aging, as well as the ability to control for relevant confounders at different time points.

In conclusion, much of the nutrient-depression relationship is still to be explored. Nonetheless, we have demonstrated that energy intake plays a major role in decreasing the risks for depression in later in life, and energy likely mediates the protective effect of $\mathrm{B}_{6}$ intake in elderly women. Contrary to our expectations, those who became depressed did not change their intakes 
significantly in the short term. Together, these findings suggest that changes in dietary intakes precede depression in generally healthy older adults at a mean age of 75 years, not the opposite.

The role of B-vitamin intake in protection against depression is difficult to study as the relationship is possibly governed directly by these nutrients themselves, such as in the case of a deficient state, or indirectly by other social, psychological, and biological factors in the pathway of the relationship. Yet, we side with other studies showing a potential link between B vitamins and depression in late life. 


\section{BIBLIOGRAPHY}

Abou-Saleh, M. T., \& Coppen, A. (1986). The biology of folate in depression: implications for nutritional hypotheses of the psychoses. Journal of Psychiatric Research, 20(2), 91-101.

Aguilar-Navarro, S., \& Avila-Funes, J. A. (2007). Depression: Clinical features and consequences among the elderly. Gaceta Medica De Mexico, 143(2), 141-148.

Akbaraly, T. N., Brunner, E. J., Ferrie, J. E., Marmot, M. G., Kivimaki, M., \& Singh-Manoux, A. (2009). Dietary pattern and depressive symptoms in middle age. British Journal of Psychiatry, 195(5), 408-413.

Akhondzadeh, S., Gerbarg, P. L., \& Brown, R. P. (2013). Nutrients for prevention and treatment of mental health disorders. Psychiatric Clinics of North America, 36(1), 25-36. doi: 10.1016/j.psc.2012.12.003

Alexopoulos, G. S. (2005). Depression in the elderly. Lancet, 365(9475), 19611970. doi: 10.1016/S0140-6736(05)66665-2

Almeida, O. P., Marsh, K., Alfonso, H., Flicker, L., Davis, T. M. E., \& Hankey, G. J. (2010). B-vitamins reduce the long-term risk of depression after stroke: The VITATOPS-DEP trial. Annals of Neurology, 68(4), 503-510. doi: 10.1002/ana.22189

Alpert, J. E., Mischoulon, D., Nierenberg, A. A., \& Fava, M. (2000). Nutrition and depression: focus on folate. Nutrition, 16(7-8), 544-546. doi: Doi: 10.1016/s0899-9007(00)00327-0

American Psychiatric Association. (2000). Diagnostic and Statistical Manual of Mental Disorders DSM-IV-TR Fourth edition (Text revision) (4th ed.). Washington, DC: American Psychiatric Association.

American Psychiatric Association. (2010). Practice guideline for the treatment of patients with major depressive disorder (3 ed.). Arlington (VA): American Psychiatric Association (APA).

American Psychiatric Association. (2013). Highlights of changes from DSM-IVTR to DSM-5 Retrieved Jan 16, 2014, from 
http://www.dsm5.org/Documents/changes\%20from\%20dsm-ivtr\%20to\%20dsm-5.pdf

An, J.-Y., \& Tak, Y.-R. (2009). Depressive symptoms and related risk factors in old and oldest-old elderly people with arthritis. Journal of the Korean Academy of Nursing, 39(1), 72-83.

Anderson, A. L., Harris, T. B., Tylavsky, F. A., Perry, S. E., Houston, D. K., Hue, T. F., . . Sahyoun, N. R. (2011). Dietary patterns and survival of older adults. Journal of the American Dietetic Association, 111(1), 84-91. doi: 10.1016/j.jada.2010.10.012

Anderson, D. N. (2001). Treating depression in old age: the reasons to be positive. Age and Ageing, 30(1), 13-17.

Anderson, J. J., Suchindran, C. M., Kritchevsky, S. B., \& Barrett-Connor, E. (2004). Macronutrient intakes of elderly in the Lipid Research Clinics Program Prevalence Study. Journal of Nutrition, Health and Aging, 8(5), 395-399.

Areán, P. A., \& Reynolds III, C. F. (2005). The impact of psychosocial factors on late-life depression. Biological Psychiatry, 58(4), 277-282. doi: DOI: 10.1016/j.biopsych.2005.03.037

Astorg, P., Couthouis, A., de Courcy, G. P., Bertrais, S., Arnault, N., Meneton, P., ... Hercberg, S. (2008). Association of folate intake with the occurrence of depressive episodes in middle-aged French men and women. British Journal of Nutrition, 100(1), 183-187.

Atta-Konadu, E., Keller, H. H., \& Daly, K. (2011). The food-related role shift experiences of spousal male care partners and their wives with dementia. Journal of Aging Studies, 25(3), 305-315.

Avila-Funes, J. A., Melano-Carranza, E., Payette, H., \& Amieva, H. (2007). [Depressive symptoms as a risk factor for dependence in elderly people]. Salud Pública de México, 49(5), 367-375.

Bailey, R. L., Gutschall, M. D., Mitchell, D. C., Miller, C. K., Lawrence, F. R., \& Smiciklas-Wright, H. (2006). Comparative strategies for using cluster 
analysis to assess dietary patterns. Journal of the American Dietetic Association, 106(8), 1194-1200. doi: 10.1016/j.jada.2006.05.012

Bamia, C., Orfanos, P., Ferrari, P., Overvad, K., Hundborg, H. H., Tjønneland, A., ... Trichopoulou, A. (2005). Dietary patterns among older Europeans: the EPIC-Elderly study. [10.1079/BJN20051456]. British Journal of Nutrition, 94(01), 100-113.

Bartali, B., Frongillo, E. A., Bandinelli, S., Lauretani, F., Semba, R. D., Fried, L. P., \& Ferrucci, L. (2006). Low nutrient intake is an essential component of frailty in older persons. The Journals of Gerontology Series A: Biological Sciences and Medical Sciences, 61(6), 589-593.

Basiotis, P. P., Welsh, S. O., Cronin, F. J., Kelsay, J. L., \& Mertz, W. (1987). Number of days of food intake records required to estimate individual and group nutrient intakes with defined confidence. The Journal of Nutrition, 117(9), 1638-1641.

Baune, B. T., Smith, E., Reppermund, S., Air, T., Samaras, K., Lux, O., . . . Trollor, J. N. (2012). Inflammatory biomarkers predict depressive, but not anxiety symptoms during aging: the prospective Sydney Memory and Aging Study. Psychoneuroendocrinology, 37(9), 1521-1530. doi: 10.1016/j.psyneuen.2012.02.006

Beaudry, M., Galibois, I., \& Chaumette, P. (1998). Dietary patterns of adults in Quebec and their nutritional adequacy. Canadian Journal of Public Health, 89(5), 347-351.

Beydoun, M. A., Shroff, M. R., Beydoun, H. A., \& Zonderman, A. B. (2010). Serum folate, vitamin B-12, and homocysteine and their association with depressive symptoms among U.S. adults. Psychosomatic Medicine, 72(9), 862-873.

Bhat, R. S. (2009). You are what you eat: of fish, fat and folate in late-life psychiatric disorders. Current Opinion in Psychiatry, 22(6), 541-545.

Bjelland, I., Tell, G. S., Vollset, S. E., Refsum, H., \& Ueland, P. M. (2003). Folate, vitamin B12, homocysteine, and the MTHFR $677 \mathrm{C}->$ T polymorphism in 
anxiety and depression: the Hordaland Homocysteine Study. Archives of General Psychiatry, 60(6), 618-626.

Blake, H., Mo, P., Malik, S., \& Thomas, S. (2009). How effective are physical activity interventions for alleviating depressive symptoms in older people? A systematic review. Clinical Rehabilitation, 23(10), 873-887. doi: $10.1177 / 0269215509337449$

Blazer, D. G. (2003). Depression in late life: Review and commentary. Journals of Gerontology Series a-Biological Sciences and Medical Sciences, 58(3), 249-265.

Blazer, D. G., \& Hybels, C. F. (2005). Origins of depression in later life. Psychological Medicine, 35(9), 1241-1252. doi:

$10.1017 / \mathrm{s} 0033291705004411$

Blazer, D. G., Hybels, C. F., \& Pieper, C. F. (2001). The association of depression and mortality in elderly persons: A case for multiple, independent pathways. The Journals of Gerontology Series A: Biological Sciences and Medical Sciences, 56(8), M505-M509. doi: 10.1093/gerona/56.8.M505

Bodnar, L. M., \& Wisner, K. L. (2005). Nutrition and depression: Implications for improving mental health among childbearing-aged women. Biological Psychiatry, 58(9), 679-685.

Bots, S., Tijhuis, M., Giampaoli, S., Kromhout, D., \& Nissinen, A. (2008). Lifestyle- and diet-related factors in late-life depression--a 5-year follow-up of elderly European men: the FINE study. International Journal of Geriatric Psychiatry, 23(5), 478-484.

Bottiglieri, T. (2013). Folate, vitamin B12, and S-adenosylmethionine. Psychiatric Clinics of North America, 36(1), 1-13. doi: 10.1016/j.psc.2012.12.001

Bridle, C., Spanjers, K., Patel, S., Atherton, N. M., \& Lamb, S. E. (2012). Effect of exercise on depression severity in older people: systematic review and meta-analysis of randomised controlled trials. British Journal of Psychiatry, 201, 180-185. doi: 10.1192/bjp.bp.111.095174 
Brink, T. L., Yesavage, J. A., Lum, O., Heersema, P. H., Adey, M., \& Rose, T. L. (1982). Screening Tests for Geriatric Depression. Clinical Gerontologist, 1(1), 37 - 43.

Brown, P. J., \& Roose, S. P. (2011). Age and anxiety and depressive symptoms: the effect on domains of quality of life. International Journal of Geriatric Psychiatry, n/a-n/a. doi: 10.1002/gps.2675

Brownie, S. (2006). Why are elderly individuals at risk of nutritional deficiency? International Journal of Nursing Practice, 12(2), 110-118. doi: 10.1111/j.1440-172X.2006.00557.x

Bruce, M. L. (2002). Psychosocial risk factors for depressive disorders in late life. Biological Psychiatry, 52(3), 175-184. doi: Doi: 10.1016/s00063223(02)01410-5

Bryan, J., Calvaresi, E., \& Hughes, D. (2002). Short-term folate, vitamin B-12 or vitamin B-6 supplementation slightly affects memory performance but not mood in women of various ages. Journal of Nutrition, 132(6), 1345-1356.

Carpenter, K. M., Hasin, D. S., Allison, D. B., \& Faith, M. S. (2000). Relationships between obesity and DSM-IV major depressive disorder, suicide ideation, and suicide attempts: results from a general population study. American Journal of Public Health, 90(2), 251-257.

Cassidy, K., Kotynia-English, R., Acres, J., Flicker, L., Lautenschlager, N. T., \& Almeida, O. P. (2004). Association between lifestyle factors and mental health measures among community-dwelling older women. Australian \& New Zealand Journal of Psychiatry, 38(11-12), 940-947.

Chocano-Bedoya, P. O., O'Reilly, E. J., Lucas, M., Mirzaei, F., Okereke, O. I., Fung, T. T., . . Ascherio, A. (2013). Prospective study on long-term dietary patterns and incident depression in middle-aged and older women. American Journal of Clinical Nutrition, 98(3), 813-820. doi: 10.3945/ajcn.112.052761

Christensen, H., Aiken, A., Batterham, P. J., Walker, J., Mackinnon, A. J., Fenech, M., \& Hickie, I. B. (2011). No clear potentiation of antidepressant 
medication effects by folic acid+vitamin $\mathrm{B}(12)$ in a large community sample. Journal of Affective Disorders, 130(1-2), 37-45. doi: 10.1016/j.jad.2010.07.029

Christensen, L. (2001). The effect of food intake on mood. Clinical Nutrition, 20(Supplement 1), 161-166. doi: 10.1054/clnu.2001.0420

Colapinto, C. K., O'Connor, D. L., \& Tremblay, M. S. (2011). Folate status of the population in the Canadian Health Measures Survey. Canadian Medical Association Journal, 183(2), E100-E106. doi: 10.1503/cmaj.100568

Cole, M. G., \& Dendukuri, N. (2003). Risk factors for depression among elderly community subjects: A systematic review and meta-analysis. American Journal of Psychiatry, 160(6), 1147-1156.

Coppen, A., \& Bolander-Gouaille, C. (2005). Treatment of depression: time to consider folic acid and vitamin B12. Journal of Psychopharmacology, 19(1), 59-65. doi: 10.1177/0269881105048899

Cronin-Stubbs, D., de Leon, C. F., Beckett, L. A., Field, T. S., Glynn, R. J., \& Evans, D. A. (2000). Six-year effect of depressive symptoms on the course of physical disability in community-living older adults. Archives of Internal Medicine, 160(20), 3074-3080. doi: ioi90891 [pii]

Davison, K. M., Ng, E., Chandrasekera, U., Seely, C., Cairns, J., Mailhot-Hall, L., . . Grant-Moore, J. (2012). The role of nutrition in mental health promotion and prevention (1). Toronto: Dietitians of Canada.

de Castro, J. M., \& Stroebele, N. (2002). Food intake in the real world: implications for nutrition and aging. Clinics in Geriatric Medicine, 18(4), 685-697. doi: 10.1016/s0749-0690(02)00056-3

Desrosiers, J., Bravo, G., Hébert, R., \& Dubuc, N. (1995). Reliability of the Revised Functional Autonomy Measurement System (SMAF) for Epidemiological Research. Age and Ageing, 24(5), 402-406. doi: 10.1093/ageing/24.5.402 
Devine, C. M. (2005). A life course perspective: Understanding food choices in time, social location, and history. Journal of Nutrition Education and Behavior, 37(3), 121-128. doi: 10.1016/S1499-4046(06)60266-2

Dey, D. K., Rothenberg, E., Sundh, V., Bosaeus, I., \& Steen, B. (2001). Body mass index, weight change and mortality in the elderly. A $15 \mathrm{y}$ longitudinal population study of $70 \mathrm{y}$ olds. European Journal of Clinical Nutrition, 55(6), 482-492. doi: 10.1038/sj.ejcn.1601208

Dimopoulos, N., Piperi, C., Salonicioti, A., Psarra, V., Gazi, F., Papadimitriou, A., ... Kalofoutis, A. (2007). Correlation of folate, vitamin B12 and homocysteine plasma levels with depression in an elderly Greek population. Clinical Biochemistry, 40(9-10), 604-608.

Djernes, J. K. (2006). Prevalence and predictors of depression in populations of elderly: a review. Acta Psychiatrica Scandinavica, 113(5), 372-387. doi: 10.1111/j.1600-0447.2006.00770.x

Donini, L. M., Savina, C., \& Cannella, C. (2003). Eating habits and appetite control in the elderly: the anorexia of aging. International Psychogeriatrics, 15(1), 73-87.

Drayer, R. A., Mulsant, B. H., Lenze, E. J., Rollman, B. L., Dew, M. A., Kelleher, K., . . Reynolds, C. F., 3rd. (2005). Somatic symptoms of depression in elderly patients with medical comorbidities. International Journal of Geriatric Psychiatry, 20(10), 973-982. doi: 10.1002/gps.1389

Drewnowski, A., \& Shultz, J. M. (2001). Impact of aging on eating behaviors, food choices, nutrition, and health status. Journal of Nutrition, Health and Aging, 5(2), 75-79.

Dupont, W. D., \& Plummer, W. D., Jr. (1990). Power and sample size calculations. A review and computer program. Control Clinical Trials, 11(2), 116-128.

Ellis, G. K., Robinson, J. A., \& Crawford, G. B. (2006). When symptoms of disease overlap with symptoms of depression. Australian Family Physician, 35(8), 647-649. 
Ellison, J. M., Kyomen, H. H., \& Verma, S. K. (2008). Mood disorders in later life (2nd ed.). New York, NY: Informa Healthcare USA, Inc.

Elsner, R. J. F. (2002). Changes in eating behavior during the aging process. Eating Behaviors, 3(1), 15-43. doi: 10.1016/s1471-0153(01)00041-1

Farmer, M. E. (1994). Depressive symptoms and attrition: The NHANES I Epidemiologic Follow-Up Study. International Journal of Methods in Psychiatric Research, 4(1), 19-27.

Fava, M., \& Mischoulon, D. (2009). Folate in depression: efficacy, safety, differences in formulations, and clinical issues. Journal of Clinical Psychiatry, 70 Supp/ 5, 12-17. doi: 10.4088/JCP.8157su1c.03 [doi]

Fillenbaum, G. G. (1988). Multidimensional functional assessment of older adults: The Duke Older Americans Resources and Services procedures: Hillsdale, NJ, England: Lawrence Erlbaum Associates, Inc.

Fillenbaum, G. G., \& Smyer, M. A. (1981). The Development, Validity, and Reliability of the Oars Multidimensional Functional Assessment Questionnaire. Journal of Gerontology, 36(4), 428-434. doi: 10.1093/geronj/36.4.428

Flaskerud, J. H., \& Winslow, B. J. (1998). Conceptualizing Vulnerable Populations Health-Related Research. Nursing Research, 47(2), 69-78.

Folstein, M., Liu, T., Peter, I., Buell, J., Arsenault, L., Scott, T., \& Qiu, W. W. (2007). The homocysteine hypothesis of depression. American Journal of Psychiatry, 164(6), 861-867. doi: 10.1176/appi.ajp.164.6.861

Ford, A. H., Flicker, L., Thomas, J., Norman, P., Jamrozik, K., \& Almeida, O. P. (2008). Vitamins B12, B6, and folic acid for onset of depressive symptoms in older men: results from a 2-year placebo-controlled randomized trial. Journal of Clinical Psychiatry, 69(8), 1203-1209.

Forti, P., Rietti, E., Pisacane, N., Olivelli, V., Dalmonte, E., Mecocci, P., \& Ravaglia, G. (2010). Blood homocysteine and risk of depression in the elderly. Archives of Gerontology \& Geriatrics, 51(1), 21-25. 
Fox, K. R. (1999). The influence of physical activity on mental well-being. Public Health Nutrition, 2(3A), 411-418.

Frederick, J. T., Steinman, L. E., Prohaska, T., Satariano, W. A., Bruce, M., Bryant, L., . . Late Life Depression Special Interest Group Project Panelists (2007). Community-based treatment of late life depression - An expert panel-informed literature review. American Journal of Preventive Medicine, 33, 222-249. doi: 10.1016/j.amerpe.2007.04.035

Freeman, M. P. (2010). Nutrition and psychiatry. American Journal of Psychiatry, 167(3), 244-247. doi: 10.1176/appi.ajp.2009.09121746

Freudenstein, U., Jagger, C., Arthur, A., \& Donner-Banzhoff, N. (2001).

Treatments for late life depression in primary care-a systematic review. Family Practice, 18(3), 321-327.

Galimanis, A., Mono, M. L., Arnold, M., Nedeltchev, K., \& Mattle, H. P. (2009). Lifestyle and stroke risk: a review. Current Opinion in Neurology, 22(1), 60-68. doi: 10.1097/WCO.0b013e32831fda0e

Gallagher, D., Mhaolain, A. N., Greene, E., Walsh, C., Denihan, A., Bruce, I., . . . Lawlor, B. A. (2010). Late life depression: a comparison of risk factors and symptoms according to age of onset in community dwelling older adults. International Journal of Geriatric Psychiatry, 25(10), 981-987. doi: 10.1002/gps.2438

Gallegos-Carrillo, K., García-Peña, C., Mudgal, J., Romero, X., Durán-Arenas, L., \& Salmerón, J. (2009). Role of depressive symptoms and comorbid chronic disease on health-related quality of life among community-dwelling older adults. Journal of Psychosomatic Research, 66(2), 127-135. doi: 10.1016/j.jpsychores.2008.07.007

Gallo, J. J., \& Rabins, P. V. (1999). Depression without sadness: alternative presentations of depression in late life. American Family Physician, 60(3), 820-826.

Garcia, A. A., Day, A. G., Zanibbi, K., \& Zunzunegui, M. V. (2008). Long-term effects of folic acid fortification and B-vitamin supplementation on total 
folate, homocysteine, methylmalonic scid and cobalamin in older adults. Canadian Journal of Public Health, 99(5), 428-433.

Gaudreau, P., Morais, J. A., Shatenstein, B., Gray-Donald, K., Khalil, A., Dionne, I., . . Payette, H. (2007). Nutrition as a determinant of successful aging: description of the Quebec longitudinal study Nuage and results from cross-sectional pilot studies. Rejuvenation Research, 10(3), 377-386. doi: 10.1089/rej.2007.0596

Gibson, R. S. (2005a). Measuring food consumption of individuals. In R. S. Gibson (Ed.), Principals of nutritional assessment (2 ed.). New York (NY): Oxford University Press.

Gibson, R. S. (2005b). Principles of nutritional assessment (2nd ed.). New York, NY: Oxford University Press, Inc.

Gilbody, S., Lightfoot, T., \& Sheldon, T. (2007). Is low folate a risk factor for depression? A meta-analysis and exploration of heterogeneity. Journal of Epidemiology \& Community Health, 61(7), 631-637. doi:

10.1136/jech.2006.050385

Gottfries, C. G. (2001). Late life depression. European Archives of Psychiatry \& Clinical Neuroscience, 251 Suppl 2, II57-61.

Gougeon, L., Payette, H., Morais, J. A., Gaudreau, P., Shatenstein, B., \& GrayDonald, K. (in press). Dietary patterns and incidence of depression in a cohort of community-dwelling older Canadians. Journal of Nutrition, Health and Aging.

Gougeon, L., Payette, H., Morais, J. A., \& Gray-Donald, K. (2014). Vitamin B6 and B12 from food, but not folate, are protective for depression in a cohort of healthy community-dwelling older Canadians. in preparation.

Guralnik, J. M., \& Kritchevsky, S. B. (2010). Translating research to promote healthy aging: The complementary role of longitudinal studies and clinical trials. Journal of the American Geriatrics Society, 58, S337-S342. doi: 10.1111/j.1532-5415.2010.02938.x 
Hamer, M., Bates, C. J., \& Mishra, G. D. (2011). Depression, Physical Function, and Risk of Mortality: National Diet and Nutrition Survey in Adults Older Than 65 Years. American Journal of Geriatric Psychiatry, 19(1), 72-78 10.1097/JGP.1090b1013e3181df1465e.

Harbottle, L., \& Schonfelder, N. (2008). Nutrition and depression: a review of the evidence. Journal of Mental Health, 17(6), 576-587.

Health Canada. (2003). Canadian guidelines for body weight classification in adults: Quick reference tool for professionals. Retrieved Jul 7, 2014, from http://www.hc-sc.gc.ca/fn-an/alt_formats/hpfbdgpsa/pdf/nutrition/cg_quick_ref-Idc_rapide_ref-eng.pdf

Health Canada. (2007). Canadian nutrient file. Version 2007b. Retrieved Feb 18, 2008, from http://www.hc-sc.gc.ca/fn-an/nutrition/fiche-nutridata/index_e.html

Hearty, Á. P., \& Gibney, M. J. (2009). Comparison of cluster and principal component analysis techniques to derive dietary patterns in Irish adults. British Journal of Nutrition, 101(04), 598-608. doi: doi:10.1017/S0007114508014128

Hébert, R., Carrier, R., \& Bilodeau, A. (1988). The Functional Autonomy Measurement System (SMAF): Description and validation of an instrument for the measurement of handicaps. Age and Ageing, 17(5), 293-302. doi: 10.1093/ageing/17.5.293

Heiat, A., Vaccarino, V., \& Krumholz, H. M. (2001). An evidence-based assessment of federal guidelines for overweight and obesity as they apply to elderly persons. Archives of Internal Medicine, 161(9), 1194-1203.

Hickson, M. (2006). Malnutrition and ageing. Postgraduate Medical Journal, 82(963), 2-8.

Hodge, A., Almeida, O. P., English, D. R., Giles, G. G., \& Flicker, L. (2013). Patterns of dietary intake and psychological distress in older Australians: benefits not just from a Mediterranean diet. International Psychogeriatrics, 25(03), 456-466. 
Hu, F. B. (2002). Dietary pattern analysis: a new direction in nutritional epidemiology. Current Opinion in Lipidology, 13(1), 3-9.

Huang, C. Q., Dong, B. R., Lu, Z. C., Yue, J. R., \& Liu, Q. X. (2010). Chronic diseases and risk for depression in old age: A meta-analysis of published literature. Ageing Research Reviews, 9(2), 131-141. doi:

10.1016/j.arr.2009.05.005

Huang, C. Q., Zhang, X. M., Dong, B. R., Lu, Z. C., Yue, J. R., \& Liu, Q. X. (2010). Health status and risk for depression among the elderly: a metaanalysis of published literature. Age and Ageing, 39(1), 23-30. doi: 10.1093/ageing/afp187

Hussin, N. M., Shahar, S., Teng, N. I., Ngah, W. Z., \& Das, S. K. (2013). Efficacy of fasting and calorie restriction (FCR) on mood and depression among ageing men. Journal of Nutrition, Health and Aging, 17(8), 674-680. doi: 10.1007/s12603-013-0344-9

Hvas, A. M., Juul, S., Lauritzen, L., Nexo, E., \& Ellegaard, J. (2004). No effect of vitamin B-12 treatment on cognitive function and depression: a randomized placebo controlled study. Journal of Affective Disorders, 81(3), 269-273. doi: 10.1016/s0165-0327(03)00169-1

Illner, A.-k., Nöthlings, U., Wagner, K., Ward, H., \& Boeing, H. (2010). The assessment of individual usual food intake in large-scale prospective studies. Annals of Nutrition \& Metabolism, 56(2), 99-105. doi: 10.1159/000277667

Institute of Medicine. (2006). Dietary reference intakes: The essential guide to nutrient requirements. Washington, DC: The National Academies Press.

Isaac, V., Stewart, R., Artero, S., Ancelin, M. L., \& Ritchie, K. (2009). Social activity and improvement in depressive symptoms in older people: a prospective community cohort study. American Journal of Geriatric Psychiatry, 17(8), 688-696. doi: 10.1097/JGP.0b013e3181a88441 Iwasa, H., Yoshida, Y., Kumagai, S., Ihara, K., Yoshida, H., \& Suzuki, T. (2009). Depression status as a reliable predictor of functional decline among 
Japanese community-dwelling older adults: a 12-year population-based prospective cohort study. International Journal of Geriatric Psychiatry, 24(11), 1192-1200.

Jacka, F. N., Mykletun, A., Berk, M., Bjelland, I., \& Tell, G. S. (2011). The association between habitual diet quality and the common mental disorders in community-dwelling adults: The Hordaland Health Study. Psychosomatic Medicine, 73(6), 483-490. doi:

10.1097/PSY.0b013e318222831a

Jacques, P. F., Selhub, J., Bostom, A. G., Wilson, P. W., \& Rosenberg, I. H. (1999). The effect of folic acid fortification on plasma folate and total homocysteine concentrations. New England Journal of Medicine, 340(19), 1449-1454. doi: 10.1056/nejm199905133401901

Janssen, I., \& Mark, A. E. (2007). Elevated body mass index and mortality risk in the elderly. Obesity Reviews, 8(1), 41-59. doi: 10.1111/j.1467789X.2006.00248.x

Jensen, G. L., Friedmann, J. M., Coleman, C. D., \& Smiciklas-Wright, H. (2001). Screening for hospitalization and nutritional risks among communitydwelling older persons. The American Journal of Clinical Nutrition, 74(2), 201-205.

Jeste, D. V., Savla, G. N., Thompson, W. K., Vahia, I. V., Glorioso, D. K., Martin, A. S., . . Depp, C. A. (2013). Association between older age and more successful aging: Critical role of resilience and depression. American Journal of Psychiatry, 170(2), 188-196.

Johansson, L. (2013). Foodwork and meals in everyday life among persons with dementia and their partners. Doctorate, Jönköping University, Jönköping. Retrieved Apr 13, 2014, from http://www.divaportal.org/smash/record.jsf?pid=diva2:621673

Johansson, M., Van Guelpen, B., Vollset, S. E., Hultdin, J., Bergh, A., Key, T., . . . Stattin, P. (2009). One-carbon metabolism and prostate cancer risk:

Prospective investigation of seven birculating $B$ vitamins and metabolites. 
Cancer Epidemiology Biomarkers \& Prevention, 18(5), 1538-1543. doi: 10.1158/1055-9965.epi-08-1193

Johnson-Down, L., Ritter, H., Starkey, L. J., \& Gray-Donald, K. (2006). Primary food sources of nutrients in the diet of Canadian adults. Canadian Journal of Dietetic Practice and Research, 67(1), 7-13.

Johnson, C. S. (2002). Nutritional considerations for bereavement and coping with grief. Journal of Nutrition, Health and Aging, 6(3), 171-176.

Jorm, A. F. (2000). Does old age reduce the risk of anxiety and depression? A review of epidemiological studies across the adult life span. Psychological Medicine, 30(1), 11-22.

Kant, A. K. (1996). Indexes of overall diet quality: A review. Journal of the American Dietetic Association, 96(8), 785-791. doi: 10.1016/S00028223(96)00217-9

Kant, A. K. (2004). Dietary patterns and health outcomes. Journal of the American Dietetic Association, 104(4), 615-635. doi: 10.1016/j.jada.2004.01.010

Kaplan, B. J., Crawford, S. G., Field, C. J., \& Simpson, J. S. (2007). Vitamins, minerals, and mood. Psychological Bulletin, 133(5), 747-760. doi: 10.1037/0033-2909.133.5.747 [doi]

Keller, H. H., Østbye, T., \& Goy, R. (2004). Nutritional risk predicts quality of life in elderly community-living Canadians. The Journals of Gerontology Series A: Biological Sciences and Medical Sciences, 59(1), M68-M74. doi: 10.1093/gerona/59.1.M68

Kendrick, T., Dunn, N., Robinson, S., Oestmann, A., Godfrey, K., Cooper, C., . . . Southampton Women's Survey Study, G. (2008). A longitudinal study of blood folate levels and depressive symptoms among young women in the Southampton Women's Survey. Journal of Epidemiology \& Community Health, 62(11), 966-972. 
Kim, J.-M., Stewart, R., Kim, S.-W., Yang, S.-J., Shin, I.-S., \& Yoon, J.-S. (2008). Predictive value of folate, vitamin B12 and homocysteine levels in late-life depression. British Journal of Psychiatry, 192(4), 268-274.

Kohatsu, W. (2005). Nutrition and depression. Explore (NY), 1(6), 474-476. doi: 10.1016/j.explore.2005.08.017 [doi]

Kohn, R., Gum, A. M., \& King-Kallimanis, B. (2008). The epidemiology of major depression in geriatric populations. In J. M. Ellison, H. H. Kyomen \& S. K. Verma (Eds.), Mood disorders in later life (2nd ed., pp. 392). New York, NY: Informa Healthcare USA, Inc.

Krishnan, K. R. R. (2002). Biological risk factors in late life depression. Biological Psychiatry, 52(3), 185-192. doi: Doi: 10.1016/s0006-3223(02)01349-5

Kuczmarski, M. F., Cremer Sees, A., Hotchkiss, L., Cotugna, N., Evans, M. K., \& Zonderman, A. B. (2010). Higher Healthy Eating Index-2005 scores associated with reduced symptoms of depression in an urban population: findings from the Healthy Aging in Neighborhoods of Diversity Across the Life Span (HANDLS) study. Journal of the American Dietetic Association, 110(3), 383-389.

Lamprecht, S. A., \& Lipkin, M. (2003). Chemoprevention of colon cancer by calcium, vitamin D and folate: molecular mechanisms. Nature Reviews Cancer, 3(8), 601-614.

Langa, K. M., Valenstein, M. A., Fendrick, A. M., Kabeto, M. U., \& Vijan, S. (2004). Extent and cost of informal caregiving for older Americans with symptoms of depression. American Journal of Psychiatry, 161(5), 857863.

Langlois, K., Garriguet, D., \& Findlay, L. (2009). Diet composition and obesity among Canadian adults. Health Report, 20(4), 11-20.

Lawrence, J. M., Petitti, D. B., Watkins, M., \& Umekubo, M. A. (1999). Trends in serum folate after food fortification. Lancet, 354(9182), 915-916.

Le Port, A., Gueguen, A., Kesse-Guyot, E., Melchior, M., Lemogne, C., Nabi, H., .. . Czernichow, S. (2012). Association between dietary patterns and 
depressive symptoms over time: A 10-year follow-up study of the GAZEL cohort. PLoS One, 7(12), e51593. doi: 10.1371/journal.pone.0051593

Lee, S., Wing, Y. K., \& Fong, S. (1998). A controlled study of folate levels in Chinese inpatients with major depression in Hong Kong. Journal of Affective Disorders, 49(1), 73-77.

Lefrançois, R., Leclerc, G., Dubé, M., Hamel, S., \& Gaulin, P. (2001). Valued Activities of Everyday Life Among the Very Old -- A One-Year Trend. Activities, Adaptation \& Aging, 25(3), 19 - 34.

Lindeman, R. D., Romero, L. J., Koehler, K. M., Liang, H. C., LaRue, A., Baumgartner, R. N., \& Garry, P. J. (2000). Serum vitamin B12, C and folate concentrations in the New Mexico elder health survey: correlations with cognitive and affective functions. Journal of the American College of Nutrition, 19(1), 68-76.

Lopresti, A. L., Hood, S. D., \& Drummond, P. D. (2013). A review of lifestyle factors that contribute to important pathways associated with major depression: Diet, sleep and exercise. Journal of Affective Disorders, 148(1), 12-27. doi: 10.1016/j.jad.2013.01.014

Lucas, M., Chocano-Bedoya, P., Shulze, M. B., Mirzaei, F., O’Reilly, É. J., Okereke, O. I., ... Ascherio, A. (2014). Inflammatory dietary pattern and risk of depression among women. Brain, Behavior, and Immunity, 36, 4653. doi: 10.1016/j.bbi.2013.09.014

MacFarlane, A. J., Greene-Finestone, L. S., \& Shi, Y. (2011). Vitamin B-12 and homocysteine status in a folate-replete population: results from the Canadian Health Measures Survey. The American Journal of Clinical Nutrition. doi: 10.3945/ajcn.111.020230

Mamplekou, E., Bountziouka, V., Psaltopoulou, T., Zeimbekis, A., Tsakoundakis, N., Papaerakleous, N., . . Panagiotakos, D. (2010). Urban environment, physical inactivity and unhealthy dietary habits correlate to depression among elderly living in eastern Mediterranean islands: the MEDIS 
(MEDiterranean ISlands Elderly) study. Journal of Nutrition, Health and Aging, 14(6), 449-455.

Marian, M., \& Sacks, G. (2009). Micronutrients and older adults. Nutrition in Clinical Practice, 24(2), 179-195. doi: 10.1177/0884533609332177

Mathers, C. D., \& Loncar, D. (2006). Projections of global mortality and burden of disease from 2002 to 2030. PLoS Medicine, 3(11), 2011-2030. doi: 10.1371/journal.pmed.0030442

McCormack, P. (1997). Undernutrition in the elderly population living at home in the community: a review of the literature. Journal of Advanced Nursing, 26(5), 856-863.

McDowell, I. (2006). Measuring health: A guide to rating scales and questionnaires (3 ed.). New York: Oxford University Press.

McMartin, S. E., Jacka, F. N., \& Colman, I. (2013). The association between fruit and vegetable consumption and mental health disorders: evidence from five waves of a national survey of Canadians. Preventive Medicine, 56(34), 225-230. doi: 10.1016/j.ypmed.2012.12.016

Mercille, G., Richard, L., Gauvin, L., Kestens, Y., Shatenstein, B., Daniel, M., \& Payette, H. (2012). Associations between residential food environment and dietary patterns in urban-dwelling older adults: results from the VoisiNuAge study. Public Health Nutrition, 15(11), 2026-2039. doi: doi:10.1017/S136898001200273X

Merete, C., Falcon, L. M., \& Tucker, K. L. (2008). Vitamin B6 is associated with depressive symptomatology in Massachusetts elders. Journal of the American College of Nutrition, 27(3), 421-427.

Mezuk, B., Eaton, W. W., \& Golden, S. H. (2008). Depression and osteoporosis: epidemiology and potential mediating pathways. Osteoporosis International, 19(1), 1-12.

Mezzich, J. E. (2002). International surveys on the use of ICD-10 and related diagnostic systems. Psychopathology, 35(2/3), 72-75. 
Morais, J. A., Chevalier, S., \& Gougeon, R. (2006). Protein turnover and requirements in the healthy and frail elderly. Journal of Nutrition, Health and Aging, 10(4), 272-283.

Mozaffarian, D., Kumanyika, S. K., Lemaitre, R. N., Olson, J. L., Burke, G. L., \& Siscovick, D. S. (2003). Cereal, fruit, and vegetable fiber intake and the risk of cardiovascular disease in elderly individuals. JAMA, 289(13), 16591666. doi: 10.1001/jama.289.13.1659

Munro, B. H. (2005). Statistical methods for health care research (5 ed.). Philadelphia, PA: Lippincott Williams \& Wilkins.

Murakami, K., Mizoue, T., Sasaki, S., Ohta, M., Sato, M., Matsushita, Y., \& Mishima, N. (2008). Dietary intake of folate, other B vitamins, and omega3 polyunsaturated fatty acids in relation to depressive symptoms in Japanese adults. Nutrition, 24(2), 140-147. doi: 10.1016/j.nut.2007.10.013 [doi]

Murakami, K., \& Sasaki, S. (2010). Dietary intake and depressive symptoms: A systematic review of observational studies. Molecular Nutrition \& Food Research, 54(4), 471-488. doi: 10.1002/mnfr.200900157

Murray, C. J., \& Lopez, A. D. (1996). Evidence-based health policy--lessons from the Global Burden of Disease Study. Science, 274(5288), 740-743.

Murray, C. J., Vos, T., Lozano, R., Naghavi, M., Flaxman, A. D., Michaud, C., . . . Lopez, A. D. (2013). Disability-adjusted life years (DALYs) for 291 diseases and injuries in 21 regions, 1990-2010: a systematic analysis for the Global Burden of Disease Study 2010. Lancet, 380(9859), 2197-2223. doi: 10.1016/S0140-6736(12)61689-4

Nanri, A., Hayabuchi, H., Ohta, M., Sato, M., Mishima, N., \& Mizoue, T. (2012). Serum folate and depressive symptoms among Japanese men and women: a cross-sectional and prospective study. Psychiatry Research, 200(2-3), 349-353. doi: 10.1016/j.psychres.2012.04.040

Nanri, A., Kimura, Y., Matsushita, Y., Ohta, M., Sato, M., Mishima, N., . . . Mizoue, T. (2010). Dietary patterns and depressive symptoms among 
Japanese men and women. European Journal of Clinical Nutrition, 64(8), 832-839.

Nanri, A., Mizoue, T., Matsushita, Y., Sasaki, S., Ohta, M., Sato, M., \& Mishima, N. (2010). Serum folate and homocysteine and depressive symptoms among Japanese men and women. European Journal of Clinical Nutrition, 64(3), 289-296.

Nelson, M., Black, A. E., Morris, J. A., \& Cole, T. J. (1989). Between- and withinsubject variation in nutrient intake from infancy to old age: estimating the number of days required to rank dietary intakes with desired precision. American Journal of Clinical Nutrition, 50(1), 155-167.

Newman, A. B. (2010). An overview of the design, implementation, and analyses of longitudinal studies on aging. Journal of the American Geriatrics Society, 58, S287-S291. doi: 10.1111/j.1532-5415.2010.02916.x

Ng, T. P., Feng, L., Niti, M., Kua, E. H., \& Yap, K. B. (2009). Folate, vitamin B12, homocysteine, and depressive symptoms in a population sample of older Chinese adults. Journal of the American Geriatrics Society, 57(5), 871876.

Ng, T. P., Niti, M., Zaw, M. H., \& Kua, E. H. (2009). Depressive symptoms and incident cognitive impairment in cognitively well-functioning older men and women. Journal of the American Geriatrics Society, 57(6), 1058-1063. doi: 10.1111/j.1532-5415.2009.02262.x

Nilsson, K., Gustafson, L., \& Hultberg, B. (2006). Plasma homocysteine, cobalamin/folate status, and vascular disease in a large population of psychogeriatric patients. Dementia \& Geriatric Cognitive Disorders, 22(4), 358-366.

Ortega, R. M., Manas, L. R., Andres, P., Gaspar, M. J., Agudo, F. R., Jimenez, A., \& Pascual, T. (1996). Functional and psychic deterioration in elderly people may be aggravated by folate deficiency. Journal of Nutrition, 126(8), 1992-1999. 
Ostbye, T., Kristjansson, B., Hill, G., Newman, S. C., Brouwer, R. N., \& McDowell, I. (2005). Prevalence and predictors of depression in elderly Canadians: The Canadian Study of Health and Aging. Chronic Diseases in Canada, 26(4), 93-99.

Palaniappan, U., Cue, R. I., Payette, H., \& Gray-Donald, K. (2003). Implications of day-to-day variability on measurements of usual food and nutrient intakes. Journal of Nutrition, 133(1), 232-235.

Palsson, S., \& Skoog, I. (1997). The epidemiology of affective disorders in the elderly: a review. International Clinical Psychopharmacology, 12(Suppl 7), S3-13.

Parnetti, L., Bottiglieri, T., \& Lowenthal, D. (1997). Role of homocysteine in agerelated vascular and non-vascular diseases. Aging-Clinical \& Experimental Research, 9(4), 241-257.

Patten, S. B., Wang, J. L., Beck, C. A., \& Maxwell, C. J. (2005). Measurement issues related to the evaluation and monitoring of major depression prevalence in Canada. Chronic Diseases in Canada, 26(4), 100-106.

Payette, H., Guigoz, Y., \& Vellas, B. J. (1999). Study design for nutritional assessments in the elderly. In B. P. Yu (Ed.), Methods in Aging Research (pp. 301-320). Boca Raton: CRC Press LLC.

Payette, H., \& Shatenstein, B. (2005). Determinants of healthy eating in community-dwelling elderly people. Canadian Journal of Public Health, 96 Supp/ 3, S27-31, S30-25.

Payne, M. E., Haines, P. S., Chambless, L. E., Anderson, J. J. B., \& Steffens, D. C. (2007). Food group intake and brain lesions in late-life vascular depression. International Psychogeriatrics, 19(2), 295-305.

Payne, M. E., Hybels, C. F., Bales, C. W., \& Steffens, D. C. (2006). Vascular nutritional correlates of late-life depression. American Journal of Geriatric Psychiatry, 14(9), 787-795.

Pearson, C., Ali, J., \& Janz, T. (2013). Mental and substance use disorders in Canada. (Catalogue no.82-624-X). Ottawa (ON): Health at a Glance. 
Peel, N. M., McClure, R. J., \& Bartlett, H. P. (2005). Behavioral determinants of healthy aging. American Journal of Preventive Medicine, 28(3), 298-304. doi: 10.1016/j.amepre.2004.12.002

Penninx, B. W., Guralnik, J. M., Ferrucci, L., Fried, L. P., Allen, R. H., \& Stabler, S. P. (2000). Vitamin B12 deficiency and depression in physically disabled older women: epidemiologic evidence from the Women's Health and Aging Study. American Journal of Psychiatry, 157(5), 715-721.

Penninx, B. W., Leveille, S. G., Ferrucci, L., van Eijk, J. T., \& Guralnik, J. M. (1999). Exploring the effect of depression on physical disability: longitudinal evidence from the established populations for epidemiologic studies of the elderly. American Journal of Public Health, 89(9), 13461352. doi: $10.2105 / a j p h .89 .9 .1346$

Preville, M., Boyer, R., Vasiliadis, H. M., Grenier, S., Voyer, P., Hudon, C., . . . Brassard, J. (2010). One-year incidence of psychiatric disorders in Quebec's older adult population. Canadian Journal of Psychiatry, 55(7), 449-457.

Public Health Agency of Canada. (2011). Diabetes in Canada: Facts and figures from a public health perspective, Chapter 1 - The burden of diabetes in Canada. Retrieved Jul 22, 2014, from http://www.phac-aspc.gc.ca/cdmc/publications/diabetes-diabete/facts-figures-faits-chiffres-2011/chap1eng.php

Radloff, L. S. (1977). The CES-D scale: A self-report depression scale for research in the general population. Applied Psychological Measurement, 1(3), 385-401. doi: 10.1177/014662167700100306

Ramage-Morin, P., \& Garriguet, D. (2013). Nutritional risk among older

Canadians. Health Reports, 24(3), 3-13.

Ramage-Morin, P., Shields, M., \& Martel, L. (2010). Health-promoting factors and good health among Canadians in mid- to late-life. (Catalogue no. 82-003XPE). Ottawa, ON: Retrieved Mar 17, 2014, from http://www.statcan.gc.ca/pub/82-003-x/2010003/article/11289-eng.htm. 
Ramos, M. I., Allen, L. H., Haan, M. N., Green, R., \& Miller, J. W. (2004). Plasma folate concentrations are associated with depressive symptoms in elderly Latina women despite folic acid fortification. American Journal of Clinical Nutrition, 80(4), 1024-1028.

Ray, J. G., Cole, D. E. C., \& Boss, S. C. (2000). An Ontario-wide study of vitamin B12, serum folate, and red cell folate levels in relation to plasma homocysteine: is a preventable public health issue on the rise? Clinical Biochemistry, 33(5), 337-343.

Ray, J. G., Vermeulen, M. J., Langman, L. J., Boss, S. C., \& Cole, D. E. C. (2003). Persistence of vitamin B12 insufficiency among elderly women after folic acid food fortification. Clinical Biochemistry, 36(5), 387-391.

Reif, A., Schneider, M. F., Kamolz, S., \& Pfuhlmann, B. (2003). Homocysteinemia in psychiatric disorders: association with dementia and depression, but not schizophrenia in female patients. Journal of Neural Transmission, 110(12), 1401-1411.

Reynolds, E. H. (2002). Folic acid, ageing, depression, and dementia. British Medical Journal, 324(7352), 1512.

Reynolds, E. H. (2006). Vitamin B12, folic acid, and the nervous system. Lancet Neurology, 5(11), 949-960.

Rienks, J., Dobson, A. J., \& Mishra, G. D. (2013). Mediterranean dietary pattern and prevalence and incidence of depressive symptoms in mid-aged women: results from a large community-based prospective study. European Journal of Clinical Nutrition, 67(1), 75-82. doi: 10.1038/ejcn.2012.193

Robinson, D. J., O'Luanaigh, C., Tehee, E., O'Connell, H., Hamilton, F., Chin, A. V., . . Lawlor, B. A. (2011). Associations between holotranscobalamin, vitamin B12, homocysteine and depressive symptoms in communitydwelling elders. International Journal of Geriatric Psychiatry, 26(3), 307313. doi: $10.1002 / g p s .2530$ 
Roman, B., Carta, L., Martinez-Gonzalez, M. A., \& Serra-Majem, L. (2008). Effectiveness of the Mediterranean diet in the elderly. Clinical Interventions in Aging, 3(1), 97-109.

Royall, D. R., Palmer, R., Chiodo, L. K., \& Polk, M. J. (2011). Depressive symptoms predict longitudinal change in executive control but not memory. International Journal of Geriatric Psychiatry, 27(1), 89-96. doi: $10.1002 / g p s .2697$

Royston, P. (2004). Multiple imputation of missing values. Stata Journal, 4, 227241.

Russell, R. M. (2000). The aging process as a modifier of metabolism. American Journal of Clinical Nutrition, 72(2 Suppl), 529S-532S.

Sachdev, P. S., Parslow, R. A., Lux, O., Salonikas, C., Wen, W., Naidoo, D., . . . Jorm, A. F. (2005). Relationship of homocysteine, folic acid and vitamin B12 with depression in a middle-aged community sample. Psychological Medicine, 35(4), 529-538.

Sachs-Ericsson, N., Burns, A. B., Gordon, K. H., Eckel, L. A., Wonderlich, S. A., Crosby, R. D., \& Blazer, D. G. (2007). Body mass index and depressive symptoms in older adults: the moderating roles of race, sex, and socioeconomic status. American Journal of Geriatric Psychiatry, 15(9), 815-825.

Samieri, C., Jutand, M.-A., Feart, C., Capuron, L., Letenneur, L., \& BarbergerGateau, P. (2008). Dietary patterns derived by hybrid clustering method in older people: association with cognition, mood, and self-rated health. Journal of the American Dietetic Association, 108(9), 1461-1471.

Sanchez-Villegas, A., Delgado-Rodriguez, M., Alonso, A., Schlatter, J., Lahortiga, F., Majem, L. S., \& Martinez-Gonzalez, M. A. (2009). Association of the Mediterranean dietary pattern with the incidence of depression: The Seguimiento Universidad de Navarra/University of Navarra Follow-up (SUN) cohort. Archives of General Psychiatry, 66(10), 1090-1098. doi: 10.1001/archgenpsychiatry.2009.129 
Sanchez-Villegas, A., Doreste, J., Schlatter, J., Pla, J., Bes-Rastrollo, M., \& Martinez-Gonzalez, M. A. (2009). Association between folate, vitamin B(6) and vitamin $B(12)$ intake and depression in the SUN cohort study. Journal of Human Nutrition and Dietetics, 22(2), 122-133. doi: 10.1111/j.1365277X.2008.00931.x

Sanchez-Villegas, A., Henriquez, P., Bes-Rastrollo, M., \& Doreste, J. (2006). Mediterranean diet and depression. Public Health Nutrition, 9(8A), 11041109. doi: $10.1017 / S 1368980007668578$

Sapolsky, R. M. (2004). Social status and health in humans and other animals. Annual Review of Anthropology, 33(1), 393-418. doi: doi:10.1146/annurev.anthro.33.070203.144000

Schafer, J. L. (1999). Multiple imputation: a primer. Statistical Methods in Medical Research, 8(1), 3-15. doi: 10.1177/096228029900800102

Schafer, J. L., \& Olsen, M. K. (1998). Multiple imputation for multivariate missingdata problems: A data analyst's perspective. Multivariate Behavioral Research, 33(4), 545-571. doi: 10.1207/s15327906mbr3304_5

Schoevers, R. A., Smit, F., Deeg, D. J. H., Cuijpers, P., Dekker, J. M., van Tilburg, W., \& Beekman, A. T. F. (2006). Prevention of late-life depression in primary care: Do we know where to begin? American Journal of Psychiatry, 163(9), 1611-1621. doi: 10.1176/appi.ajp.163.9.1611

Schuit, A. J. (2006). Physical activity, body composition and healthy ageing. Science \& Sports, 21(4), 209-213. doi: 10.1016/j.scispo.2006.06.004

Sebastian, R. S., Cleveland, L. E., Goldman, J. D., \& Moshfegh, A. J. (2007). Older adults who use vitamin/mineral supplements differ from nonusers in nutrient intake adequacy and dietary attitudes. Journal of the American Dietetic Association, 107(8), 1322-1332. doi: 10.1016/j.jada.2007.05.010

Selhub, J. (2002). Folate, vitamin B12 and vitamin B6 and one carbon metabolism. Journal of Nutrition, Health and Aging, 6(1), 39-42.

Shakur, Y. A., Tarasuk, V., Corey, P., \& O'Connor, D. L. (2012). A comparison of micronutrient inadequacy and risk of high micronutrient intakes among 
vitamin and mineral supplement users and nonusers in Canada. The Journal of Nutrition, 142(3), 534-540. doi: 10.3945/jn.111.149450

Sheehan, B., \& Banerjee, S. (1999). Review: Somatization in the elderly. International Journal of Geriatric Psychiatry, 14(12), 1044-1049.

Simpson, K. R., Meadows, G. N., Frances, A. J., \& Patten, S. B. (2012). Is mental health in the Canadian population changing over time? Canadian Journal of Psychiatry, 57(5), 324-331.

Skarupski, K. A., Tangney, C., Li, H., Ouyang, B., Evans, D. A., \& Morris, M. C. (2010). Longitudinal association of vitamin B-6, folate, and vitamin B-12 with depressive symptoms among older adults over time. American Journal of Clinical Nutrition, 92(2), 330-335.

Skarupski, K. A., Tangney, C. C., Li, H., Evans, D. A., \& Morris, M. C. (2013). Mediterranean diet and depressive symptoms among older adults over time. Journal of Nutrition, Health, and Aging, 17(5), 441-445. doi: 10.1007/s12603-012-0437-x

Smith, A. D. (2008). The worldwide challenge of the dementias: a role for $B$ vitamins and homocysteine? Food and Nutrition Bulletin, 29(2 Suppl), S143-172.

Smith, A. D., Emmett, P. M., Newby, P. K., \& Northstone, K. (2013). Dietary patterns obtained through principal components analysis: the effect of input variable quantification. British Journal of Nutrition, 109(10), 18811891. doi: $10.1017 / \mathrm{s} 0007114512003868$

Spitzer, R. L., Endicott, J., \& Robins, E. (1978). Research diagnostic criteria: rationale and reliability. Archives of General Psychiatry, 35(6), 773-782.

Stanner, S., Thompson, R., Buttriss, J., \& British Nutrition Foundation (Eds.). (2009). Healthy ageing: The role of nutrition and lifestyle. The report of a British Nutrition Foundation task force. London: Wiley-Blackwell.

Statistics Canada. (2010). Body composition of Canadian adults 2007 to 2009. Health Fact Sheets. Retrieved Jul 7, 2014, from http://www.statcan.gc.ca/pub/82-625-x/2010001/article/11091-eng.htm 
Statistics Canada. (2013a). Canada's population estimates: Age and sex, 2013. The Daily. Retrieved Jul 22, 2014, from Statistics Canada website: http://www.statcan.gc.ca/daily-quotidien/131125/dq131125a-eng.pdf

Statistics Canada. (2013b, September 18, 2013). Canadian Community Health Survey: Mental Health, 2012, The Daily. Retrieved Jul 22, 2014, from Statistics Canada website http://www.statcan.gc.ca/dailyquotidien/130918/dq130918a-eng.htm

Sterne, J. A., White, I. R., Carlin, J. B., Spratt, M., Royston, P., Kenward, M. G., . . Carpenter, J. R. (2009). Multiple imputation for missing data in epidemiological and clinical research: potential and pitfalls. British Medical Journal, 338, b2393.

Stewart, J. C., Rand, K. L., Muldoon, M. F., \& Kamarck, T. W. (2009). A prospective evaluation of the directionality of the depression-inflammation relationship. Brain, Behavior, and Immunity, 23(7), 936-944. doi: 10.1016/j.bbi.2009.04.011

Straand, J., \& Rokstad, K. (1997). General practitioners' prescribing patterns of benzodiazepine hypnotics: Are elderly patients at particular risk for overprescribing? Scandinavian Journal of Primary Health Care, 15(1), 1621. doi: doi:10.3109/02813439709043423

Stuck, A. E., Walthert, J. M., Nikolaus, T., Bula, C. J., Hohmann, C., \& Beck, J. C. (1999). Risk factors for functional status decline in community-living elderly people: a systematic literature review. Social Science \& Medicine, 48(4), 445-469.

Takeda, M., \& Tanaka, T. (2010). Depression in the elderly. Geriatrics \& Gerontology International, 10(4), 277-279. doi: 10.1111/j.14470594.2010.00644.x

Tamblyn, R. M., McLeod, P. J., Abrahamowicz, M., Monette, J., Gayton, D. C., Berkson, L., . . . et, a. (1994). Questionable prescribing for elderly patients in Quebec. Canadian Medical Association Journal, 150(11), 1801-1809. 
Teng, E. L., \& Chui, H. C. (1987). The Modified Mini-Mental State (3MS) examination. Journal of Clinical Psychiatry, 48(8), 314-318.

The Chief Public Health Officer's Report on the State of Public Health in Canada. (2010). The health and well-being of Canadian seniorsGrowing Older Adding Life to Years (pp. 19-42): Public Health Agency of Canada. Retrieved Jul 22, 2014, from http://www.phac-aspc.gc.ca/cphorsphcrespcacsp/2010/fr-rc/pdf/cpho_report_2010_e.pdf.

Thompson, F. E., \& Subar, A. F. (2013). Chapter 1 - Dietary Assessment Methodology. In A. M. Coulston, C. J. Boushey \& M. G. Ferruzzi (Eds.), Nutrition in the Prevention and Treatment of Disease (Third Edition) (pp. 5-46): Academic Press.

Tiemeier, H., van Tuijl, H. R., Hofman, A., Meijer, J., Kiliaan, A. J., \& Breteler, M. M. B. (2002). Vitamin B12, folate, and homocysteine in depression: the Rotterdam Study. American Journal of Psychiatry, 159(12), 2099-2101. Tolmunen, T., Hintikka, J., Ruusunen, A., Voutilainen, S., Tanskanen, A., Valkonen, V.-P., . . S Salonen, J. T. (2004). Dietary folate and the risk of depression in Finnish middle-aged men. A prospective follow-up study. Psychotherapy \& Psychosomatics, 73(6), 334-339.

Tolmunen, T., Hintikka, J., Voutilainen, S., Ruusunen, A., Alfthan, G., Nyyssonen, K., . . Salonen, J. T. (2004). Association between depressive symptoms and serum concentrations of homocysteine in men: a population study. American Journal of Clinical Nutrition, 80(6), 1574-1578.

Tolmunen, T., Voutilainen, S., Hintikka, J., Rissanen, T., Tanskanen, A., Viinamaki, H., . . Salonen, J. T. (2003). Dietary folate and depressive symptoms are associated in middle-aged Finnish men. Journal of Nutrition, 133(10), 3233-3236.

Topp, R., Fahlman, M., \& Boardley, D. (2004). Healthy aging: health promotion and disease prevention. Nursing Clinics of North America, 39(2), 411-422. doi: 10.1016/j.cnur.2004.01.007 
Troppmann, L., Johns, T., \& Gray-Donald, K. (2002). Natural health product use in Canada. Canadian Journal of Public Health, 93(6), 426-430.

Tucker, K. L. (2010). Dietary patterns, approaches, and multicultural perspective. Applied Physiology, Nutrition, and Metabolism, 35(2), 211-218. doi: 10.1139/h10-010

Unützer, J. M. D. M. P. H. (2007). Late-Life Depression. The New England Journal of Medicine, 357(22), 2269-2276. doi: 10.1056/NEJMcp073754

van Kessel, G. (2013). The ability of older people to overcome adversity: a review of the resilience concept. Geriatric Nursing, 34(2), 122-127. doi: 10.1016/j.gerinurse.2012.12.011

Vesnaver, E., Keller, H. H., Payette, H., \& Shatenstein, B. (2012). Dietary resilience as described by older community-dwelling adults from the NuAge study "If there is a will - there is a way!". Appetite, 58(2), 730-738. doi: 10.1016/j.appet.2011.12.008

Vink, D., Aartsen, M. J., \& Schoevers, R. A. (2008). Risk factors for anxiety and depression in the elderly: A review. Journal of Affective Disorders, 106(12), 29-44. doi: 10.1016/j.jad.2007.06.005

Waijers, P. M. C. M., Feskens, E. J. M., \& Ocké, M. C. (2007). A critical review of predefined diet quality scores. British Journal of Nutrition, 97(02), 219-231. doi: doi:10.1017/S0007114507250421

Walker, J. G., Mackinnon, A. J., Batterham, P. J., Jorm, A. F., Hickie, I. B., McCarthy, A., ... Christensen, H. (2010). Mental health literacy, folic acid and vitamin B12, and physical activity for the prevention of depression in older adults: randomised controlled trial. British Journal of Psychiatry, 197(1), 45-54.

Washburn, R. A., McAuley, E., Katula, J., Mihalko, S. L., \& Boileau, R. A. (1999). The Physical Activity Scale for the Elderly (PASE): Evidence for validity. Journal of Clinical Epidemiology, 52(7), 643-651.

Washburn, R. A., Smith, K. W., Jette, A. M., \& Janney, C. A. (1993). The Physical Activity Scale for the Elderly (PASE): Development and 
evaluation. Journal of Clinical Epidemiology, 46(2), 153-162. doi: Doi: 10.1016/0895-4356(93)90053-4

Whiteford, H. A., Degenhardt, L., Rehm, J., Baxter, A. J., Ferrari, A. J., Erskine, H. E., . . Vos, T. (2013). Global burden of disease attributable to mental and substance use disorders: findings from the Global Burden of Disease Study 2010. Lancet, 382(9904), 1575-1586. doi: 10.1016/S01406736(13)61611-6

Whitney, E., \& Rolfes, S. R. (2008). The water-soluble vitamins: B vitamins and vitamin C. In E. Whitney \& S. R. Rolfes (Eds.), Understanding nutrition (11 ed.). Belmont, CA: Thomson Wadsworth.

Wild, B., Herzog, W., Schellberg, D., Lechner, S., Niehoff, D., Brenner, H., . . . Raum, E. (2011). Association between the prevalence of depression and age in a large representative German sample of people aged 53 to 80 years. International Journal of Geriatric Psychiatry, 27(4), 375-381. doi: $10.1002 / g p s .2728$

Willett, W. C. (2006). The Mediterranean diet: science and practice. Public Health Nutrition, $9(1 a), 105-110$. doi: doi:10.1079/PHN2005931

Willett, W. C., Howe, G. R., \& Kushi, L. H. (1997). Adjustment for total energy intake in epidemiologic studies. American Journal of Clinical Nutrition, 65(4 Suppl), 1220S-1228S; discussion 1229S-1231S.

Williams, A.-L., Cotter, A., Sabina, A., Girard, C., Goodman, J., \& Katz, D. L. (2005). The role for vitamin B-6 as treatment for depression: a systematic review. Family Practice, 22(5), 532-537. doi: 10.1093/fampra/cmi040

Wittchen, H. U., Jacobi, F., Rehm, J., Gustavsson, A., Svensson, M., Jönsson, B., . . Salvador-carulla, L. (2011). The size and burden of mental disorders and other disorders of the brain in Europe 2010. European Neuropsychopharmacology, 21, 655-679. doi:

10.1016/j.euroneuro.2011.07.018 
Wolters, M., Ströhle, A., \& Hahn, A. (2004). Cobalamin: a critical vitamin in the elderly. Preventive Medicine, 39(6), 1256-1266. doi:

10.1016/j.ypmed.2004.04.047

Woo, J., Ho, S. C., \& Yu, A. L. M. (2002). Lifestyle factors and health outcomes in elderly Hong Kong chinese aged 70 years and over. Gerontology, 48(4), 234-240.

Woo, J., Lynn, H., Lau, W. Y., Leung, J., Lau, E., Wong, S. Y. S., \& Kwok, T. (2006). Nutrient intake and psychological health in an elderly Chinese population. International Journal of Geriatric Psychiatry, 21(11), 10361043.

Yesavage, J. A., Brink, T. L., Rose, T. L., Lum, O., Huang, V., Adey, M., \& Leirer, V. O. (1983). Development and validation of a geriatric depression screening scale: a preliminary report. Journal of Psychiatric Research, 17(1), 37-49.

Young, K., Bunn, F., Trivedi, D., \& Dickinson, A. (2011). Nutritional education for community dwelling older people: A systematic review of randomised controlled trials. International Journal of Nursing Studies, 48(6), 751-780. doi: 10.1016/j.jijnurstu.2011.03.007

Young, S. N., \& Ghadirian, A. M. (1989). Folic acid and psychopathology. Progress in Neuro-Psychopharmacology \& Biological Psychiatry, 13(6), 841-863. 


\section{APPENDICES}

Appendix 1. The Geriatric Depression Scale

Appendix 2. Manuscript 1: Supplementary Tables 


\section{Appendix 1. The Geriatric Depression Scale}

Note: $\mathrm{N}$ or $\mathrm{Y}$ indicates which answer is scored (1 point).

\section{Choose the best answer for how you felt over the past week}

1. Are you basically satisfied with your life? $\quad$ Yes / No N

2. Have you dropped many of your activities and interests? Yes / No Y

3. Do you feel that your life is empty? $\quad$ Yes / No Y

4. Do you often get bored? $\quad$ Yes / No Y

5. Are you hopeful about the future? $\quad$ Yes / No N

6. Are you bothered by thoughts you can't get out of your Yes / No Y head?

7. Are you in good spirits most of the time? $\quad$ Yes / No N

8. Are you afraid that something bad is going to happen to Yes/ No $Y$ you?

9. Do you feel happy most of the time?

Yes/No N

10. Do you often feel helpless?

Yes / No Y

11. Do you often get restless and fidgety?

Yes / No Y

12. Do you prefer to stay at home, rather than going out and

Yes / No Y doing new things?

13. Do you frequently worry about the future?

Yes / No Y

14. Do you feel you have more problems with memory than

Yes / No Y most?

15. Do you think it is wonderful to be alive now?

Yes/No N

16. Do you often feel downhearted and blue?

Yes / No Y

17. Do you feel pretty worthless the way you are now?

Yes / No Y 


\section{Choose the best answer for how you felt over the past week}

18. Do you worry a lot about the past?

Yes/No Y

19. Do you find life very exciting?

Yes/ No N

20. Is it hard for you to get started on new projects?

Yes/No Y

21. Do you feel full of energy?

Yes/No N

22. Do you feel that your situation is hopeless?

Yes/No Y

23. Do you think that most people are better off than you are?

Yes / No Y

24. Do you frequently get upset over little things?

Yes / No Y

25. Do you frequently feel like crying?

Yes / No Y

26. Do you have trouble concentrating?

Yes / No Y

27. Do you enjoy getting up in the morning?

Yes / No N

28. Do you prefer to avoid social gatherings?

Yes / No Y

29. Is it easy for you to make decisions?

Yes / No N

30. Is your mind as clear as it used to be?

Yes / No N

Available on Wikipedia at <http://en.wikipedia.org/wiki/Geriatric_Depression_Scale>, last accessed March 24, 2014. 
Appendix 2. Manuscript 1: Supplementary Tables

Supplementary Table 1. Food categories used in principal component analysis

\begin{tabular}{|c|c|}
\hline Food category & Examples of food items \\
\hline Red meat & Beef, pork, lamb, game meat \\
\hline Poultry & Chicken or other poultry \\
\hline Processed meats & Bacon, ham, corned beef, luncheon meats, sausages \\
\hline Fish and seafood & White fish, fatty fish, shellfish, shrimp \\
\hline Eggs & Eggs, omelet \\
\hline Butter and animal fats & Butter, lard \\
\hline $\begin{array}{l}\text { Margarine, oils, and } \\
\text { salad dressings }\end{array}$ & $\begin{array}{l}\text { Margarines, spread, vegetable oil, salad dressings, } \\
\text { mayonnaise }\end{array}$ \\
\hline High-fat dairy & $\begin{array}{l}\text { Milk and yogurt with } \geq 2 \% \text { M.F., Full cream milk, dairy } \\
\text { coffee whitener, cream, cheese }\end{array}$ \\
\hline Low-fat dairy & $\begin{array}{l}\text { Skimmed milk or } 1 \% \text { M.F., dried milk, yogurt } \leq 1 \% \text { M.F., } \\
\text { cottage cheese }(\leq 2 \% \text { M.F.) }\end{array}$ \\
\hline Hot beverages & $\begin{array}{l}\text { Tea, regular coffee, decaffeinated coffee, hot chocolate, } \\
\text { chicory }\end{array}$ \\
\hline Alcoholic beverages & Port, sherry, liqueurs, spirits, wine, beers, ciders \\
\hline Sugar beverages & $\begin{array}{l}\text { soft drinks, fruit squash, sports drinks, sweetened fruit } \\
\text { juice }\end{array}$ \\
\hline Low-energy beverages & Low-energy or diet soft drinks, water \\
\hline $\begin{array}{l}\text { Fruit juice and } \\
\text { vegetable juice }\end{array}$ & $100 \%$ real fruit juice or vegetable juice \\
\hline Fruits & $\begin{array}{l}\text { Fresh fruits, fruit salads, canned fruits, dried fruits, } \\
\text { frozen fruits, sweetened fruits }\end{array}$ \\
\hline Leafy vegetables & Spinach, lettuce, salads \\
\hline Other vegetables & $\begin{array}{l}\text { Carrots, zucchini, parsnips, leeks, mushrooms, peppers, } \\
\text { onion, garlic, broccoli, kales, Brussels sprouts, cabbage, } \\
\text { cauliflower, coleslaw, tomatoes }\end{array}$ \\
\hline
\end{tabular}

(continued on the next page) 


\section{Food category}

Peas and dried legumes

Potatoes, tubers, and starchy vegetables

Nuts and seeds

Refined grain products

Whole grain products

Soups

Pizza, pasta, quiche

Fried food

Snack food

Desserts, pastries, pudding

Chocolate and sweets

Sauce and condiments

Mixed dishes

Fast foods

Supplements and meal replacements

\section{Examples of food items}

Canned beans, peas, baked beans, dried lentils, bean paste (e.g. hummus), soy milk, tofu, textured vegetable protein, toasted soy beans

Boiled, mashed potatoes, jacket potatoes, potato salad, corn, cassava, yam, sweet-potato

Peanuts, , peanut butter other nuts, seeds

White bread, cream crackers, cheese biscuits, refined grain ready-to-eat cereals, white pasta, white rice

Brown bread and rolls, whole-wheat bread and rolls, whole-wheat pasta, brown rice, whole grain ready-to-eat cereals, oatmeal

Vegetable soup, meat soup

Pizza, lasagna, pasta, quiche, meat pie, tomato sauce

Any food deep fried, chips or French fries, fish fingers, fried fish in batter. (Pan-fried not included)

Granola bars, sweet biscuits, cakes, cookies, muffins, salty snacks

Pastries, fruit pies, tarts, milk pudding, sponge puddings, ice cream

Chocolate bars, candies, toffees, sugar added to tea/coffee, jam, non-dairy coffee whitener, frosting

Sauce in general (including soy sauce), gravy, tomato ketchup, pickles, vinegar. Spices, herbs, and seasonings (e.g. parsley, oregano, curry, vanilla extract, table salt, ginger root, garlic powder). Baking powder, bread yeast.

Canned and frozen meals and entrees, ready-to-eat dinners, mixed dishes

Hamburgers, hot dogs,

Drinks (e.g. Ensure), powder (e.g. protein supplement) 
Supplementary Table 2. Rotated factor loading for high-loading items $(\geq 0.20)$ on the three dietary patterns

\begin{tabular}{|c|c|c|c|}
\hline \multirow[b]{4}{*}{ Food category } & \multicolumn{3}{|c|}{ Dietary Patterns (Factors) } \\
\hline & & & Factor 3 \\
\hline & Factor 1 & Factor 2 & Convenience \\
\hline & Varied Diet & Traditional Diet & Diet \\
\hline Red meat & - & 0.483 & - \\
\hline Poultry & - & - & -0.223 \\
\hline Processed meats & 0.213 & 0.211 & - \\
\hline Fish and seafood & - & - & -0.383 \\
\hline Eggs & - & - & - \\
\hline Butter and fats & - & 0.338 & - \\
\hline Margarine, oils, salad dressings & - & 0.221 & -0.342 \\
\hline High-fat dairy & 0.249 & 0.242 & - \\
\hline Low-fat dairy & 0.225 & -0.379 & - \\
\hline Hot beverages & 0.257 & - & - \\
\hline Alcoholic beverages & - & 0.339 & - \\
\hline Sugar beverages & - & - & 0.373 \\
\hline Low-energy beverages & - & - & - \\
\hline Fruit juice and vegetable juice & 0.320 & - & - \\
\hline Fruits & 0.352 & - & - \\
\hline Leafy vegetables & - & - & -0.520 \\
\hline Other vegetables & 0.339 & - & - \\
\hline Peas and dried legumes & - & 0.262 & - \\
\hline $\begin{array}{l}\text { Potatoes, tubers, and starchy } \\
\text { vegetables }\end{array}$ & - & 0.577 & - \\
\hline Nuts and seeds & 0.308 & - & 0.261 \\
\hline Refined grain products & 0.428 & - & - \\
\hline Whole grain products & 0.468 & - & - \\
\hline
\end{tabular}




\begin{tabular}{lccc}
\hline & \multicolumn{3}{c}{ Dietary Patterns (Factors) } \\
\cline { 2 - 4 } & & & Factor 3 \\
& Factor 1 & Factor 2 & Convenience \\
\multicolumn{1}{c}{ Food category } & Varied Diet & Traditional Diet & Diet \\
\hline Soups & - & 0.316 & - \\
Pizza, lasagna, and pasta & 0.300 & - & - \\
dishes & & & \\
Fried foods & - & - & 0.460 \\
Snacks items & 0.224 & & - \\
Desserts, pastries, pudding & - & 0.207 & - \\
Chocolate and sweets & 0.405 & - & - \\
Sauce, condiments, spices & - & - & - \\
Mixed dishes & - & - & 0.230 \\
Fast foods & - & - & 0.387 \\
Supplements and meal & - & -0.207 & - \\
replacements & & & \\
\hline
\end{tabular}

Notes: The three dietary patterns were extracted using factor analysis (principal component analysis). Factor loadings issued from Varimax rotation with Kaiser Normalization represent the correlation between the factors and individual items from food group. The factor score for each pattern was calculated by summing intakes in grams of the 32 predefined food categories (see Supplementary Table 1) weighted by their factor loadings. In order to simplify interpretation of the two patterns, values $<0.20$ were not listed in the table but were used in the construction of the factors. 